\title{
NICOLE ORESME À LA FACULTÉ DES ARTS DE PARIS : LES QUESTIONS SUR LES MÉTÉOROLOGIQUES
}

\author{
par Aurora PANZICA \\ Université de Fribourg \\ Faculté de Lettres, Departement de Philosophie \\ Avenue de l'Europe, 20 \\ 1700 Fribourg
}

Suisse

Résumé

Cet article porte sur les Questions sur les Météorologiques de Nicole Oresme, l'un des rares textes encore inédits de ce philosophe. Dans la première partie, il est question de la tradition manuscrite du commentaire d'Oresme, et en particulier de la découverte d'une autre rédaction, fort différente et antérieure à celle qui a été répertoriée. Dans un second temps, il s'agit de clarifier la place occupée par les deux rédactions de ces Questions dans la chronologie des écrits d'Oresme issus de son enseignement à la Faculté des Arts de Paris. Finalement, la dernière partie porte sur les problèmes que posent les attributions des Questions sur les Météorologiques rédigées au XIVe siècle, notamment en ce qui concerne les textes d'Oresme, d'Albert de Saxe et de Thémon le Juif, tous trois actifs à l'Université de Paris.

\section{Abstract}

This paper deals with Nicole Oresme's Questions on Meteorology, one of the few unedited works of this philosopher. The first part concerns the manuscript tradition of this commentary, and particularly the discovery of an earlier redaction, which differs considerably from the currently known one. Subsequently, an attempt will be made to clarify the chronological position of these two redactions within Oresme's activity at the Parisian Arts Faculty. Finally, the last part deals with the problems related to the attributions of the Parisian Questions on Meteorology of the fourteenth century, namely those by Nicole Oresme, Themo Iudaeus and Albert of Saxony.

\section{Zusammenfassung}

Dieser Beitrag befasst sich mit den Questionen zu den Meteorologica des Nikolaus Oresme, einer der einzigen Texte dieses Philosophs, der noch nicht ediert wurde. Der erste Teil behandelt die hanschriftliche Überlieferung dieses Kommentars, und insbesondere die Entdeckung einer anderen Fassung, die älter ist und von der bekannten erheblich abweicht. Anschliessend wird eine chronologische Abfolge der beiden Fassungen dieser Questiones im Rahmen der Schriften für die Lehrtätigkeit des Oresme an der Universität Paris vorgeschlagen. Der letze Teil behandelt die Probleme, die von den Zuschreibungen der pariser Questiones zu den Meteorologica, nämlich die von Nikolaus Oresme, Albert von Sachsen und Themo Judaeus, aufgeworfen wurden.

[Mots-clés : Nicole Oresme, Météorologiques, Aristote, Albert de Saxe, Thémon le Juif, Jean Buridan] 
T'intérêt de Nicole Oresme pour la cosmologie et pour la météorologie est Lattesté non seulement par ses nombreux écrits consacrés aux phénomènes célestes $^{1}$, mais aussi par le témoignage de Jean Buridan ${ }^{\star}$. Ce dernier, dans ses Questions sur les Météorologiques, se réfère explicitement à l'autorité de son jeune collègue, lorsqu'il écrit: «Ego numquam vidi parelios [ $m s$.: paralios] vel nescio quos viderim, ideo parum possum loqui de illis [...] et reverendus magister Nicolaus Oresme dixit mihi se semel vidisse ex utroque latere Solis unum ${ }^{2}$. Cet intérêt pour les phénomènes naturels, et notamment pour ceux qui affectent la région céleste, amena Nicole Oresme, alors au tout début de sa carrière à la Faculté des Arts de Paris ${ }^{3}$, à commenter plusieurs fois le Traité sur la sphère de Johannes de Sacrobosco, le traité $\mathrm{Du}$ ciel $^{4}$ et le traité des Météorologiques d'Aristote.

*Cette étude a été rédigée dans le cadre de mes recherches doctorales, dirigées par le Prof. Dr. Tiziana Suarez-Nani à l'Université de Fribourg (Suisse) et financées par le Fonds National Suisse de la Recherche. Je remercie ma directrice, ainsi que le Dr. Valérie Cordonier, qui a suivi avec intérêt et patience les différentes étapes de ce travail, le Dr. William O. Duba, pour sa lecture et ses conseils avisés, Roberta Padlina, pour l'aide informatique, et Valentin Braekman, qui m'a aidée à corriger la version finale de ce travail.

(1) Nous citons seulement ici, parmi les textes édités: le Traité de l'espère, ed. L. M. McCARTHY, Maistre Nicole Oresme, "Traité de l'espère", PhD diss. Univ. of Toronto 1943; la Quaestio: Utrum omnes impressiones quae sunt in parte superioris aeris regionis sint eiusdem speciei vel ad invicem differant, ed. R. MATHIEU, "L'inter onmes impressiones de Nicole Oresme», Archives d'histoire doctrinale et littéraire du Moyen Âge, 35 (1960), p. 277-294; les Quaestiones super Aristotelis de caelo et mundo, ed. C. KREN, The Quaestiones super de Celo of Nicole Oresme, PhD diss. Univ. of Wisconsin 1965; les Quaestiones de sphaera, ed. G. Droppers, The Quaestiones De spera of Nicholas Oresme, Latin Text with English Translation, Comment and Variants, Madison 1966; le Ad pauca respicientes, ed. E. Grant, Nicole Oresme: De proportionibus proportionum and Ad pauca respicientes, Madison 1966; Le livre du ciel et du monde, ed. A. D. Menut, Madison-Milwaukee-Londres 1968; le Tractatus de commensurabilitate vel incommensurabilitate motum celi, ed. E. GRANT, Nicole Oresme and the Kinematics of Circular Motion: Edition with an Introduction, English Translation and Commentary, Madison-Milwaukee-Londres 1971; le De visione stellarum, ed. D. BurToN, Nicole Oresme's De visione stellarum (On Seeing the Stars): A Critical Edition of Oresme's Treatise on Optics and Atmospheric Refraction, with an Introduction, Commentary, and English Translation, LeydeBoston, 2007.

(2) Jean Buridan, Questiones in Meteorologica, III, 20, Utrum virge et parelii debent semper apparere ex latere Solis et numquam superius nec directe inferius, ms. Paris, BnF, lat. 14723, f. 247ra. Pour cette citation, $c f$. aussi le texte du manuscrit Erfurt, Wissenschaftliche Allgemeinbibliothek, CA $2^{\circ} 334$, f. 154vb : «Ego numquam vidi parallias vel nescio quod viderim, ideo parum possum loqui de illis [...] et magister Nicolaus dixit se simul vidisse duas ex utroque lateri Solis unum, et dicebant gentes venientes de campis se vidisse tres soles». Il n'existe pas encore d'édition complète de cet ouvrage, qui a été daté par S. Bages des années 1357-1358, cf. S. BAGES, Les Questiones super tres libros Metheororum Aristotelis de Jean Buridan. Étude suivie de l'édition du l. I, «École Nationale des Chartes. Positions des thèses" 1986, p.13-21, ici p.15. On peut consulter la liste des questions in E. FARAL, "Jean Buridan: notes sur les manuscrits, les éditions et le contenu de ses ouvrages", Archives d'histoire doctrinale et littéraire du Moyen Âge, 21 (1946), p. 1-53, ici p. 22-24.

(3) Cf. W. J. CourTENAY, «The Early Career of Nicole Oresme», Isis 91/3, (2000), p. 542-548.

(4) À côté du commentaire par questions édité par C. KREN, The Quaestiones super de Celo of Nicole Oresme, Ph. D. diss. Univ. of Wisconsin 1965, il y en a un autre, transmis par le manuscrit München, Bayerische Staatsbibliothek, Clm 4375, f. 19ra-46rb : S. KIRSCHNER, «Eine weitere Fassung eines lateinischen 'De caelo-Kommentars'von Nicolaus Oresme? », in B. FrITSCHER - G. BrEY (ed.), Cosmographica et Geographica. Festschrift für Heribert M. Nobis zum 70. Geburtstag, vol. I, Munich 1994, p. 209-222. 
Cependant, les deux rédactions de ses Questions sur les Météorologiques, transmises par une riche tradition manuscrite ${ }^{5}$, n'ont fait l'objet d'aucune édition, ni à l'époque contemporaine ni avant. Cela tient aussi à la grande complexité de la tradition manuscrite relative aux commentaires sur les Météorologiques rédigés pour l'enseignement à la Faculté des Arts de Paris vers la moitié du XIV ${ }^{\mathrm{e}}$ siècle $^{6}$.

(5) Pour l'une, on a identifié dix-huit manuscrits, pour une période comprise entre la seconde moitié du XIV e siècle et la seconde moitié du XV e : Basel, Universtitätsbibliothek, F I 11, f. 4r-85v; F V 2, f. 2r-63v; Berlin, Staatsbibliothek zu Berlin - Preußischer Kulturbesitz, lat. fol. 631, f. 39r-114r; Erfurt, Wissenschaftliche Allgemeinbibliothek, CA $2^{\circ} 334, \mathrm{f} .158 \mathrm{v}-167 \mathrm{r}$ (seulement le quatrième livre); Kassel, Landesbibliothek Phys $2^{\circ} 12$, f. 1r-107r; Klagenfurt, Bischöfliche Bibliothek, XXXI b. 5, f. 1r124r; Kraków, Uniwersytet Jagielloński, Biblioteka Jagiellońska, 749, f. 59v-110v; 751, f. 3r-53r; 2095, f. 245r-307r; 2117, f. 195r-322r; Leipzig, Universitäts-bibliothek, Ms. 1387, f. 181r-275r; München, Bayerische Staatsbibliothek, Clm 4376, f. 1r-64r; 17226, f. 1r-140r (seulement quelques questions); Paris, BnF, lat.15156, f.226r-288v (jusqu'à la question II. 10); Sankt Gallen, Stiftsbibliothek, Cod.Sang. 839, f. 1r-175v; Uppsala, Universitetsbiblioteket, C. 596, f. 2r-97v; Wrocław, Biblioteka Uniwersytecka, IV Q. 27, f. 1r-163r, Wien, Österreichische Nationalbibliothek, Cod. 5453, f. 49r-109v. Cette liste, avec quelques variations, est présente dans les ouvrages suivants, tous également antérieurs à la découverte du manuscrit de Darmstadt par Caroti : C. LoHR, «Medieval Latin Aristotle Commentaries Authors: Narcissus - Richardus», Traditio, 28 (1972), p. 281-396, ici p. 296; S. C. MCCLUSKEY, Nicole Oresme on Light, Color, and the Rainbow. An Edition and Translation, with Introduction and Critical Notes, of Part of Book III of his "Questiones super IV libros Meteororum", diss. Univ. of Wisconsin 1974; O. WeIJERs, Le Travail intellectuel à la Faculté des arts de Paris: textes et maîtres (ca. 1200-1500), vol.6, Turnhout 1994, p. 175. Pour l'autre rédaction nous avons jusqu'à maintenant identifié quatre manuscrits : deux copies complètes, à savoir München, Bayerische Staatsbibliothek, Clm 4375, f. 19ra-46vb et Kraków, Uniwersytet Jagielloński, Biblioteka Jagiellońska 753, f. 51ra-83vb, et trois copies partielles: deux contenues dans le manuscrit Kraków, Uniwersytet Jagielloński, Biblioteka Jagiellońska, 686, f. 101ra-134va et f. 81ra-97va, et une transmise par le manuscrit Kraków, Uniwersytet Jagielloński, Biblioteka Jagiellońska, 635, p. 177r-236v. À ces copies il faut ajouter le manuscrit Darmstadt, Universitäts- und Landesbibliothek (olim Hessische Landes- und Hochschulbibliothek), 2197, f. 58r-92v et 125r-127v, découvert par Caroti. En raison de la grande quantité de manuscrits qui transmettent les Questions sur les Météorologiques de Nicole Oresme, Markowski a affirmé que, à l'intérieur de l'école parisienne du XIV ${ }^{e}$ siècle, Jean Buridan a exercé son influence surtout à travers son commentaire de la Physique d'Aristote, Marsile d'Inghen à travers son commentaire du traité De la génération et de la corruption, Albert de Saxe à travers son commentaire du traité $\mathrm{Du}$ ciel, et Nicole Oresme à travers son commentaire des Météorologiques, $c f$. M. MARKOWsKI, «Die handschriftliche Überlieferung der Werke des Marsilius von Inghen", in H.A. G. BRAAKHUIS M. J. F. M. HoENEN (ed.), Marsilius of Inghen. Acts of the International Marsilius of Inghen Symposium, Nimègue 1992, p. 173-193, ici, p. 184.

(6) B. MicHAEL, Johannes Buridan: Studien zu seinem Leben, seinem Werken und zur Rezeption seiner Theorien im Europa des Späten Mittelalters, Berlin 1985, p.660: «Ungenauigkeiten und Zuschreibungen in der handschriftlichen Überlieferung, starke inhaltliche Abhängigkeiten und die relative chronologische Nähe der verschiedenen Werke aber haben zu Verwirrung geführt, die bis heute nicht beseitigt werden konnten. Bei den genannten Kommentaren handelt es sich um die Questionen zu den Meteora von Nikolaus Oresme, Themo Judei, Albert von Sachsen und Johannes Buridan, hinzu kommen noch die fälschlich unter dem Namen von Johannes Duns Scotus publizierten Questionen». Cf. aussi S. KIRSCHNER, Nicolaus Oresmes Kommentar zur Physik des Aristoteles. Kommentar mit Edition der Quaestionen zu Buch 3 und 4 der Aristotelischen Physik sowie von vier Quaestionen zu Buch 5, Stuttgart 1997, p. 30-34. 


\section{LA TRADITION MANUSCRITE DES QUESTIONS SUR LES MÉTÉOROLOGIQUES DE NICOLE ORESME}

Heinrich Suter a été le premier à avoir attiré l'attention des chercheurs sur les Météorologiques de Nicole Oresme, en signalant, dans un article de 1882, la présence d'un texte "jusqu'alors inconnu» dans un manuscrit de la Stiftsbibliothek de Saint Gall ${ }^{7}$. Il se montrait toutefois déçu par le contenu de cet ouvrage qui lui paraissait d'une qualité bien inférieure à celle des autres textes de mathématique et de philosophie naturelle d'Oresme, ainsi que par le caractère scolastique du texte, texte auquel il reprochait en outre une proximité trop grande avec les Questions sur les Météorologiques de Duns Scot.

Trente ans après l'article de Suter, Alexander Birkenmajer s'intéressa aux Questions sur les Météorologiques dans le cadre de ses études sur Witelo ${ }^{8}$. Il remarqua les rapports très étroits qui existaient entre les Questions sur les Météorologiques de Nicole Oresme, celles de Thémon le Juif ${ }^{9}$, celles d'Albert de Saxe ${ }^{10}$, et celles d'un auteur scotiste de la fin du XIV ${ }^{\mathrm{e}}$ siècle ${ }^{11}$. En ce qui concerne

(7) H. SuTER, «Eine bis jetzt unbekannte Schrift des Nic. Oresme», Zeitschrift für Mathematik und Physik, XXVII, 1882, Historisch-literarische Abteilung, p. 121-125.

(8) A. Birkenmajer, Études d'histoire des sciences en Pologne, Wrocław-Warszawa-KrakówGdańsk 1972, p. 178-239.

(9) Maître ès arts en 1349 à Paris, il fut rector scholarium au Schottenkloster d'Erfurt en 1350; de retour à Paris, il fut procurateur de la nation anglaise pour plusieurs années. Il existe cinq éditions des Questions sur les Météorologiques de Thémon: Pavia, 1480; Venice, par Octavianus Scotus, 1507, 1516, 1518 (semblable à l'édition de 1516); Venice, par Octavianus Scotus, 1520 (semblable à l'édition de 1507). Les manuscrits de ce texte que l'on a identifiés jusqu'à présent sont les suivants: Paris, BnF, lat. 6547, f. 1r-33r; Città del Vaticano, Biblioteca Apostolica Vaticana, Vat. lat. 2177, f. 1r-92v; Padova, Seminario vescovile, cod.24, f. 1r-50v; Ferrara, Biblioteca comunale Ariostea, Ms. Classe II, n. 380, f. 1r-60v; München, Bayerische Staatsbibliothek, Clm 6962, f. 93r-146r; Venezia, Biblioteca Nazionale Marciana, lat. XIV, 129, f. 77r-122v (olim: Venezia, Biblioteca del Monastero di S. Michele, 136).

(10) Maître ès arts à Paris vers les années ‘ 50 du XIV e siècle, recteur de cette Université en 1353, il fonda l'Université de Vienne et en devint le premieur recteur en 1356; il devint évêque d'Halberstadt en 1366. Birkenmajer (Études, p. 180) liste quatre manuscrits qui, d'après lui, transmettraient les Questions sur les Météorologiques d'Albert de Saxe: Kraków, Uniwersytet Jagielloński, Biblioteka Jagiellońska, 635, p. 177r-236v (voir plus bas); Kraków, Uniwersytet Jagielloński, Biblioteka Jagiellońska, 686, f.101ra-134va (voir plus bas); Erfurt, Wissenschaftliche Allgemeinbibliothek, CA $4^{\circ}$ 299, f.53r-103v; Berlin, Staatsbibliothek zu Berlin - Preußischer Kulturbesitz, lat. $2^{\circ} 387$, f. $63 \mathrm{r}-102 \mathrm{v}$.

(11) Cet auteur avait autrefois été identifié avec Duns Scot et ses Questions publiées par Wadding dans l'Opera omnia de Duns Scot: IoANnEs Duns Scotus, Opera omnia, ed. L. WADDING, 12 vol., Lyon, 1639. Facsimile: Hildesheim, Olms, 1968, vol. III, p. 1-125. Il y a toutefois au moins deux éléments, considérés par Wadding lui-même dans sa préface (ibid., p. 1-2.), qui témoignent à l'encontre de l'attribution de ce texte à Duns Scot: tandis que celui-ci était mort en 1308, dans les Questions, on qualifie Thomas d'Aquin de «beatus » (livre I, q. 10), titre qui ne lui sera attribué qu'en 1323, et on cite le Tractatus de proportionibus de Thomas Bradwardine (livre I. q. 13), texte qui a été composé en 1328. C'est pourquoi Wadding avait avancé l'hypothèse que ces questions pourraient être attribuées à Simon Tunsted, auteur scotiste mort en 1369. Cette supposition, acceptée, entre autres, par L. Thorndike ( $O$ Oresme and Fourteenth Century Commentaries on the Meteorologica», Isis, 45 [1954], p. 145-152, ici p. 145 sq.) et H. HugONNARD-RocHE (L'œuvre astronomique de Thémon Juif, maître parisien du XIV e siècle, Genève-Paris 1973, p. 40), mais mise en doute par Ch. Lohr (Traditio, 29 [1973],p. 146), n'a pas encore été confirmée. 
les Questions sur les Météorologiques de Thémon, en particulier, il montra que les deux tiers du troisième livre concordaient presque mot pour mot avec les Questions de Nicole Oresme, d'où le problème de savoir si les passages communs appartenaient à Thémon ou bien à Oresme. Pour résoudre cette question, Birkenmajer examina en détail le contenu du troisième livre des Questions de Thémon et d'Oresme ${ }^{12}$ et parvint à affirmer, sur la base de nombreux éléments doctrinaux et textuels, qu'Oresme est l'auteur des questions 1-17 et 20 du troisième livre, tandis que les autres questions du même livre sont de Thémon. Or, puisque tous les manuscrits d'Oresme qu'il avait à disposition contenaient aussi, au troisième livre, ces questions de Thémon, il en tira la conclusion que tous les manuscrits étaient contaminés. Tout en admettant la difficulté de l'hypothèse qu'une «œuvre si connue et tellement lue n'ait pas été conservée sous une forme autre qu'un remaniement relativement tardif » ${ }^{13}$, il soulignait toutefois que tous les témoins qu'il avait réussi à identifier provenaient de l'Europe centrale, et aucun de Paris, lieu d'origine du texte, raison pour laquelle il était possible de supposer qu'ils dérivaient tous d'un unique exemplaire contaminé, rédigé vers 1370-1375. Indépendamment de la validité de son hypothèse, le chercheur polonais eut le mérite de fournir une première liste des manuscrits des Questions sur les Météorologiques de Nicole Oresme, de les décrire et d'en étudier les rapports ${ }^{14}$.

Cependant, encore en 1954, dans un article où il signalait la découverte d'un nouveau manuscrit des Questions oresmiennes ${ }^{15}$, L. Thorndike denonçait l'absence d'une étude systématique de ce texte ${ }^{16}$.

Dans les années '70, S. C. McCluskey, de l’Université du Wisconsin, consacra sa thèse doctorale à l'étude et à l'édition critique des questions concernant le thème de la vision présentes dans le troisième livre des Questions d'Oresme ${ }^{17}$. Il répertoria tous les témoins de ce texte jusqu'alors identifiés, en en ajoutant des

(12) En se limitant toutefois, pour ce dernier, aux questions 11-33, et en laissant de côté les questions 1-11. Tandis que la division des livres du texte de Thémon suit en effet celle de la traduction du grec de Guillaume de Moerbeke, Oresme, tout en utilisant comme texte de base pour son commentaire la traduction du grec, suit toutefois la division de la traduction de l'arabe, qui fait commencer le troisième livre à la question II. 4 du texte grec, raison pour laquelle il faut chercher l'équivalent des premières questions (1-11) du texte oresmien au deuxième livre du texte de Thémon (questions 5-11).

(13) Ibid., p. 239.

(14) Ibid., p.181-198. Il avait identifié les manuscrits suivants: Erfurt, Wissenschaftliche Allgemeinbibliothek, CA $2^{\circ} 334$, f. 158v-167r; Berlin, Staatsbibliothek zu Berlin - Preußischer Kulturbesitz lat. fol. 631, f. 39r-114r; Kraków, Uniwersytet Jagielloński, Biblioteka Jagiellońska, 2095, f. $245 \mathrm{r}-307 \mathrm{r} ; 2117$ f. 195r-322r; 749, f. 59v-110v; 751, f. 3r-53r; St. Gallen, Stifts-bibliothek, Cod. Sang. 839, f. 1r-177r; Leipzig, Universitätsbibliothek, 1387, f. 181r-275r; München, Bayerische Staatsbibliothek, Clm 4376, f. 1r-64r; München, Bayerische Staats-bibliothek, Clm 6962, f. 93r-146r; München, Bayerische Staatsbibliothek, Clm 17226, f.1r-140r; Uppsala, Universitetsbiblioteket, Ms. C. 596, f. 2r-97v; Wrocław, Biblioteka Uniwersytecka, IV. Q. 27, f. 1r-163r.

(15) Il s'agit du manuscrit Paris, BnF, lat. 15156, f. 226r-288v. Nous reviendrons sur ce témoin par la suite.

(16) Thorndike, Oresme and Fourteenth Century Commentaries, p. 145-152, ici p. 148. Aux p. 150-152, il a présenté la liste des questions de ce manuscrit.

(17) MCCLUSKey, Nicole Oresme on Light, Color, and the Rainbow. 
nouveaux ${ }^{18}$, et formula une hypothèse alternative à celle de Birkenmajer à propos de l'attribution des questions identiques dans les Commentaires d'Oresme et de Thémon. D’après lui, Oresme aurait compilé ses Questions en utilisant de longs passages provenant de celles de Thémon le Juif. Pour fonder sa thèse, il examina un certain nombre de passages qui apparaissent dans les Questions de Thémon et dans celles d'Oresme, avec le but de démontrer qu'ils étaient sortis de la plume de Thémon et qu'ils avaient ensuite été adaptés aux doctrines d'Oresme ${ }^{19}$. Selon lui, en effet, dans les Questions d'Oresme, on se trouverait face à des incohérences doctrinales et à des références internes erronées, qui démontreraient le fait que les questions identiques dans les recueils d'Oresme et de Thémon sont à attribuer à ce dernier. Ces éléments, on l'a vu, avaient été déjà remarqués par Birkenmajer, qui, de même que McCluskey, en avait tiré la conclusion que ces questions provenaient du recueil de Thémon. Toutefois - et c'est ici que l'on touche à la différence entre les deux hypothèses -, pour expliquer la présence de ces passages issus de Thémon dans les Questions transmises sous le nom d'Oresme, Birkenmajer avait postulé l'intervention d'une troisième personne, qui aurait contaminé les deux textes; McCluskey, en revanche, soutenait que c'était Oresme lui-même qui était l'auteur de cette contamination: d'après lui, en effet, le compilateur de Prague aurait pris soin de rendre son texte cohérent avec des corrections, ce qui n'est pas le $\operatorname{cas}^{20}$. On aurait envie de demander à McCluskey pourquoi il refuse à Oresme le souci de cohérence qu'il ne nie pas au compilateur de Prague ${ }^{21}$.

Quoi qu'il en soit, jusqu'à aujourd'hui les questions étudiées par McCluskey représentent la seule partie de l'ouvrage oresmien à avoir été éditée et aucun chercheur n'a examiné de façon systématique ce texte. Il a toutefois attiré l'attention de Kirschner qui, en 1997, publiait une édition partielle des Questions sur la Physique d'Oresme. En étudiant ce texte du jeune Maître normand, alors également inédit, Kirschner y avait trouvé deux autocitations des Questions surles

(18) Basel, Universitätsbibliothek, F I 11, f. 4r-85v; Basel, Universitätsbibliothek, F V 2, f. 2r-63v; Kassel, Landes- und Murhardsche Bibliothek der Stadt Kassel, 2o Phys. et hist. nat. 12, f. 1v-107r; Klagenfurt, Bischöfliche Bibliothek XXXI.b. 5, f. 1r-124r.

(19) Parmi ces passages, par exemple, il y en a un où l'on affirme que, dans la question précedente, on avait démontré que l'arc-en-ciel secondaire n'est pas produit par la réflexion du premier. Cette démonstration n'apparaît toutefois pas dans le texte d'Oresme, qui omet un long passage de la seizième question de Thémon, où l'on traite de la cause de l'arc-en-ciel secondaire, et où l'on démontre que l'arc-en-ciel secondaire n'est pas une image du premier (MCCLUSKEY, Nicole Oresme, p. 44-45). Une autre anomalie est présente dans la discussion qui porte sur la cause du halo, à savoir s'il apparaît par réflexion ou par réfraction. Dans le texte d'Oresme on lit que le halo apparaît par réfraction, et on renvoie aux questions précédentes, où une telle affirmation aurait été démontrée. Mais Oresme affirme dans les mêmes questions que le halo est causé par réflexion, tandis que la doctrine disant que le halo est causé par réfraction est propre à Thémon (ibid., p. 45-46).

(20) MCCluskey, Nicole Oresme, p. 62, n. 51.

(21) C'est aussi pour cette raison que Kirschner critiquel'explication de McCluskey: « McCluskey sieht also in der Tatsache, daß die erroneous internal reference nicht beiseitig wurde, ein Indiz dafür, daß die Quaestio von Oresme übernommen wurde. Dies setzt allerdings voraus, daß Oresme Quaestio III. 22 völlig unkritisch von Themon abgeschrieben hat, was man sich bei einem Denker wie Oresme nur schwer vorstellen kann" (KIRSCHNER, Nicolaus Oresmes Kommentar zur Physik des Aristoteles, p. 32, n. 102). 
Météorologiques, dont l'une ne correspondait à aucun passage dans la version connue de ce texte oresmien ${ }^{22}$, raison pour laquelle il avait renvoyé à des Questions sur les Météorologiques anonymes conservées dans le manuscrit Munich, Staatsbibibliothek, $\operatorname{Clm} 4375, \mathrm{f} .19 \mathrm{r}-46 \mathrm{r}^{23}$. Ces questions anonymes firent l'objet de deux autres articles de Kirschner. Le premier, publié en 2000, dans lequel l'auteur signalait la présence de la thèse de la nature supralunaire des comètes et de la Voie lactée ${ }^{24}$, théorie minoritaire au Moyen Âge, et partagée, comme le remarque Kirschner, par Albert le Grand, Henri de Langestein et, justement, Nicole Oresme ${ }^{25}$; le deuxième, paru en 2010, dans lequel il mentionnait la présence de la théorie oresmienne de l'accident en tant que «condition» (condicio) d'une substance ${ }^{26}$. Ces contributions, avec la découverte d'un nouveau manuscrit des Questions sur les Météorologiques de Nicole Oresme par Caroti, ont révolutioné le status questionis à propos de cet ouvrage.

\section{LE MANUSCRIT DE DARMSTADT ET LA DÉCOUVERTE DE LA REDACTIO ANTIQUA}

En 1996, Caroti publia une édition critique des Questiones super De generatione et corruptione de Nicole Oresme. Il utilisa trois manuscrits, qu'il décrivit dans son Introduction ${ }^{27}$. Celui qui porte la cote "Darmstadt, Universitäts- und Landesbibliothek, 2197", doit attirer notre attention. Le manuscrit se présente comme un recueil d'ouvrages de philosophie naturelle et de logique de Nicole Oresme et de Johannes de Wesalia, et contient deux textes attribués à Nicole Oresme et jusqu'alors complètement inconnus: une Sententia sur les Météorologiques ${ }^{28}$ et des Questions sur les Météorologiques ${ }^{29}$. Il ne faut pas

(22) Kirschner, Nicolaus Oresmes Kommentar zur Physik des Aristoteles, p. 30. Cf. aussi : NiCOLE ORESME, Questiones super physicam (Books I-VII), ed. S. CAROTI - J. CELEYRETTE - S. KIRSCHNER E. MAZET, Leyde-Boston 2013, p. XXIV.

(23) KIRSCHNER, Nicolaus Oresmes Kommentar zur Physik, p. 30-31, n. 91.

(24) ID., "An Anonymous Medieval Commentary on Aristotle's Meteorology Stating the Supralunar location of Comets ", in M. FOLKERTS - R. LORCH (ed.), "Sic itur ad astra”. Studien zur Geschichte der Mathematik und Naturwissenschaften. Festschrift für den arabisten Paul Kunitzsch Zum 70. Geburtstag, Wiesbaden 2000, p. 334-361.

(25) Ibid., p. 343.

(26) S. Kirschner, "A Possible Trace of Oresme's Condicio-Theory of Accident in an Anonymous Commentary on Aristotle's Meteorology ", Vivarium, 48 (2010), p. 349-367.

(27) Nicolaus ORESME, Questiones super De generatione et corruptione, ed. S.CAROTI, Veröffentlichungen der Kommission für die Herausgabe ungedruckter Texte aus der mittelalterlichen Geisteswelt, vol.20, Munich 1996, p. 35*sq.

(28) Aux f.100r-123r. Pour l'attribution de ce texte à Nicole Oresme, cf.f. 106ra: «Explicit sententia primi Metheororum reportata ante Magistrum Nicholaum Oresme nationis Normannorum. Incipit sententia secundi eiusdem reportata ab eodem ». Dans la marge supérieure du f. 100ra, en tête de l'ouvrage, une autre main (probablement celle du possesseur du manuscrit, Philipphus de Othey), a repris cette formule: «Sententia primi Metheororum reportata ante magistrum Nicholaum Oresme nationis Normannorum». Caroti lui-même souligne que ce texte était absent dans les bibliographies oresmiennes (NICOLE ORESME, Questiones super de generatione et corruptione, ed. CAROTI, p. $40^{*}$, n. 6 ). 
se laisser tromper par l'intitulé du deuxième texte: il suffit en effet de parcourir rapidement la liste des questions de ce commentaire pour s'apercevoir qu'il ne s'agit pas d'une copie de la rédaction répertoriée et étudiée par Birkenmajer et McCluskey ${ }^{30}$. Il semble que cette découverte soit passée presque inaperçue à la suite de la publication de Caroti, en effet, presqu'aucune contribution n'est parue faisant référence à ces nouveaux textes d'Oresme ${ }^{31}$. Ch. Lohr, dans son volume récent sur les commentateurs latins d'Aristote ${ }^{32}$, a simplement ajouté ce manuscrit aux autres copies de la rédaction connue, sans signaler que le texte transmis est complètement différent de celui des témoins jusqu'alors répertoriés.

Essayons maintenant, dans la mesure où cela nous est possible, de puiser le maximum d'informations dans ce témoin précoce de l'activité de Nicole Oresme à la Faculté des Arts de Paris. Le codex se présente comme un recueil hétérogène de textes universitaires. D'après la description de Caroti, il a été écrit par deux copistes: Johannes Balduini de Yvia, dit de Margan ${ }^{33}$, et Henricus Johannis de Dauderiche ${ }^{34}$, tous les deux alors étudiants à la Faculté des Arts de Paris et tous les deux originaires du diocèse de Liège ${ }^{35}$.

Le colophon de Johannes Balduini de Yvia nous donne deux informations importantes: le lieu de la copie, Paris - ou, plus précisement, la Faculté des Arts, « in vico straminum»-, et la date, 1346. La terminologie des colophons nous renseigne sur l'origine universitaire de ce manuscrit, qui est constitué par des

(29) Aux f. $58 \mathrm{r}-93 \mathrm{r}$ et $125 \mathrm{r}-127 \mathrm{v}$. Pour l'attribution de ce texte à Nicole Oresme, $c f$.f. $81 \mathrm{rb}$ : «Expliciunt questiones primi Metheororum compilate ante venerabilem magistrum Nicholaum de Oresme normannum».

(30) Cf. NiCOle OReSme, Questiones super de generatione et corruptione, ed. CAROTI, p. $38^{\star}-40^{\star}$, cf. aussi p. $38^{*}$, n. 5 .

(31) Il y a toutefois au moins une exception: Ch. Flüeler, dans son article sur les commentaires de Buridan à la Métaphysique, s'est intéressé au contenu de ce manuscrit, dont il a remarqué la similarité avec le codex 516, C. FlǗleR, "From Oral Lectures to Written Commentaries: John Buridan's Commentaries on Aristotle's Metaphysics", in S. EBBESEN - R. FRIEDMAN (ed.), Medieval Analyses in Language and Cognition, Copenhague 1999, p. 497-521, ici p.511-512, n. 43. Pour ce codex, voir aussi B. Patar, Nicolai Oresme Expositio et Quaestiones in Aristotelis De anima: édition, étude critique, Louvain-Paris 1995 , p. $52^{*}-63^{*}$.

(32) C. LoHr, Latin Aristotle Commentaries 1, Medieval authors, Florence 2010-2013,p. 34.

(33) Qui a écrit les f.1r-192v. Cf.f. 192vb: «Expliciunt questiones supra librum de anima reportate ante magistrum Johannem de Vezalia in vico straminum Parisius per manus Johannis Margan de Yvia anno domini $\mathrm{m} \operatorname{ccc} 46^{\circ}$ Deo gratias », cité d'après NiCOLE ORESME, Questiones super de generatione et corruptione, ed. CAROTI, p. $35^{\star}-36^{\star}$.

(34) Qui a copié les f. 193r-231r. Cf. le f. 231rb: «Expliciunt questiones libri Elencorum scripte coram reverendo magistro Johanne de Vezalia per manum Henrici Johannis de Dauderiche dyocesis Leodiensis ", cité d'après NICOLE ORESME, Questiones super de generatione et corruptione, ed. CAROTI, p. $35^{*}-36^{*}$. Johannes de Dauderiche a copié aussi la Sententia de Buridan sur la Métaphysique d'Aristote transmise aux folios 1ra-32va du manuscrit 516 de la même bibliothèque, $c f$. FLÜELER, «From Oral Lectures to Written Commentaries », p. 512-513 et ID., «Two Manuscripts of Buridan on the Methaphysics: Paris, BN, lat 16131 and Darmstadt, Hessische Lu\&HB 516», Cahiers de l'Institut du Moyen Âge grec et latin, 67 (1997), p. 78-92.

(35) Pour d'autres informations sur ces deux personnages, $c f$. NICOLE ORESME, Questiones super de generatione et corruptione, ed. CAROTI, p. $46^{*}$. 
notes de cours prises par les étudiants sous la dictée des maîtres et par des rédactions révisées par les maîtres ${ }^{36}$.

Le même colophon des Questiones sur les Météorologiques nous apprend aussi qu'elles ont été « compilate ante magistrum Nicolaum Oresme». Or, quelle est la signification qu'il faut attribuer à cette formule? Ch. Flüeler, qui a étudié la terminologie des colophons et des souscriptions des textes universitaires ${ }^{37}$, souligne que le terme technique "compilatus», qui apparaît assez fréquemment dans les colophons, n'indique pas un texte assemblé à partir de différentes sources, mais plutôt une version d'une reportatio corrigée et approuvée par le maître ${ }^{38}$. Cette expression se retrouve dans un manuscrit qui transmet une copie de la version répertoriée des Questions sur les Météorologiques de Nicole Oresme: Kraków, Uniwersytet Jagielloński, Biblioteka Jagiellońska, 2095, f. 245r-307r. Au f. 307rb, on lit en effet: «Et sic patent questiones tocius libri Metheororum, compilate per reverendum magistrum Orem Parisiensem et comparate per Johannem Stolle in Studio alme Universitatis Pragensis, a. D. $1406{ }^{39}$. Le texte transmis aux folios 58r-92v du manuscrit 2197 représenterait donc une version approuvée des Questions sur les Météorologiques de Nicole Oresme. Il s'agit d'ailleurs, s'il faut se fier à la date du colophon au folio 192vb, d'une version antérieure à celle qui avait été répertoriée, et dont le premier témoin daté n'a été copié que vingt ans après, en $1366^{40}$. C’est pourquoi, dans la suite nous nous référerons à cette rédaction avec l'appelation de redactio antiqua, et à la rédaction étudiée par Birkenmajer et McCluskey avec celle de redactio nova.

(36) Cf.f. 81rb: "Expliciunt questiones primi Metheororum compilate ante magistrum Nicholaum de Oresme Normannum Deo gratias. Incipiunt questiones secundi eiusdem ab eodem »; f. 106ra: "Explicit sententia primi Metheororum reportata ante magistrum Nicholaum Oresme nationis Normannorum. Incipit sententia secundi eiusdem reportata ab eodem»; f.176rb: «Expliciunt questiones super primum et secundum De anima in numero 37 reportate ante magistrum Johannem»; f. 192vb: «Expliciunt questiones supra librum De anima reportate ante magistrum Johannem de Vezalia in vico straminum parisius per manus Johannis Margan de Yvia anno domini $\mathrm{m}^{\circ} \mathrm{ccc}^{\circ} 46$ Deo gratias »; f. 231 rb: «Expliciunt questiones libri Elencorum scripte coram reverendo magistro Johanne de Vezalia ». Cf. NICOLE ORESME, Questiones super de generatione et corruptione, ed. CAROTI, p. $38^{*}-44^{*}$ et FlÜELER, « From Oral Lectures to Written Commentaries », p. 512, n. 43.

(37) ID., «Die verschiedenen literarischen Gattungen der Aristoteles-kommentare: zur Terminologie der Überschriften und Kolophon », in J. HAMEsse (ed.), Manuels, programmes de cours et techniques d'enseignement dans les universités médiévales, Louvain-la-Neuve 1994, p. 75-116.

(38) FlÜeler, «From Oral Lectures to Written Commentaries», p. 513 et NiCOle Oresme, Questiones super Physicam (Books I-VII), ed. CAROTI - CELEYRETTE - KIRSCHNER - MAZET, p. XIX. La même terminologie se retrouve aussi, par exemple, dans un autre manuscrit de l'Universitäts- und Landesbibliothek de Darmstadt, le codex 516, lui-aussi écrit en 1346 par Iohannes de Danrediche, l'un des copistes du codex 2197. Au f. 8vb, on lit en effet: « Et in hoc terminatur sententia tocius quarti libri methafisice que fuit completa in nocte sancti martini anno domini $\mathrm{m}^{\circ} \mathrm{ccc}^{\circ} \mathrm{xlvi}^{\circ}$ per manum Henrici Iohannis de dandrediche ante magistrum iohannem bridan nacionis picardie. Explicit sententia quarti methafisice compilata ante reverendum doctorem et magistrum magistrum Iohannem Bridan scripta per manum Henrici Iohannis de Danrediche etc. Incipit sententia quinti eiusdem compilata a magistro eodem, etc. ", cité d'après FLÜELER, « From Oral Lectures to Written Commentaries », p. 512.

(39) Cité d'après M. MARKOWSKI - Z. WŁODEK, Repertorium commentariorum medii aevi in Aristotelem Latinorum quae in Bibliotheca Jagellonica Cracoviae asservantur, Wrocław 1974, p. 109.

(40) Il s'agit du texte transmis dans le manuscrit München, Bayerische Staatsbibliothek, Clm 4376, f. 1r-64r. 
Dans sa description du codex, Caroti écrit qu'il a été copié par deux scribes ${ }^{41}$ : Johannes Margan de Yvia, qui a écrit les f.1r-192v, et Henricus Johannis de Danrediche, qui a écrit les f. 193r-232v. D'après l'indication de Caroti, donc, les Questions sur les Météorologiques, transmises aux f.58r-98r et $125 \mathrm{r}-127 \mathrm{v}$, devraient être l'œuvre d'un seul copiste, que l'on devrait identifier avec Johannes Margan de Yvia du f. 192vb. Il est toutefois évident que les f. $80 \mathrm{r}-82 \mathrm{r}$ et $125 \mathrm{r}-127 \mathrm{v}$ ont été écrits par une main différente de celle qui a copié les f. 58rb-79v et 85r-92v. Si l'on compare les deux écritures avec celle du colophon du f.192vb, on peut identifier Margan avec le scribe des f. 58r-79v et $85 \mathrm{r}-98 \mathrm{v}$, donc la partie plus importante du texte ${ }^{42}$.

Au cours du texte des Questions sur les Météorologiques transmis aux f. 58r$98 \mathrm{r}$ et $125 \mathrm{r}-127 \mathrm{v}$, on peut distinguer au moins trois mains: une première main, très probablement celle de Johannes Margan de Yvia, qui a écrit avec une encre brun pâle; une deuxième main, d'un scribe inconnu, qui a utilisé la même encre; une troisième main, qui a écrit avec une encre noire, et que l'on peut probablement identifier à celle du possesseur du manuscrit, Philippus de Othey ${ }^{43}$ ). Les deux premières mains sont contemporaines à la rédaction du texte; la troisième y est postérieure. Pour la suite, nous nous référerons à la première main avec la lettre $\mathrm{A}$, à la deuxième avec la lettre $\mathrm{B}$, et à la troisième avec la lettre $\mathrm{C}$. La main $\mathrm{A} a$ copié le texte principal (à savoir, tout le texte du premier livre des Questiones sur les Météorologiques, sauf celui transmis aux f.80r-82r). La main B a copié les questions du premier livre transmises aux f.80r-82r (Utrum habitatio terre permutentur propter mare, f.80rb; Utrum habitatio terre permutetur propter intemperantiam in qualitatibus secundis, f. 80vb; Utrum locus naturalis elementi aque sit ubi nunc est mare, f. 81rb; Utrum mare fluat et refluat, f. 81v), et les questions du quatrième livre, transmises aux f.125r-127v (IV.1, Utrum sint tantum quatuor qualitates prime; IV.2, Utrum qualitatum primarum due sunt active et due passive, scilicet caliditas et siccitas active, et alie passive; IV. 3, Utrum caliditas sit magis qualitas activa quam frigiditas); la main $\mathrm{C}$ a écrit des intitulés et des notes (f.58r: "Questiones primi metheororum compilate ante magistrum nicholaum de oresme normannum, sed de questionibus secundi libri non sunt nisi quatordecim questiones»; f. 80r: «Istud folium est idem quod precedens, quere ad tale signum»; f.81rb «compilate ante venerabilem magistrum Nicholaum de Oresme normannum. Incipiunt questiones secundo eiusdem ab eodem »; f. 85ra: "Ista questio et due sequentes habentur etiam post quintum

(41) Nicole Oresme, Questiones super de generatione et corruptione, ed. CAROTI, p. $35^{*}$.

(42) Ce fait nous a été confirmé par M.Björn Gebert, bibliothécaire à l'Universitäts- und Landesbibliothek de Darmstadt.

(43) Prieur au monastère de Saint-Jacques de Liège, il est le possesseur de deux autres manuscrits conservés à l'Universitäts- und Landesbibliothek de Darmstadt: le ms. 14 et le ms. 756. Pour l'identification de la main qui écrit en encre noire avec celle de ce personnage, $c f$. FLÜELER, "From Oral Lectures to Written Commentaries", p.512, n. 43. En revanche, M. Björn Gebert, bibliothécaire à l'Universitäts- und Landesbibliothek de Darmstadt, affirme ne pas être sûr que la main qui a écrit la marque de possession soit la même que celle qui a ajouté des titres et complété les colophons des ouvrages contenus dans le manuscrit. 
folium, et sunt idem»; f. 125r: "Questiones super quartum Metheororum, sed non sunt nisi tria folia»).

À partir du f. 80r, et jusqu'au f. 85r, le texte présente une anomalie. Dans la marge inférieure du f. $79 \mathrm{v}$, après un espace d'une demi-colonne laissé blanc (après la fin de la question I.32, Utrum habitatio terre permutetur propter mare), la main A a écrit: "nihil deest", pour indiquer que le texte, quoique suivi par un espace blanc, est complet; toutefois, un peu plus bas, on trouve la réclame: "putridos exalatos », écrite par la main C. Le texte qui commence au folio suivant, 80r et qui a été copié par la main $B$, reprend effectivement avec les mots « putridos exalatos", au milieu d'une question. Cette anomalie est signalée par une remarque, elle-aussi écrite par la main $C$, dans la marge supérieure du folio 80r: "Istud folium est idem quod precendes, quere ad tale signum ». Le signe renvoie au f. 79r, question I. 31 (Utrum habitationes permutentur), ligne 33, où l'on trouve effectivement: "propter fumos putridos exalatos a terra ». Dans le texte copié par la main B, toutefois, cette question est la I.30, la question I.31 commençant seulement à la colonne b du f. 80v. Le copiste qui a écrit ce texte (main B) a donc suivi une numérotation différente de celui qui a copié le reste du texte (main A). La première et la moitié de la seconde colonne du f.80r sont occupées par la question I. 30, qui correspond à la I. 31 du texte principal (main A). La seconde moitié de la colonne b est occupée par la question I.31, Utrum habitatio terre permutetur propter mare, qui correspond à la question I. 32 (f. 79rb-79vb) du texte principal. Cette question continue jusqu'au f. $80 \mathrm{vb}$, où elle est suivie par la question I. 32 (Utrum habitatio terre permutentur propter intemperantiam in qualitatibus secundis), qui, dans le texte principal, est la I. 33 et se trouve au f. 85ra. Dans la marge inférieure du folio, la main $\mathrm{C}$ a écrit, en se référant à cette question I.32: "Ista questio et due sequentes habentur etiam post quintum folium, et sunt idem». Les due sequentes sont la question II. 1, Utrum locus naturalis elementi aque sit ubi nunc est mare, qui se trouve pour la première fois au f. 81rb, par la main B, et après au f. 85va, par la main A; et la question II. 2, Utrum mare fluat et refluat, qui se trouve au f. 81vb, par la main $B$, et après au f. 86ra, par la main A.Il semble donc que le faux emplacement de la réclame "putridos exalatos» ait déterminé une erreur dans l'assemblage des cahiers et, de ce fait, l'interpolation d'un certain nombre de questions provenant d'une autre version du cours d'Oresme. À cause de ce phénomène d'interpolation, on trouve deux incipits et deux intitulés de fin du premier livre et de début du deuxième. Le premier, écrit en grands caractères par la main B, au f.81rb («Expliciunt questiones primi Metheororum compilate ante venerabilem magistrum Nicholaum de Oresme normannum. Deo gratias. Incipiunt questiones secundi eiusdem ab eodem »); le second, écrit avec la même police que le reste du texte par la main A, au f. 85rb: "Expliciunt questiones super primum metheororum ». La main C, copiant la formule utilisée au f. 81 rb par la main B, a ajouté: «compilate ante venerabilem magistrum Nicholaum de Oresme normannum. Incipiunt 
questiones secundo eiusdem ab eodem ». On peut représenter le contenu de cette interpolation comme suit ${ }^{44}$ :

-f. 80r:q. I. 30 [I. 31,f. 79ra]; q. I. 31 [I. 32, f. 79rb]

-f. 80v:q. I. 31 [I. 32, f. 79rb]; I. 32 [I. 33, f. 85ra]

-f. 81 r:I. 32 [I. 33, f. 85ra]; II. 1 [II. 1, f. 85va]

-f. $81 \mathrm{v}$ :II. 1 [II. 1,f. 85va]; II. 2 [II. 2, f. 86ra]

- f. 82 r: II. 2 [II. 2, f. 86ra]

- f. $82 \mathrm{v}-84 \mathrm{v}$ : vides

Au cours du texte transmis aux f. 58r-98r, on trouve trois attributions à Nicole Oresme:

1)f.58r, marg. sup.: "Questiones primi metheororum compilate ante magistrum nicholaum de oresme normannum, sed de questionibus secundi libri non sunt nisi quatordecim questiones »;

2)f.58rb: «Expliciunt questiones primi metheororum compilate ante magistrum nicholaum de oresme normannum »;

3) f. $85 \mathrm{rb}$ : «Expliciunt questiones super primum metheororum compilate ante venerabilem magistrum nicholaum de oresme normannum ».

Si on les regarde de plus près, toutefois, on s'aperçoit qu'aucune de ces formules, en tant que telle, ne peut nous aider à attribuer à Oresme le texte des Questiones. L'attribution au f.58r a en effet été ajoutée par la main C, probablement sur la base d'une formulation identique qui apparaît au f.81rb: «Expliciunt questiones primi Metheororum compilate ante venerabilem magistrum Nicholaum de Oresme normannum ${ }^{45}$. Cette mention, écrite par la main $B$, se réfère très probablement au texte présent aux $\mathrm{f}$. 80r-82r et copié par la même main $B$, et non au texte principal, copié par la main A. La dernière attestation de l'attribution, au f. 85rv, est particulièrement intéressante: en effet, la main A y a écrit, avec la même police que le reste du texte: «Expliciunt questiones super primum metheororum »; la main $C$, utilisant de nouveau la formule employée au f. 81rb par la main B, a atout: «compilate ante venerabilem magistrum Nicholaum de Oresme normannum. Incipiunt questiones secundo eiusdem $\mathrm{ab}$ eodem». On peut résumer ces observations concernant les attributions comme suit :

-f. 58r: main C

$-\mathrm{f} .81 \mathrm{rb}:$ main B

- f. $85 \mathrm{rb}$ : main C

(44) Nous avons ajouté entre guillemets la numérotation et le folio correspondants dans le texte principal, à savoir le texte copié par la main $\mathrm{A}$.

(45) Un phénomène analogue se vérifie dans le cas de la Sententia sur les Météorologiques transmise aux. f. 100r-123v du même manuscrit: au f. 106ra, en effet, la main qui a copié le texte (et que l'on peut identifier avec la main A), a écrit: «Explicit sententia primi Metheororum reportata ante Magistrum Nicholaum Oresme nationis Normannorum. Incipit sententia secundi eiusdem reportata ab eodem ». Dans la marge supérieure du f. 100ra, en tête de l'ouvrage, la main C a repris cette formule comme suit: «Sententia primi Metheororum reportata ante magistrum Nicholaum Oresme nationis Normannorum». 
On le voit donc: aucune de ces formulations n'a été écrite par la main A. Le texte des Questions sur les Météorologiques transmis aux f. 58ra-79vb et 85ra-98rb (à savoir tout le texte sauf les questions interpolées) est donc anonyme. Cela ne signifie toutefois pas qu'il ne peut pas être attribué à Oresme. De ces trois attributions, la seule qui nous intéresse est celle écrite par la main B, la seule à être contemporaine à la rédaction du texte: or, il suffit de comparer le texte des questions interpolées avec les questions correspondantes dans le texte principal pour constater que, avec quelques variantes, il s'agit du même texte, raison pour laquelle, si l'on peut attribuer le texte écrit par la main B à Nicole Oresme, et que celui-ci correspond à peu près avec le texte écrit par la main $\mathrm{A}$, il faudra attribuer au maître parisien ce dernier aussi.

Nous avons déjà évoqué le fait que cette rédaction des Questions sur les Météorologiques est fort différente de celle qui avait été jusqu’à présent transmise sous le nom de Nicole Oresme. Cette différence touche à plusieurs aspects du texte: nombre et type des questions, divisions des livres, éléments doctrinaux. Pour mieux saisir une partie de ces aspects, nous avons établi la liste des questions des deux rédactions de façon synoptique:

\begin{tabular}{|c|c|}
\hline Questions de la redactio antiqua & Questions de la redactio nova \\
\hline & $\begin{array}{l}\text { I.1 Utrum possibile de impressionibus } \\
\text { meteorologicis sit habere simul scientiam et } \\
\text { opinionem }\end{array}$ \\
\hline $\begin{array}{l}\text { I.1 Utrum impressiones meteorologice fiant } \\
\text { secundum naturam inordinatiorem ea que est } \\
\text { primi elementi corporum, id est secundum } \\
\text { naturam minus ordinatam quam natura celi }\end{array}$ & $\begin{array}{l}\text { I.2 Utrum impressiones meteorologice fiant } \\
\text { secundum naturam inordinatiorem quam sit } \\
\text { natura celi }\end{array}$ \\
\hline $\begin{array}{l}\text { I. } 2 \text { Utrum iste mundus inferior sit contiguus } \\
\text { ipsi celo }\end{array}$ & \\
\hline $\begin{array}{l}\text { I.3 Utrum omnis virtus inferior a superioribus, } \\
\text { scilicet supercelestibus, gubernetur }\end{array}$ & $\begin{array}{l}\text { I. } 3 \text { Utrum iste mundus inferior sit contiguus } \\
\text { lationibus superioribus ut virtus eius inde } \\
\text { gubernetur }\end{array}$ \\
\hline \multicolumn{2}{|l|}{$\begin{array}{l}\text { I.4 Utrum aliquis motus localis in istis } \\
\text { inferioribus sit effective a celo }\end{array}$} \\
\hline $\begin{array}{l}\text { I. } 5 \text { Utrum, cessante motu celi, fierent } \\
\text { generationes, alterationes, impressiones et } \\
\text { similia in istis inferioribus }\end{array}$ & $\begin{array}{l}\text { I. } 4 \text { Utrum, cessante motu celi, cessarent motus } \\
\text { in isto mundo inferiori }\end{array}$ \\
\hline \multirow[t]{3}{*}{$\begin{array}{l}\text { I.6 Utrum, solo primo motu superiorum } \\
\text { cessante, fierent generationes, impressiones } \\
\text { etc., posito quod Sol et alii planete moverentur }\end{array}$} & \\
\hline & $\begin{array}{l}\text { I. } 5 \text { Utrum eedem opiniones infinities } \\
\text { reiterentur }\end{array}$ \\
\hline & $\begin{array}{l}\text { I.7 Utrum quatuor elementa semper et } \\
\text { immutabiliter habeant eandem proportionem } \\
\text { adinvicem sic quod una vice ignis non sit maior } \\
\text { quam in alia et similiter etc. }\end{array}$ \\
\hline
\end{tabular}


I.7 Utrum motus localis sit causa caloris I.8 Utrum aer superior et ignis in suis speris calefiant ex motu celi

I.10 Utrum quatuor elementa sint continue proportionalia

I.9 Utrum lumen in istis inferioribus a corporibus celestibus generetur

I.11 Utrum omne lumen sit calefactivum

I.12 Utrum omne corpus oppositum luminoso sit calefactibile per lumen

I.13 Utrum aliquod agens posset agere in passum distans ab eo sine hoc quod agat in intermedium

I.14 Utrum aliquod agens fortius agat in remotum quam in sibi propinquum

I.15 Utrum unum contrarium posset movere localiter alterum sibi contrarium

I.16 Utrum media regio aeris sit semper frigida

I.17 Utrum flamme apparentes de nocte in aere fiant ibi naturaliter

I.18 Utrum serenitate existente appareant in celo de nocte iatus seu aperture et voragines et sanguinei colores

I.19 Utrum stelle comete sint de natura celi aut elementari

I.20 Utrum naturalis motus stelle comete sit naturalis

I.21 Utrum comete significent guerras, mortes principum, pestilentias et huiusmodi

I.22 Utrum omnes comete sint eiusdem speciei inter se et cum galaxia

I.23 Utrum impressiones humide fiant a calido

I.24 Utrum omnes impressiones aque sint eiusdem speciei

I.25 Utrum nix et pluvia generentur in media aeris regione
I.8 Utrum motus celi sit causa calefaciendi ignis in sua spera et etiam aeris superioris

I.6 Utrum elementa sint continue proportionalia adinvicem

I.9 Utrum lumen sit productivum caloris

I.10 Utrum contrarium circumstans suum contrarium fortificet ipsum

I.11 Utrum semper media regio aeris sit frigida

I.12 Utrum omnium impressionum meteorologicarum vapor et exalatio fuerit principium materiale

I.13 Utrum impressiones ignite seu ille que fiunt per inflammationem fiant naturaliter in aere

I.14 Utrum de nocte serenitate existente debeant apparere hyatus et voragines et sanguinei colores in celo

I.15 Utrum cometa sit de natura celi vel elementari

I.16 Utrum cometa sit exalatio calida et inflammata

I.19 Utrum galaxia sit de natura celi vel elementari

II.1 Utrum locus generationis pluviarum sit media regio aeris 
I.26 Utrum grando debeat magis fieri in hieme, vel estate, aut in temporibus medibus sicut in vere aut in autompno

I.27 Utrum nebula sit signum serenitatis

I.28 Utrum aqua naturaliter ascendat ad orificia fontium

I.29 Utrum fontes et fluvii veniant ex aqua pluviali, vel ex mari, vel aliunde

I.30 Utrum fontes et flumina derivantur a montibus

I.31 Utrum habitationes permutentur I.32 Utrum habitatio permutetur propter mare I.33 Utrum habitatio terre permutetur propter intemperantiam in qualitatibus secondi

II.1 Utrum locus naturalis elementi aque sit ubi nunc est mare

II.2 Utrum mare fluat et refluat

II.3 Utrum aqua maris sit salsa

II.4 Utrum fontes et fluvii debant esse salsi

II.5 Utrum ventus sit exalatio sicca

II.6 Utrum Auster veniat a polo antartico et Boreas ab artico

\section{II.7 Utrum terremotus sit possibilis}

II.8 Utrum terremotus, ventus et tonitrum et similia sint eiusdem nature

II 9 Utrum fulgur sit exalatio calida et sicca ignita
II.2 Utrum ros et pruina, pluvia et nix sint eiusdem speciei

II.3 Utrum grandines magis debent generari in hieme quam in vere vel in autumno

II.4 Utrum aqua calida applicata frigori citius congeletur quam aqua frigida

II.5 Utrum rubedo matutina sit signum future pluvie

II.6 Utrum caligo sit signum future pluvie

II.7 Utrum aqua naturaliter ascendat ad orificia fontium

II.8 Utrum aque fontium generentur in terra

II.9 Utrum mare sit perpetuum vel aliquando fiat de non vel aliquando non

II.10 Utrum mare debeat fluere et refluere

II.11 Utrum aqua maris debeat esse salsa

II.12 Utrum aque puteales esse debeant salse

III.1 Utrum ventus sit exalatio calida et sicca

III. 2 Utrum Sol faciat cessare ventos et commoveat eos

III.3 Utrum Boreas veniat a polo artico et Auster a polo antartico

III.4 Utrum motus terre sit possibilis

III.5 Utrum tranquillitas sit signum terre motus III.6 Utrum tonitrum sit extinctio ignis in nube III.7 Utrum exalatio ex qua fiunt tonitrua et corruscationes debeat descendere versus terram

III.8 Utrum corruscatio sit possibilis 
II.10 Utrum visus refrangantur a corporibus densis

II.11 Utrum halo fiat ex refractione radiorum abipsa nube

II.12 Utrum sit aliquis color spiritualis II.13 Utrum colores apparentes in yride sint ibi vere et realiter

II.14 Utrum yris debeat apparere secundum circuli periferiam

II.15 Utrum yris posset apparere maior semicirculo

II.16 Utrum yris quandoque appareat secundum proportionem maioris et quandoque minoris circuli
III.9 Utrum fulmen aliquod sit penetrans et aliud adurens

III.10 Utrum indifferenter quodlibet posset percutifulmine

III.11 Utrum tiphon et ecnephia et incensio sint exalationes calide et sicce

III.12 Utrum visus frangatur in occursu medii densioris vel rarioris puta aque vel aeris

III.13 Utrum cuiuslibet corporis superficies reflectat virtutes super ipsam incidentes, sicut sunt lumen, species coloris et huiusmodi

III.14 Utrum virtutes reflexe sint debiliores virtutibus non reflexis

III.15 Utrum aliqua specula reflectent solum colorem et non figuram, accipiendo colorem prout extendit se ad lucem et ad colorem proprie dictum

III.16 Utrum in apparitione ipsius halonis interponatur vapor inter visum et astrum III.17 Utrum halo fiat per refractionem vel per reflexionem radiorum visualium super vaporem medium inter astrum sub quo halo apparet et visum nostrum

III.18 Utrum halo debeat apparere secundum circuli periferiam vel circumferentiam

III.19 Utrum radius visualis debeat reflecti ab aere uniformi non condensato nec mixto vaporibus et ad oculum videntis existentis in eodem aere sine adiutorio speculorum

III.20 Utrum colores yridis sint colores secundum rei veritatem vel solum secundum apparentiam

III.21 Utrum yris sit forma realis nubi impressa vel sit solum forma ymaginaria

III.22 Utrum yris sit forma dyaphanalis vel specularis vel utrum yris fiat per reflexionem vel refractionem 
IV.1 Utrum sint tantum quatuor qualitates prime

IV.2 Utrum qualitatum primarum due sint active et due passive, scilicet caliditas et siccitas active, et alie passive
III.23 Utrum, supposito quod yris fiat per reflexionem radiorum, utrum tunc fiat in nube vel super guttulas roridas vel super stillicidia

III.24 Utrum omnis yris debeat esse tricolor III.25 Utrum yris solum dupliciter et non multipliciter potest apparere

III.26 Utrum semper, apparentibus duabus yridibus, superior yris debet habere colores conversim positos

III.27 Utrum yris superior vel secundaria necessarie debeat apparere et esse remissior in coloribus quam principalis yris

III.28 Utrum yris debeat apparere secundum circuli periferiam si non sit impedimentum

III.29 Utrum semper, tempore apparitionis yridis, necesset sit centrum solis et centrum yridis et polos eorundem esse in eadem linea recta

III.30 Utrum, tempore apparitionis yridis et halonis, dyameter yridis sit precise dupla ad dyametrum halonis

III.31 Utrum omni hora diei artifici lis, oculo existente in superficiem orizontis, posset aliqua portio yridis apparere ubicumque fuerit homo vel oculus videntis

III.32 Utrum yris lune potest pluries apparere quam bis in quinquaginta annis in consimilibus coloribus et proprietatibus sicut yris solis

III.33 Utrum, visa yride et sole vel astro elevato notabiliter, super orizontem apparet minor portio maioris circuli quam appareat sole exeunte in fine orizontis

III.34 Utrum virge et parelii fiant ex reflexionem vel refractionem radiorum sicut yris vel halo

III.35 Utrum per iuvamen artis possunt fieri metalla

IV.1 Utrum tantum quattuor sunt qualitates prime, scilicet caliditas, humiditas, frigiditas, siccitas

IV.2 Utrum quattuor qualitates videlicet caliditas, frigiditas, etc., sint principia activa in generatione cuiuslibet mixti, accipiendo tamen generationem pro alteratione precedente introductionem forme substantialis mixti, eo modo quo Aristoteles accipit in secondo capitulo huius quarti 
IV.3 Utrum caliditas sit magis qualitas activa quam frigiditas

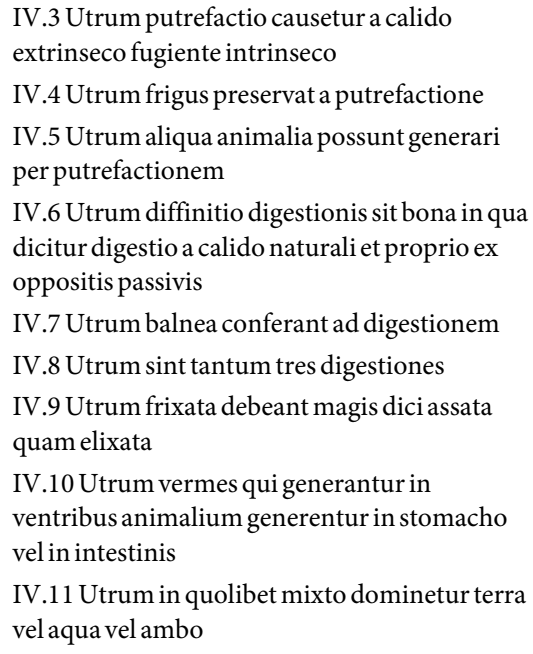

Plusieurs différences entre les listes des questions des deux rédactions sautent aux yeux. En premier lieu, la division des livres du texte aristotélicien commenté est différente. Dans la redactio antiqua, en effet, Oresme adopte la division des livres de la traduction gréco-latine de Guillaume de Moerbeke ${ }^{46}$, tandis que dans la redactio nova, il adopte la division présente dans le commentaire d'Albert le Grand et propre à certains manuscrits de la traduction arabo-latine de Gérard de Crémone ${ }^{47}$. La division différente des livres dans les deux rédactions détermine l'organisation respective des questions et des thématiques. Ainsi, une partie des questions qui, dans la redactio nova, sont abordées dans le troisième livre, trouvent leur correspondant dans des questions du deuxième livre de la redactio antiqua $^{48}$. En outre, quoique à partir d'une comparaison purement formelle, il semble que certaines des questions de la redactio antiqua, notamment dans le premier livre, n'aient aucun correspondant dans la redactio nova, une analyse du contenu révèle que, dans plusieurs cas, les questions de la redactio nova condensent la matière qui avait fait l'objet de questions distinctes dans la redactio antiqua ${ }^{49}$. Ces considérations, tout en montrant qu'entre les questions des deux

(46) Meteorologica, Translatio Guillemi de Moerbeka, ed. G. VueILlemin-DiEM, Bruxelles 2008 (AL X 2.1)

(47) P. SchoonheIm (ed.), Aristotle's Meteorology in the arabico-latin Tradition. A Critical Edition of the Textes, with Introduction and Indices, Leyde-Boston-Cologne 2000 (Aristoteles semiticolatinus, 12). Sur les différentes divisions des livres des Météorologiques d'Aristote, cf.ibid., p. 39-40, BirkenMajER, Etudes, p. 198, et ThORNDIKe, Oresme and Fourteenth Century Commentaries, p. 149.

(48) Par exemple, la question III. 1 Utrum ventus sit exalatio calida et sicca de la redactio nova, correspond à la question II. 5 de la redactio antiqua; la III. 3, Utrum Boreas veniat a polo artico et Auster a polo antartico à la II. 6; la III. 4, Utrum motus terre sit possibilis à la II. 7, etc.

(49) C'est le cas, par exemple, des questions I. 2 et I. 3 de la redactio antiqua, qui trouvent leur correspondant dans la question I. 3 de la redactio nova, et des questions I. 7 et I. 8 de la redactio antiqua, qui ont été résumées dans la question I. 8 de la redactio nova. 
rédactions il y a un certain parallélisme, nous amènent à porter notre attention sur le contenu des deux textes. C'est en effet seulement à travers une analyse des éléments doctrinaux de la redactio antiqua qu'il sera possible d'argumenter en faveur ou non de l'attribution de ce texte à Nicole Oresme.

Nous avons évoqué plus haut ${ }^{50}$ le fait que, à plusieurs occasions, Kirschner s'était occupé d'un commentaire sur les Météorologiques anonyme, conservé à la Staatsbibibliothek de Munich et présentant des doctrines proches de celles de Nicole Oresme. Résumons brièvement les résultats de ses investigations :

1) Dans ses Questions sur la Physique, Oresme cite deux fois ses Questions sur les Météorologiques. À la question IV.14, en effet, on lit: «Respondetur quod est qualitas eque prima, sicut alie; immo ex motu locali sequitur condensatio, et ex illa sequitur calefactio et caliditas, que est qualitas prima, sicut dictum fuit in primo Methaurorum»; et à la question VII.3: «Respondetur, sicut ponit Commentator secundo Celi, quod non oportet quod eadem actione agat aliquid in medium et in distans, tamen requiritur quod aliqua; omnino sufficit quod celum sit illuminatum. Et de hoc dictum fuit in primo Methaurorum ${ }^{51}$. Or, tandis que, dans la version répertoriée des Questions, à savoir la redactio nova, il est possible de trouver un seul des passages cités ${ }^{52}$, selon Kirschner, qui ne connaissait pas le manuscrit de Darmstadt, dans les Questions sur les Météorologiques anonymes, transmises dans le manuscrit 4375 de la Staatsbibliothek de Munich, on trouve les deux ${ }^{53}$;

(50) Cf. supra, p.\#\#.

(51) NiCOLE ORESME, Questiones superphysicam (books I-VII), p. XXIV, p. 517, et p. 733.

(52) C'est-à-dire la citation à la question IV.14. À la question I.8 des Questions sur les Météorologiques traditionnellement attribuées à Nicole Oresme, Utrum motus celi sit causa calefactionis ignis in sua spera et etiam aeris superioris, on lit en effet : " Alia est opinio modernorum, et est opinio Alberti. Sed premittatur primo una distinctio, quod motus localis potest fieri dupliciter: uno modo potest fieri per quem sit distractio et confricatio partium ipsius mobilis; alio modo potest fieri per quem non fit aliquod tale, sicut si aliquid movetur in vacuo. Tunc dicit Albertus quod ratio est quod ex tali confricatione et collisione fit rarefactio violente, et istam rarefactionem violente consequitur calefactio. Et hec opinio concordat cum omnibus experientiis, unde videmus quod ex tali confricatione et calefactione corrumpunt quasdam partes certe confricationis. Et etiam videmus quod quanto sunt aliqua corpora magis polita, tanto est minor confricatio et calefactio. Tunc, secundum opinionem Alberti, sit prima conclusio : motus localis qui fit primo modo est causa caloris et calefacit, nisi sit aliquod impediens». Ce texte, de même que celui des autres citations des Questions sur les Météorologiques de Nicole Oresme, soit dans leur redactio antiqua, soit dans leur redactio nova, sont issus de notre édition du texte. Les citations de la Sententia sur les Météorologiques, quant à elles, sont issues d'une transcription de travail que nous sommes en train de réaliser.

(53) KirsCHNER, Nicolaus Oresmes Kommentar zur Physik, p. 30-31, n. 91. Dans le premier cas, le renvoi est à la question I. 7, Utrum motus localis sit causa caloris: «Tunc pono suppositiones. Prima est quod ex motu turbido fit distensio et detractio partium et rarefactio, et in tranquillo non sunt, nisi aliunde. Secunda distinctio est quod quedam sunt qualitates que se invicem consequuntur naturaliter, sicut caliditas, raritas, levitas, et etiam frigiditas, densitas, gravitas; unde primo huius dicitur quod frigidum condensat aerem in nubem et calidum disgregat. Tertia est quod in motu turbido virtus moti excitatur: si sit naturalis, quia movet; si sit violentus, quia resistit et conatur ad oppositum, unde sic excitari est agere et exire ad actum secundum. Quarta est quod dum agit est in nobiliori dispositione, et ideo inducit, secundum posse, nobiliorem conditionem et dispositionem magis convenientem, cuiusmodi est caliditas [...]. Tunc sunt tres conclusiones. Prima est quod nichil precise calefit propter motum tranquillum et uniformem [...]. Secunda conclusio est quod motus turbidus calefacit. Patet, 
2) dans les Questions anonymes de Munich, on défend la théorie - contraire à la doctrine aristotélicienne - de la localisation supralunaire des comètes, une théorie minoritaire au Moyen Âge et soutenue par Albert le Grand, Nicole Oresme et Henri de Langenstein;

3) dans ses Questions sur la Physique, Oresme propose une théorie assez particulière concernant le statut ontologique des accidents, d'après laquelle les accidents sont considérés comme des conditions, conditiones de la substance. Cette théorie est présente aussi dans les Questions anonymes de Munich ${ }^{54}$.

Tous ces éléments, ainsi que d'autres parallélismes doctrinaux frappants entre les ouvrages oresmiens et les Questions de Munich ${ }^{55}$, amenèrent Kirschner à affirmer que l'auteur anonyme des Questions sur les Météorologiques du manuscrit $\mathrm{Clm} 4375$ avait été fortement influencé par les doctrines de Nicole Oresme, voire qu'il s'agissait de Nicole Oresme lui-même ${ }^{56}$.

Dans l'article de 2010, Kirschner a fourni la liste complète des questions du manuscrit de Munich ${ }^{57}$ et a transcrit les questions I. 18-I. $21^{58}$; il avait transcrit d'autres passages de ces questions dans son article de 2001. S'il avait connu les Questions de Darmstadt, il aurait pu s'apercevoir que le texte transmis par les deux manuscrits est le même. Or, le texte des f. 19r-46r du manuscrit Clm 4375 de la Staatsbibliothek de Munich représente en réalité une autre copie de la rédaction ancienne des Questiones sur les Météorologiques de Nicole Oresme.

Pour résumer, à la lumière de ces éléments doctrinaux et des résultats de la transcription que nous sommes en train de réaliser, il nous semble que, à ce jour, il n'y a aucune raison de douter de l'authenticité des Questions sur

quia ex tali motu partes distrahuntur et rarefiunt, per primam suppositionem, et ad rarefactionem sequitur calefactio, per secundam. Secundo: forma taliter distracta excitatur, et fit actu movens et resistens, per tertiam; ergo est in nobiliori dispositione et inducit nobiliorem qualitatem, scilicet caliditatem, per quartam ». Dans le deuxième cas, Oresme renvoie à la question I. 12 (Utrum aliquod agens posset agere in passum distans ab eo sine hoc quod agat in intermedium), absente dans la version répertoriée de ses Questions sur les Météorologiques, mais présente aux f. 25ra-25vb du manuscrit de Munich. Le passage visé est celui-ci: «quia sol agit calorem in inferioribus mediante lumine, ideo oportet quod lumine sit immediatum istis illuminatis, et quod omnia intermedia sint illuminata, sed non oportet quod sint calefacta ». Bien que Kirschner ait remarqué ce fait dans sa première édition des Questions sur la Physique d'Oresme (p.30, n.91), dans l'édition des Questions sur la Physique par les éditeurs, on renvoie, pour la citation des Questions sur Météorologiques de la question VII. 3, à la question I. 8 de la rédaction répertoriée, où un tel passage est absent (NICOLE ORESME, Questiones super Physicam, p. 733, n. 20).

(54) KIRSCHNER, «A Possible Trace of Oresme’s Condicio-Theory of Accidents », p. 349-367.

(55) Ibid., p. 359-366.

(56) Cela d'autant plus que le codex 4375 témoigne d'une rédaction plus ancienne des Questions d'Oresme sur le De caelo. Cf. KIRSCHnER, «A Possible Trace of Oresme's Condicio-Theory of Accidents", p. 366-367; ID., "Eine weitere Fassung eines lateinischen 'De caelo-Kommentars'von Nicolaus Oresme?», p.209-222; ID., "Oresme's Concepts of Place, Space, and Time in His Commentary on Aristotle's Physics", Oriens-Occidens. Sciences, mathématiques et philosophie de l'Antiquité à l'âge classique, 3 (2000), p. 145-179, ici p. 159 et 166.

(57) KirschneR, «A Possible Trace of Oresme's Condicio-Theory of Accidents », p. 360-361.

(58) Transmises aux f.28va-30rb du manuscrit; $c f$. KirsCHNER, "A Possible Trace of Oresme's Condicio-Theory of Accidents », p. 346-358. 
les Météorologiques attribuées à Nicole Oresme dans le manuscrit 2197 de l'Universitäts- und Landesbibliothek de Darmstadt.

Aux copies de Darmstadt et de Munich, il faut ajouter un autre témoin de cette rédaction: le manuscrit Kraków, Uniwersytet Jagielloński, Biblioteka Jagiellońska, 753, f.51r-83v, et trois copies partielles: les manuscrits Kraków, Uniwersytet Jagielloński, Biblioteka Jagiellońska, 635, p. 177r-236v, Kraków, Uniwersytet Jagielloński, Biblioteka Jagiellońska, 686, f. 101r-134v et f. 81r-97v. Les questions contenues aux pages $177 \mathrm{r}-236 \mathrm{v}$ du manuscrit 635 et celles transmises aux f. 101ra-134va du manuscrit 686 avaient déjà attiré l'attention de Birkenmajer. En effet, lorsqu'il avait discuté le problème de la contamination dans les Questions sur les Météorologiques du XIV ${ }^{\mathrm{e}}$ siècle, il avait écrit que:

Les mss. Crac. 635 et Crac. 686 sont à cet égard très instructifs; ils contiennent les Quaestiones Meteororum d'Albert de Saxe, mais pas dans leur forme authentique (p. ex. celle du cod. Ampl. Qu. 299 ou du cod. Berol. Lat. Fol. 387): les questions I, 1-14, II, 7-17 et la totalité des livres III et IV sont d'Albert; les questions I, 15-22 et II, 1-6 manquent complètement, à leur place figurent 13 questions étrangères, relatives au livre $\mathrm{I}$ (I, 18-30) et empruntées à un recueil anonyme (assez intéressant) que le cod. Crac. 753 nous a conservé dans sa forme authentique ${ }^{59}$.

Or, à travers la collation de ces textes, nous avons pu constater que le manuscrit753 de la Bibliothèque Jagiellońska - ce recueil anonyme «assez intéressant» selon Birkenmajer - représente une autre copie de la redactio antiqua des Questions sur les Météorologiques de Nicole Oresme. Il s'ensuit que les recueils de questions des pages $177 \mathrm{r}-236 \mathrm{v}$ du manuscrit 635 et des f. 101ra-134va du manuscrit 686 sont des contaminations réalisées à partir des questions d'Albert de Saxe et de celles de la redactio antiqua de Nicole Oresme ${ }^{60}$. Quant au texte transmis aux f. $81 \mathrm{ra}-97 \mathrm{va}$ du codex 686 de la Bibliothèque Jagellońska, jusqu'à présent considéré comme anonyme ${ }^{61}$, il contient un choix de questions issues de la redactio antiqua de Nicole Oresme ${ }^{62}$. Un dépouillement systématique des commentaires par questions anonymes conservées dans les bibliothèques nous livrera probablement d'autres copies de cette rédaction des Questions sur les Météorologiques de Nicole Oresme.

Pour l'instant, limitons-nous à essayer de proposer une chronologie relative de ces nouveaux textes oresmiens dans le cadre des autres commentaires aux ouvrages aristotéliciens rédigés par Nicole Oresme pendant son activité à la Faculté des Arts. Nous avons vu que, dans ses Questions sur la Physique, Oresme

(59) BIRKENMAJER, Études, p.222; voir aussi S. KIRSCHNER, Nicolaus Oresmes Kommentar zur Physik, p. 31, n. 93, et M. Kowalczyk et alii, Catalogus codicum manuscriptorum medii aevi Latinorum, qui in Bibliotheca Jagellonica Cracoviae asservantur, vol. V: Numeros continens inde a 668 usque ad 771, Wratislaviae-Varsaviae 1993, p. 42-43.

(60) Voir plus bas, l'annexe V.

(61) MARKOWSKI - WŁODEK, Repertorium commentariorum medii aevi in Aristotelem Latinorum quae in Bibliotheca Jagellonica Cracoviae asservantur, p. 37.

(62) Voir plus bas, l'annexe VI. 
citait en deux occasions ses Questions sur les Météorologiques, dans leur version antiqua $^{63}$. Cependant, les éditeurs des Questions sur la Physique renvoient, pour les deux citations, à la redactio nova des Questions sur les Météorologiques ${ }^{64}$. Or, ces renvois ne nous semblent pas corrects. Concentrons-nous en particulier sur la citation présente à la question VII. 3, Utrum in omni motu movens et motum sint $\operatorname{simul}^{65}$. Les éditeurs indiquent la source de cette citation dans la question I. 8 de la redactio nova, Utrum motus celi sit causa calefactionis ignis in spera sua, alors que, dans cette question, il n'y a aucune référence au problème de la transmission de la chaleur solaire et de l'impassibilité des orbes célestes. Ce renvoi est d'autant plus problématique que, dans son édition partielle de 1997, Kirschner non seulement a remarqué cette incohérence, mais a aussi identifié la source exacte de la citation dans les Questions sur les Météorologiques transmises par le manuscrit München, Bayerische Staatsbibliothek, Clm 4375, f. 19ra-46rb ${ }^{66}$. Kirschner croyait que ce texte était anonyme, alors qu'il s'agit en réalité d'une copie de la redactio antiqua des Questions sur les Météorologiques d'Oresme. Mais il y a plus: à la fin de la question I. 8 de la redactio nova, Oresme cite ses Questions sur la Physique ${ }^{67}$. Comment serait-il donc possible d'admettre que le passage visé dans les Questions sur la Physique se trouve à la question I. 8 de la redactio nova des Questions sur les Météorologiques, alors que dans le second texte il est fait mention du premier? Ces problèmes doctrinaux et chronologiques peuvent être aisément résolus si l'on admet que le passage visé par Oresme dans ses Questions sur la Physique est la question I. 12 de la redactio antiqua.

(63) Cf. supra, p.\#\#.

(64) Cf. supra, p.\#\#.

(65) Nicole Oresme, Questiones super physicam (books I-VII), ed. CAROTI-CeleyretteKIRSCHNER - MAZET, p. 733, 1. 126-129: « Respondetur, sicut ponit Commentator secundo Celi, quod non oportet quod eadem actione agat aliquid in medium et in distans, tamen requiritur quod aliqua; omnino sufficit quod celum sit illuminatum. Et de hoc dictum fuit in primo Methaurorum ».

(66) Kirschner, Nicolaus Oresmes Kommentar zur Physik, p. 30-31, n.91: «Oresme läßt keine weiteren Erläuterungen folgen. Die Theorie, die hinter diesen knappen Ausführungen steht, muss man sich wie folgt denken : Der Himmel bzw. die Sonne führt mit Hilfe des lumen, das von ihr ausgeht, in der sublunaren Region eine Erwärmung herbei, wobei das lumen eine durch die virtus der Sonne primär induzierte, die Wärme dagegen eine sekundär induzierte Qualität darstellt. Die Vorstellung ist nun die, daß die primäre Qualität nur dann in etwas Entferntem hervorgerufen werden kann, wenn auch auf das dazwischenliegende Medium eine entsprechende Einwirkung erfolgt. Dagegen kann die sekundäre Qualität, d. h. in diesem Fall die Wärme, auch one daß das Medium, sprich der Himmel, erwärmt wird, in etwas Entferntem induziert werden, und zwar durch das lumen, das ja kontinuierlich übertragen wird. Es genügt also, wenn der Himmel nur erleuchtet (illuminatum) ist, er muß nicht zugleich erwärmt werden. (Als Grundlage für diese Erklärung dienten die Ausführungen en den anonymen Meteorologie-Kommentar München, Bayer. Staatsbibl., Clm 4375, f. 19ra-47rb, Qu. I. 12, utrum aliquod agens possit agere in passum distans ab eo sine hoc quod agat in intermedium, f. $25 \mathrm{ra}-25 \mathrm{vb}$. Der eigentliche Meteorologie-Kommentar Oresmes, der in 19 Handschriften überliefert ist [...] enthält keine entsprechende Quaestio». On le voit donc: la doctrine de la transmission de la chaleur céleste à laquelle Oresme faisait référence dans les Questions sur la Physique est exactement celle exposée dans la redactio antiqua des Questions sur les Météorologiques.

(67) Dans la réponse au cinquième argument contraire, on lit: "dico quod motus calefacit accipiendo motum pro mobili taliter se habere; sed utrum mobile sic se habere sit ipsum mobile, vel aliud, vel qua res sit, dicto est in libro Physicorum ». Oresme aborde ce problème dans les questions III. 2-III. 7 des Questions sur la Physique. 
À la question I. 8 de la redactio nova des Questions sur les Météorologiques, on trouve une autre autocitation, renvoyant cette fois aux Questions sur le traité $\mathrm{Du}$ ciel $^{68}$. Il s'agit d'un autre cas intéressant. Dans les Questions sur le traité Du ciel éditées par C. Kren, en effet, la question Utrum motus naturalis sit velocior in fine quam in principio, dans laquelle on trouve effectivement la référence à l'impetus ${ }^{69}$, ne se trouve pas dans le premier livre, mais dans le deuxième. En revanche, dans les Questions sur le livre Du ciel du manuscrit München, Bayerische Staatsbibliothek, Clm 4375, f.47ra-76ra, dont Kirschner a proposé l'attribution à Nicole Oresme ${ }^{70}$, cette question se trouve effectivement au premier livre $^{71}$.

Dans les Questions sur le livre $\mathrm{Du}$ ciel, on trouve d'autres références qui peuvent nous aider à nous orienter dans la chronologie relative des écrits oresmiens. La question II. 13, Utrum tota terra semper quiescat, est particulièrement précieuse à ce propos, car elle contient plusieurs autocitations : Oresme y cite en effet deux fois les Questions sur les Météorologiques ${ }^{72}$ et une fois ses

(68) «Ad tertiam, concedo quod lapis in descendendo calefit. Et quando dicebatur: "igitur, leve fieret", concedo - hoc est, fit minus gravis. Et cum dicebatur : "igitur in fine moveretur tardius quam in principio", concedo, nisi aliud obesset; sed modo in eius descensu acquirit quendam impetum, de quo dicebatur super primum Celi».

(69) The Quaestiones super de Celo of Nicole Oresme, ed. KREN, q. II. 7, responsio: «Quarto modo quod est ad propositum, ex velocitatione motus per quam acquiritur quedam habilitas vel impetus et quedam fortificatio accidentalis ad velocius movendum [...]».

(70) KirsCHNER, «Eine weitere Fassung eines lateinischen 'De caelo-Kommentars'von Nicolaus Oresme?»,p. 209-222.

(71) Ibid., p. 220. Cf. München, Bayerische Staatsbibliothek, Clm 4375, f.61va: «Omne motum naturaliter $\mathrm{ab}$ intrinseco in velocitando motum acquirit fortitudinem et habilitatem eo adiuvantem ipsum motum, quod potest dici impetus, vel inclinatio accidentalis ».

(72) The Quaestiones super de Celo of Nicole Oresme, ed. KREN, q. II.13, p.681, 1.144-147: « respondetur quod non oportet quia sicud dictum est super librum Meteororum, motus calefacit propter confricationem corporum que non est in proposito quia aer usque prope speram ignis movetur hoc modo ». La référence peut être soit à la question I. 7, Utrum motus localis sit causa caloris, de la redactio antiqua, responsio, conclusiones secunda et tertia: "Secunda conclusio est quod motus turbidus calefacit. Patet: quia ex tali motu partes distrahuntur et rarefiunt, per primam suppositionem, et ad rarefactionem sequitur calefactio, per secundam. [...] Et confirmatur per Albertum, qui in animatis assignat causam huius distractionem partium, et in animalibus motum spirituum et sanguinis. Ultima conclusio: quod motus tranquillus calefacit, non tamen solus, sed quia ex confricatione cum exteriori continente fit motus turbidus, ex quo sequitur distractio, deinde rarefactio, et calefactio consequentes. Patet ex exemplo de sagitta proiecta, et etiam de ferro confricato lapidi "; soit à la question I. 8, Utrum motus celi sit causa calefactionis ignis in sua spera et etiam aeris superioris, de la redactio nova, responsio, art. primum: «Sic ergo motus qui fit cum confricatione est causa caloris. Unde ymaginandum est quod ex tali confricatione fit quedam rarefactio et quedam partium distractio, quam consequitur caliditas ». La deuxième référence aux Questions sur les Météorologiques est la suivante: "Ad rationes in oppositum ad primam, sicud est de igne, et cetera, dico quod non est simile quia ignis est propinquior celo quam terra et propter hoc movetur ut patuit primo Meteororum» (q. II. 13, p. 698, 1.266-269 de l'édition de C. Kren). La référence est très probablement à la question I. 4, Utrum aliquis motus localis in istis inferioribus sit effective a celo, de la redactio antiqua: "Quinto: movet celum inferiora mediante solu motu locali; sic dicitur quod movet speram ignis, vel ignem in spera, quia propter nimiam velocitatem trahit secum ignem tali motu». La question du mouvement du feu par l'action du ciel est abordée aussi dans la redactio nova des Questions sur les Météorologiques, mais de façon un peu différente: q. I. 8, Utrum motus celi sit causa calefactionis ignis in sua spera et etiam aeris superioris: "Secunda conclusio : ignis sic movetur, videlicet circulariter una 
Questions sur le De spera ${ }^{73}$. Ce dernier texte en particulier est cité plusieurs fois au cours des Questions sur le traité Du ciel éditées par C. Kren ${ }^{74}$. Or, ces renvois ne sont pas sans poser problème, car, comme l'a remarqué M. Lejbowicz, il existe, en plus de la rédaction des Questions sur le De spera éditée par G. Droppers, une autre version de ces questions attribuée à Nicole Oresme, version transmise par le manuscrit Erfurt, Wissenschaftliche Allgemeinbibliothek, $4^{\circ} \mathrm{CA} 299$, f. 113r$126 \mathrm{r}^{75}$. Pour cette raison, seulement une analyse détaillée du texte des Questions sur le De spera éditées par G. Droppers et de celui des questions transmise par le manuscrit d'Erfurt - dont la paternité oresmienne doit encore être démontrée nous permettra d'établir à laquelle des deux rédactions de ce texte Oresme fait référence dans ses Questions sur le traité Du ciel.

Les renvois aux Questions sur la Physique contenus dans les Questions sur le Traité Du ciel ne sont moins problématiques, car Oresme y cite le huitième livre ${ }^{76}$. Or, le manuscrit Sevilla, Biblioteca Capitular y Colombina, 7-6-30, qui a été utilisé par Caroti, Kirschner, Celeyrette et Mazet pour leur édition des Questions sur la Physique, et qui est le seul témoin de ce texte qui ait été identifié, ne contient que les questions sur les sept premiers livres de la Physique. Il est toutefois vrai que, au

cum celo, per virtutem sibi impressam a celo, eo modo quo ferrum movetur insequendo magnetem. Patet: quia ex quo non movetur motu raptus, sicut dicebat prima conclusio, non videtur esse alius modus dicendi nisi dicatur quod sic movetur per virtutem sibi impressam a celo».

(73) The Quaestiones super de Celo of Nicole Oresme, ed. KREN, q. II. 13, Utrum possit esse aliquod corpus infinitum immobile, p.698, 1.270-275: "Adhuc circa secundum librum habent locum questiones de figura celi et stellarum et etiam de figura terre sed facte fuerunt super De spera, et etiam de situ et loco terre sed solet fieri circa quartam Physicorum et ideo non plus de secundo, et patet questio".

(74) The Quaestiones super de Celo of Nicole Oresme, ed. KREN, q. II. 6, Utrum tantum sint tres motus locales simplices secundum speciem, scilicet motus sursum et motus deorsum et circularis, p. 509, 1.21-24: «[...] sciendum primo quod aliquid moveri pluribus motibus localibus potest intelligi multipliciter, ut visum est primo huius et supra tractatum De spera»; q. II. 11, Utrum in celo sit materia, p. 637, 1.11-14: «De ista questione non est dubium quantum ad luna quin habeat lumen a sole quod manifeste patet ex eius augmento et eius decremento cuius causa et modus patuerunt in libro $D e$ spera »; q. II. 12, Utrum motus circularis celi habeat contrarium, p. 663, 1. 110-114: « [...] posito quod luna esset tale speculum quod tamen est improbatum, attamen terra cum suis motibus non est taliter figurata sed magis accedit ad rotunditatem, ut patet per eclipses [éd. : celipses] et probatum fuit supra librum Despera».

(75) M. LejBOWICZ, « Nicole Oresme et les voyages circumterrestres, ou Le poème entre la science et la religion ", Archives d'histoire doctrinale et littéraire du Moyen Âge, 55 (1988), p. 99-142, ici p. 101 et $133-138$.

(76) The Quaestiones super de Celo of Nicole Oresme, ed. KREN, q. I. 10, Utrum celum sit ingenitum, incorruptibile, inaugmentabile, inalterabile, p. 252, 1.50-55: "Sciendum tamen quod licet celum non sit genitum vera generatione que fit ex materia presupposita tamen factum est creatione que est ex nihilo et tunc cum arguitur quod motus est eternus, negatur sicud visum est super octavum Physicorum»; p. 617, q. II. 10, Utrum celum sit ingenitum, incorruptibile, inaugmentabile, inalterabile, 1. 144147 : « ad septimam dico quod posita diversitate specifica adhuc non sufficeret ad varietatem istorum effectuum nisi esset diversitas motuum, ut probatum fuit octavo Physicorum». La citation de la question I. 10 avait été remarquée déjà par J. Celeyrette ( «Les Questions sur la Physique dans l'œuvre de Nicole Oresme », in J. Celeyrette - C. Grellard (ed.), Nicole Oresme philosophe. Philosophie de la nature et philosophie de la connaissance à Paris au XIV siècle, Turnhout 2014, p. 63-82, ici, p. 66). 
cours de ces questions, on trouve plusieurs références au commentaire sur le huitième livre, comme cela a été souligné par les éditeurs ${ }^{77}$. Ils ont toutefois remarqué que, puisque toutes ces citations sont au futur, il est difficile de dire si elles se référent à un texte effectivement existant, ou plutôt à un texte qu'Oresme avait le projet d'écrire. Peut-être les citations au commentaire sur le huitième livre de la Physique contenues dans les Questions sur le Traité Du ciel, qui sont en revanche toutes au passé, attestent-elles de l'existence effective des questions sur le huitième livre ${ }^{78}$ ? C'est une piste à explorer.

Mais revenons aux autocitations oresmiennes présentes dans les Questions sur le Traité Du ciel. Pour les questions sur livre I-VII de la Physique, on trouve seulement des renvois génériques, qui ne nous fournissent aucun répère pour établir leur antériorité ou leur postériorité par rapport aux Questions sur le Traité Du ciel $^{79}$. La même chose se vérifie dans le cas des Questions sur le De generatione et corruptione ${ }^{80}$.

Dans les Questions sur le De generatione et corruptione aussi, on trouve un certain nombre d'autocitations: il s'agit presque toujours de renvois aux Questions sur la Physique ${ }^{81}$. Dans un seul cas, Oresme renvoie aux Questions surle

(77) Nicole ORESME, Questiones super Physicam (Books I-VII), p. XVII. Les questions concernées sont:IV.10,IV.21, VII. 1.

(78) Cette hypothèse avait déjà été formulée par CELEYRETTE, «Les Questions sur la Physique dans l'œuvre de Nicole Oresme», p. 66.

(79) The Quaestiones super de Celo of Nicole Oresme, ed. KREN, q. I. 20, Utrum quelibet potentia activa determinetur per maximum in quod potest, p. 343, 1.477-482: «Tertia conclusio [est] quod potentia proprie non determinatur per talem velocitatem quia eadem potentia potest velocius aut tardius; ymmo adhuc respectu eiusdem resistentie non est eadem proportio potentiarum que est velocitatem, ut habet videri super septimum Physicorum; q. II. 13, Utrum possit esse aliquod corpus infinitum immobile, p. 698, 1.270-275: "Adhuc circa secundum librum habent locum questiones de figura celi et stellarum et etiam de figura terre sed facte fuerunt super De spera, et etiam de situ et loco terre sed solet fieri circa quartam Physicorum et ideo non plus de secundo, et patet questio ».

(80) The Quaestiones super de Celo of Nicole Oresme, ed. KREN, q. I. 8, Utrum quodlibet mixtum sit naturaliter mobile secundum naturam elementi dominanti in ipso, p. 115, 1.36-40: «In ista questione implicantur tres difficultates. Prima est si elementa equaliter manent in mixto. Secunda est si necesse est semper alterum dominari scilicet si utrum possit esse aliquod mixtum equaliter, et ista magis pertinet ad librum De generatione»; q. III. 1, Utrum ex eo quod elementa sunt gravia vel levia possit probari corpora non componi ex athomis, p.701, 1.46-49: "tertio modo ex generatione, sicud quod impossibile est punctum esse calidum et ita de aliis et hoc pertinet ad librum De generatione».

(81) Nicole Oresme, Questiones super De generatione et corruptione, ed. CAROTI, I. 5, Utrum forme elementorum maneant in mixto, p. 40,1.213-215: «Impossibile est idem esse sursum et deorsum in duobus locis nisi respective sursum respectu unius et deorsum respectu alterius. Et de hoc visum est in quinto Physicorum»; I. 5, p. 42, 1.262-265: "Quarto, dicit Aristoteles in quinto Metaphysice quod elementum est ex quo fit aliquid cum insit, id est manet. Responditur quod ille accipit elementum pro materia et forma, que verius sunt prima elementa, ut dictum est secundo Physicorum "; I. 12, Utrum augmentatio sit generatio, p. 109, 1. 171-172: «Ultima conclusio: quod augmentatio est verus motus ad quantitatem, et potest probari ex diffinitione motus, ut visum fuit supra quinto Physicorum »; I. 16, Utrum augmentatio sit motus continuus, p. 141, p.1.171-172: «Ad sextam, cum dicitur quod omnis motus continuus est de contrario in contrarium, visum fuit in quinto Physicorum» I. 21, Utrum omnis mixtio sit naturalis, p. 177, 1.53-56: "Tertio, sciendum quod "contingens", "casuale", "monstrum" et "violentum" habent quandam convenientiam et etiam differentiam, unde "contingens" dicitur respectu liberi arbitrii, et ideo, sicut patet supra secundum Physicorum, si nullum esset liberum arbitrium, omnia evenirent de necessitate [...]»; I.21, Utrum omnis mixtio sit naturalis, p.177, 
Traité $\mathrm{Du}$ ciel $^{82}$. Il me semble que la source de cette citation sont plutôt les Questions éditées par Kren que celles découvertes par Kirschner, car, dans le premier texte, il y a un certain nombre de questions consacrées aux qualités de la légèreté et de la gravité (notamment les questions IV.1-5), tandis qu'il n'y en a pas dans le second.

Ces références intertextuelles nous permettent d'esquisser une hypothèse de chronologie relative: Oresme aurait commenté les Météorologiques une première fois vers la moitié des années ' $40 \mathrm{du} \mathrm{XIV}^{\mathrm{e}}$ siècle, au tout début de son enseignement. À cette époque-là, il aurait consacré au texte aristotélicien un commentaire littéral, la Sententia, et un commentaire par questions ${ }^{83}$. Peu après, il aurait commenté, dans l'ordre, la Physique ${ }^{84}$ le traité Du ciel, et le traité De la génération

1. 83-84: «[...] sicut dictum est supra secundum Physicorum, nihil alterat seipsum primo contra suam inclinationem, sive sit simplex sive mixtum».

(82) Nicole ORESME, Questiones super de generatione et corruptione, ed. CAROTI, q. II. 1, Utrum tantum sint quatuor qualitates prime, scilicet caliditas, frigiditas, siccitas et humiditas, p. 182, 1.32-35: «Octavo, quia gravitas et levitas immediate consequuntur prima corpora, scilicet elementa, et sunt minus separabiles, quia citius potest terra calefieri quam levefieri; et similiter de istis qualitatibus determinatum est in priori, scilicet in libro De celo et mundo [...]».

(83) Tout au long de la Sententia, on trouve des nombreux renvois aux questions: f. 100ra: «Iste dicitur liber metheorum, et quare sic vocatur patuit in prima questione», qui renvoie à la question I. 1, Utrum impressiones meteorologice fiant secundum naturam inordinatiorem ea que est primi elementi corporum : «Et quia maior pars talium fit super terram, ideo dicuntur metheorologice, a metha, quod est trans, et theros, quod est visio aut speculatio, quasi res de supra apparens, hoc est supra terram in aere»; f. 100rb: «Est autem etc. Ponit causam efficientem, dicens quod de necessitate iste mondus inferior est continuus et contiguus lationibus superioribus, id est celo, ut omnis virtus gubernetur inde tamquam a principali agente, ut dictum est in questione», qui renvoie à la question I. 3, Utrum omnis virtus inferior a superioribus, scilicet a supercelestibus, gubernetur: «Ultima conclusio est quod omnis virtus naturalis inferior a supercelestibus gubernatur. Et patet primo per primam conclusionem, quia experimus quod celum agit in aliquibus, ergo verisimile est quod etiam in aliis, pari ratione. Secundo, influentie celestium sunt ubique, nec impediuntur per opacum, per secundam conclusionem, sed cuilibet qualitati inferius agenti est aliqua influentia consimilis et conformis, per primam conclusionem, quia quidam planete sunt frigidi, alii calidi sunt, ergo per talem influentiam coagunt cum qualitatibus inferioribus. [...] Quarto, rationibus Alberti, capitulo quarto, quia motus elementorum sunt irregulares et moventur velocius in fine, igitur indigent aliquo regulante, et non est aliud quam motus celi. Secundo est quod aliter, elementis distantibus, non fieret commixtio, nisi alterum, sicut ignis, condensaretur ab ipso celo ut descenderet ad locum mixtionis; f. 100rb : «Etiam quod celum sit causa motum inferiorum ponit Albertus per duas rationes factas in questione»; dans ce cas aussi la référence est au passage qu'on vient de citer. Si ces références aux questions sont au passé, ce qui ferait supposer leur antériorité par rapport à la Sententia, dans la suite du texte on en trouve qui sont au présent (f.101ra-rb: «Tertio, sciendum quod causa quare ibi fiunt nubes et similia est quia est continue frigida, et de causa frigiditatis eiusdem videtur in questione »; où la référence est à la question I. 18, Utrum media regio aeris sit semper frigida), ou au futur (f.100va: "Removet cavillationem, dicens quod, si numquam fierent ex se invicem, adhuc non obstat quin deberent esse equalia in virtute et proportionalia in magnitudine, et illa que sunt dicenda hic videbuntur in questione», où l'on se réfère à la question I. 10, Utrum quattuor elementa sint continue proportionalia ad invicem). Il est donc possibile qu'Oresme ait donné en même temps deux cours sur les Météorologiques, l'un où il commentait le texte de façon littérale, l'autre où il se concentrait sur des questions particulières, et qu'il se soit trouvé plus avancé par rapport au texte aristotélicien parfois avec l'un et parfois avec l'autre, ce qui pourrait justifier le changement de temps verbal dans les renvois de la Sententia aux Questions.

(84) Pour lesquelles les éditeurs proposent comme terminus ante quem le 1347, année dans laquelle la théorie des modi rerum, largement utilisée par Oresme dans ce texte, sera condamnée, cf. Nicole Oresme, Questiones super Physicam (Books I-VII), p. XXV. 
et de la corruption ${ }^{85}$, pour revenir encore, vers le début des années '50, aux Météorologiques, qu'il aurait commentés à nouveau à la lumière des doctrines développées à travers l'enseignement des autres livres de philosophie naturelle d'Aristote ${ }^{86}$. Ces considérations peuvent être représentées par le tableau suivant:

\begin{tabular}{|c|c|c|}
\hline Ouvrage & Autocitations & Datation probable \\
\hline Q. in Meteora redactio antiqua & & 1346 \\
\hline Q.in Physica (1.I-VII) & Q. in Meteora redactio antiqua & ante 1347 \\
\hline Q. in De caelo & $\begin{array}{l}\text { Q. in Meteora redactio } \\
\text { antiqua; Q. in De spera; Q. in } \\
\text { Physica (1. VIII) }\end{array}$ & ca. $1348(?)$ \\
\hline Q.in De generatione & $\begin{array}{l}\text { Q. in Physica, 1. II, V; Q. in De } \\
\text { caelo }\end{array}$ & ante 1349 \\
\hline Q. in Meteora redactio nova & Q.in Physica; Q. in De caelo & ca. 1350 \\
\hline
\end{tabular}

Ces résultats, encore partiels, devront être intégrés avec l'analyse des autocitations présentes dans les Questions sur le Traité Du ciel transmises par le manuscrit München, Bayerische Staatsbibliothek, Clm 4375, f. 19ra-46rb - dont Kirschner a proposé l'attribution à Nicole Oresme -, et celles contenues dans les deux rédactions des Questions sur le De spera. De toute façon, on peut s'attendre à ce que la collation et l'étude de ses Questions sur les Météorologiques dans les deux rédactions contribueront à porter de la lumière sur le commencement de l'activité philosophique de Nicole Oresme à la Faculté des Arts de Paris.

\section{LES ATTRIBUTIONS DES QUESTIONS SUR LES MÉTÉOROLOGIQUES AU MILIEU DU XIV e SIĖCLE}

Nous avons évoqué plus haut le fait que l'une des raisons pour lesquelles les Questions sur les Météorologiques de Nicole Oresme n'ont pas encore été étudiées réside dans la grande complexité de la tradition manuscrite relative aux commentaires sur les Météorologiques rédigées pour l'enseignement à la Faculté des Arts de Paris ${ }^{87}$. Il faut en effet souligner que l'attribution de ces textes est

(85) Pour lequel Caroti propose comme terminus ante quem le 1349, année au cours de laquelle les copistes du codex de Darmstadt avaient obtenu le titre de maîtres, $c f$. NicOlE OrESME, Questiones super degeneratione et corruptione, ed. CAROTI, p. $67^{\star}$.

(86) Les résultats de nos investigations ne contredisent pas ceux auxquels était parvenu J. Celeyrette à l'issue de son analyse de la place occupée par les Questions sur la Physique dans la chronologie relative des écrits d'Oresme à la Faculté des Arts de Paris ( $c f$. CELEYRETTE, «Les Questions sur la Physique dans l'œuvre de Nicole Oresme», p. 64-66). Notre examen diffère du sien, dans la mesure où nous avons pris en considération les autocitations contenues dans les Questions sur le livre de la Génération et de la corruption et les Questions sur le Traité Du ciel, ainsi que les renvois présents dans les deux rédactions des Questions sur les Météorologiques et dans la Sententia sur les Météorologiques. Néanmoins, Celeyrette a inclu dans son analyse des éléments que nous n'avons pas pris en compte, à savoir les Questions sur le De anima et les Questions sur la Géométrie d'Euclide, dont il a demontré la postériorité par rapport aux Questions sur la Physique. Nos analyses respectives peuvent donc être considérées comme complémentaires.

(87) Cf. supra, p.\#\#. 
particulièrement problématique à cause de la pratique, courante au Moyen Âge, de la contamination, pratique à laquelle les recueils universitaires de questions se prêtaient admirablement.

Les Questions sur les Météorologiques transmises par le manuscrit Paris, BnF, lat. 15156, f. 226r-288v, représentent à ce propos un cas intéressant. Le texte, qui est anonyme, s'arrête au f.288v, à la question III. 20, Utrum omni hora diei yris posset apparere, avec les mots: "quod semper semidyameter yridis est equalis, ideo dicendum est quod hoc est ». Les folios suivants ont été déchirés. McCluskey a répertorié ce manuscrit ${ }^{88}$ mais ne l'a pas utilisé pour son édition des questions du troisième livre des Questions sur les Météorologiques de Nicole Oresme. Le texte de ce manuscrit s'interrompt au f. 265v, à la question II. 10, Utrum mare debeat fluere et refluere, avec les mots " eius a sole augetur eius virtus a sole», et reprend au f. 267r, avec la question Utrum aqua maris debeat esse salsa, le f. 266 étant resté blanc. Or, McCluskey a remarqué que, à partir de cette question, le texte transmis par le manuscrit n'est plus celui des Questions sur les Météorologiques, d'Oresme, mais celui des Questions sur les Météorologiques d'Albert de Saxe. La collation de ce texte avec celui des manuscrits qui transmettent les questions attribuées à Albert de Saxe nous a permis de valider cette affirmation, qui nécessite toutefois quelque précision. Tandis que le troisième livre des Questions sur les Météorologiques attribuées à Albert de Saxe ne contient en effet que neuf questions ${ }^{89}$, le manuscrit parisien en transmet vingt. Cela s'explique aisément avec la différente division des livres adoptée, qui fait que, dans les manuscrits d'Albert, la question Utrum ventus sit exalatio calida et sicca est la septième du deuxième livre, alors que, dans le manuscrit de Paris, elle commence le troisième livre. Le texte des Questions sur les Météorologiques transmis par ce témoin parisien se présente donc comme une compilation réalisée à partir des Questions sur les Météorologiques de Nicole Oresme (I. 1-II. 3) et des Questions sur les Météorologiques d'Albert de Saxe (II. 5-III. 9).

Nous avons déjà vu ${ }^{90}$ que, d'après Birkenmajer, Markowski et les rédacteurs du catalogue des manuscrits de Cracovie, les Questions sur les Météorologiques transmises dans les manuscrits 635 et 686 de la Bibliothèque Jagiellońska de Cracovie ont été compilées à partir des recueils d'Albert de Saxe et de Nicole Oresme. Le même phénomène se retrouve aussi dans le cas de plusieurs manuscrits qui transmettent la redactio nova des Questions sur les Météorologiques de Nicole Oresme. Les Questions sur les Météorologiques transmises aux f. 1 ra-140rb du manuscrit Clm 17226 de la Staatsbibliothek de Munich sont à cet égard particulièrement intéressantes. Le texte ne porte aucune attribution ${ }^{91}$. Markowski, dans son catalogue des commentaires à Aristote conservés à la

(88) MCClusKeY, Nicole Oresme, p. 97-98.

(89) Cf. Birkenmajer, Études, p. 199.

(90) Cf. supra, p.\#\#.

(91) Dans la marge supérieure du f. 1r, une main moderne s'est limitée à écrire: "Questiones Meteororum ». 
Staatsbibliothek de Munich, l'attribue à Jean Buridan ${ }^{92}$, probablement sur la base de l'incipit, qui correspond effectivement à celui des Questions de Buridan ${ }^{93}$. L'explicit, toutefois, comme Birkenmajer l'avait déjà remarqué, ne correspond pas à celui des Questions de Buridan, mais à celui des Questions d'Oresme ${ }^{94}$, raison pour laquelle, d'après le chercheur polonais, dans ce manuscrit on aurait affaire avec les questions de Buridan «qui cependant versent ensuite dans les Questions d'Oresme » ${ }^{95}$. Mais la réalité est encore plus complexe: le manuscrit Clm 17226 présente en effet une véritable compilation de questions sur les Météorologiques, réalisée à partir des commentaires de Jean Buridan, Nicole Oresme et Thémon le Juif. Dans les deux premiers livres, ce sont les questions d'Oresme et de Buridan qui s'alternent, tandis que, et à partir du troisième livre, le compilateur puise aussi dans le texte de Thémon le Juif. Le compilateur ne se soucie pas de donner de la cohérence à son recueil : par exemple, il n'élimine pas les références, fréquentes dans les questions de Buridan, qui indiquent la place qu'elles occupaient dans leur recueil originaire ${ }^{96}$, et cela en dépit du fait que, à la suite de l'interpolation d'autres questions dans le manuscrit, ces références aient perdu leur signification ${ }^{97}$.

Une compilation des Questions d'Oresme et de celles de Buridan se trouve aussi dans le manuscrit qui porte la cote: Erfurt, Wissenschaftliche Allgemeinbibliothek, CA $2^{\circ} 334^{98}$, qui transmet les trois premiers livres des Questions de Buridan et le quatrième d'Oresme ${ }^{99}$. Le colophon du manuscrit d'Erfurt attribue toutefois tout le texte à Jean Buridan ${ }^{100}$, ce qui a produit une certaine confusion dans les répertoires modernes ${ }^{101}$.

(92) M. MARKowsKI, Buridanica quae in codicibus manu scriptis bibliothecarum Monacensium asservantur, Wrocław-Warszawa-Kraków-Gdańsk-Łódź 1981, p. $72-73$ et p. 140.

(93) Cf.f. 1 ra: «Si scientiam oppinamur honorabiliorem ex eo ceteris paribus quod est de magis mirabilibus $[\ldots] »$.

(94) Cf. f. 140ra : «Ad sextam, dico quod in salamandra non duratur ignis in quantitate nec etiam nutritur igne, sed tale animal non est ustibile ab igne; et ideo, quia non uritur ab igne, dicitur quod tale animal habitat in igne». Les Questions de Buridan, en revanche, se terminent avec ces mots: «sive lapidibus sive plantis sive animalibus sive earum principiis et metallis et aliis ».

(95) BIRKENMAJER, Études, p. 193.

(96) Par exemple, à la question 11 du premier livre on lit: «Sicut de motu quesitum est, ita quinto querimus de lumine, videlicet utrum omne lumen sit calefactivum» (München, Bayerische Staatsbibliothek, Clm 17226, f. 18rb).

(97) Pour la liste complète des questions transmises par ce manuscrit, $c f$.l'annexe IV.

(98) Prol. : «Ut habetur in prohemio De anima, constat, quod scientiam libri Metheororum valde reputare debemus aliis nobiliorem et super cetera appetibilem, opera namqua metheoroloyca inter cetera nobis apparentia sunt mirabiliora »; inc., 1. I, f. 64rb : "Queritur primo, utrum de impressionibus metheoroloicis sit tradenda scientia naturalis distincta a scientia De celo et mundo et De generatione et corruptione, De mineralibus et De anima et animatis. Arguitur primo quod non sit scientia de eis, quia non est scientia de singularibus, contigentibus et passionibus »; expl.: « ad sextam: dico quod in salamandra non duratur ignis in quantitate, nec ibi nutritur ab igne, sed tale animal non est ustibile ab igne. Et ratio quia non uritur ab igne, dicimus quod tale animal non est ustibile ab igne ».

(99) Cf. Birkenmajer, Études, p. 181-182; MiCHael, Johannes Buridan, vol. II, p. 655.

(100) « Expliciunt questiones Metheororum reverendi magistri Biridani finite et peracte in festo s. Mathie per me Petrum filium Francisci de Grinstad, quarum conservator est reverendus magister Petrus dictus Culmach, Paulus vero de Tr. harum est possessor. anno Domini 1421 etc., de quo 
Ce fait nous amène à la considération que les attributions présentes dans les manuscrits n'aident pas nécessairement à identifier de façon sûre les auteurs des textes transmis. Le colophon du manuscrit Clm4376 de la Bayerische Staatsbibliothek de Munich, par exemple, identifie l'auteur des Questions sur les Météorologiques ${ }^{102}$ transmises aux f. $1 \mathrm{ra}-64 \mathrm{vb}$ avec Jean Buridan ${ }^{103}$, alors que le texte est celui de la redactio nova des Questions sur les Météorologiques d'Oresme.

Les Questions sur les Météorologiques contenues dans le manuscrit Wien, Österreichische Nationalbibliothek, Cod.Vind. lat.5453, f.49r-109v, anonymes, mais précédées, aux f.30r-48v, par des Questions sur le De generatione et corruptione attribuées à Buridan ${ }^{104}$, ont été elles aussi attribuées à Buridan par les rédacteurs du catalogue ${ }^{105}$. Bien qu'à travers l'examen direct du texte, Birkenmajer les avait restituées à Oresme ${ }^{106}$, Faral, en 1946, continuait à les attribuer à Buridan, en se basant sur l'attribution erronée du catalogue ${ }^{107}$.

Le colophon des Questions sur les Météorologiques contenues aux f.53r-103v du manuscrit Erfurt, Wissenschaftliche Allgemeinbibliothek, CA $4^{\circ} 299^{108}$,

laudetur Deus et sancta Maria per infinita secula seculorum. Amen ", cité d'après MARKOWSKI, Repertorium commentariorum medii aevi in Aristotelem Latinorum quae in Bibliotheca Amploniana Erffordiae asservantur, p. 70.

(101) W. SCHUM, Beschreibendes Verzeichnis der Amplonianischen Handschriften-Sammlung zu Erfurt, Berlin 1887, p. 230-231, FARAL, "Jean Buridan», p.21, C. LoHR, "Medieval Latin Aristotle Commentaries », Traditio, 26 (1970), p. 172 et MARKOWSKI, Repertorium commentariorum medii aevi in Aristotelem Latinorum quae in Bibliotheca Amploniana Erffordiae asservantur, p. 182 attribuent le texte à Jean Buridan. En revanche, Birkenmajer (Études, p. 181-182) et McCluskEY (Nicole Oresme, p. 96) font une distinction entre les trois premiers livres, qu'ils attribuent à Buridan, et le quatrième, qui provient d'Oresme.

(102) Inc.: «Primo queritur circa initium primi libri Metheororum utrum possible sit de impressionibus metroloycis habere simul scientiam et opinionem, et arguitur quod non, quia de impressionibus metheorologicis non contigit habere scientiam nec opinionem »; expl.: « et ideo, quia non uritur ab igne, dicimus quod tale animal habitet in igne etc. ».

(103) Cf. f. 64rb : «Expliciunt questiones quattuor librorum Metheororum Byridani, finite Prage anno Domino $13^{\circ} 66$-to, in vigilia beate Dorothee virginis, per pedes Johannis Kirchpaumi de Ingolstat", cité d'après MARKOWSKI, Buridanica quae in codicibus manu scriptis bibliothecarum Monacensium asservantur, p. 73-74. Cette attribution a déterminé l'erreur de Faral («Jean Buridan», p. 21) et de Lohr ( Medieval Latin Aristotle Commentaries », p. 172). Lohr en est même arrivé à classer ce manuscrit, avec Klagenfurt, Bischöfliche Bibliothek, XXXI.b. 5, f. 1r-124r et Wien Österreichische Nationalbibliothek, Cod. Vind lat. 5453, f. 49r-109v comme une autre rédaction des Questions sur les Météorologiques de Jean Buridan, alors que, à travers une confrontation des textes transmis par ces manuscrits, il est clair qu'il s'agit de copies de la redactio nova des Questions sur les Météorologiques d'Oresme.

(104) Cf.f. 48v: «Expliciunt questiones magistri biridani super de generatione et corruptione reportate prage sub anno millesimo (rayé : quarto) $\mathrm{C}^{\circ} \mathrm{C}^{\circ} \mathrm{C}^{\circ} \mathrm{LXX}$ in die sancti petri ad vincula ».

(105) Tabulae codicum manuscriptorum praeter graecos et orientales in Bibliotheca palatina Vindobonensi asservatorum, Vindobonae 1870, p. 127.

(106) BirKenMajer, Études, p. 195.

(107) FARAL, « Jean Buridan », p. 22.

(108) Inc.: «Queritur primo circa librum Metheororum utrum de impressionibus meteorologicis sit scientia, arguitur quod non "; expl.: « unde dicit Aristoteles, quod in terra et in aqua animalia solum sunt et in aere et igne non sunt, ideo ad illus de sallamandra dicitur, quod falsum est, quod viveret ex igne, sed est talis complexionis, quod non est ussibilis ab igne. Et patet questio ». Il est important de rappeler que ce manuscrit contient, aux f. 113r-126r, des Questiones supra speram attribuées à Nicole Oresme, $c f$. LEJBOWICZ, «Nicole Oresme et les voyages circumterrestres», p. 136. L'attribution se 
attribue le texte à Nicole Oresme ${ }^{109}$, raison pour laquelle Schum, dans son catalogue, les considère comme un ouvrage oresmien ${ }^{110}$, Birkenmajer, quant à lui, les attribue à Albert de Saxe ${ }^{111}$, et Faral en fait l'œuvre de Buridan ${ }^{112}$; finalement, Muñoz García revient à l'attribution à Albert de Saxe ${ }^{113}$, suivi en cela par Markowski ${ }^{114}$. À la suite de la collation de ce texte, nous pouvons affirmer qu'il s'agit bien des Questions d'Albert de Saxe. Seule la dernière question du quatrième livre, Utrum in quolibet mixto dominetur terra aut aqua, vel ambo, est issue de la redactio nova des Questions d'Oresme. Il est d'ailleurs possible que l'attribution du texte à Oresme que l'on trouve dans le colophon, au f. 103v, ait été causée par l'introduction de cette question oresmienne dans le recueil d'Albert, car sa présence à cette place fait terminer le texte avec un explicit tout à fait semblable à celui des Questions d'Oresme ${ }^{115}$.

trouve dans l'explicit, au f. 126r: «Et in hoc terminantur questiones super speram a magistro Nicholao Orim lecte». Pour une description détaillée du contenu de ce manuscrit, $c f$. LEJBOWICZ, «Nicole Oresme et les voyages circumterrestres », p. 135-138.

(109) «Expliciunt questiones super toto librorum metheororum lecte a magistro Nicolao Horem Parysius. [a.m.] Et concordant bene cum questionibus Buridani, sed breviores sunt ».

(110) SCHUM, Beschreibendes Verzeichnis, p. 538-539.

(111) BirkenMajer, Études, p. 222.

(112) FARAL, «Jean Buridan», p. 21.

(113) A. MuÑoz GARCíA, «Albert of Saxony: Bibliography», Bulletin de la Société internationale pour l'étude de la pensée médiévale, 32 (1990), p. 161-190, ici p. 182. Il faut toutefois souligner que la liste de Muñoz García n'est pas exempte d'erreurs: il attribue par exemple à Albert de Saxe les Questions sur les Météorologiques transmises par le manuscrit Paris, BnF, lat.14721, alors qu'il faudrait les attribuer à Albert le Grand! (cf. AlberTus MAGnus, Opera omnia ad fidem codicum manuscriptorum, vol. 6, pars 1, Meteora, ed. P. Hossfeld, Aschendorff 2003, p. VII-VIII). En outre, il liste, parmi les témoins des Questions sur les Météorologiques d'Albert de Saxe, le codex 757 de la Bibliothèque Jagiellońska de Cracovie, f. 1-53, tandis que ce manuscrit ne transmet pas du tout des Questions sur les Météorologiques (il contient en effet des commentaires sur des textes de logique d'Aristote, cf. MARKOWSKI -WŁODEK, Repertorium commentariorum medii aevi in Aristotelem Latinorum quae in Bibliotheca Jagellonica Cracoviae asservantur, p. 62-63). Peut-être que nous avons là une erreur typographique, et le codex auquel Muñoz García se réfère est le manuscrit751, f. 3ra$53 \mathrm{rb}$ de la Bibliothèque Jagiellońska, qui contient effectivement des Questions sur les Météorologiques. Dans ce cas aussi, la référence serait toutefois erronée, car il s'agit d'une copie de la redactio nova des Questions d'Oresme. Muñoz García a inclu dans sa liste, parmi les manuscrits des Questions sur les Météorologiques d'Albert de Saxe, le codex 648 de la Bibliothèque Jagiellońska, aux f. 1-39. Cette indication aussi est erronée : les f. 1r-39v de ce codex transmettent bien des Questions d'Albert de Saxe, mais pas celles sur les Météorologiques : celles sur le Du ciel (cf. S. WŁODEK - G. ZATHEY - M.ZWIERCAN, Catalogus codicum manuscriptorum Medii Aevi Latinorum qui in Bibliotheca Jagellonica Cracoviae asservantur, Wratislaviae 1980-, vol. IV, p. 395). Dans son Introduction à l'édition des Questions sur le Du ciel d'Albert de Saxe, B. Patar reprend la liste de Muñoz García avec toutes ses erreurs: B. PATAR, Alberti de Saxonia Quaestiones in Aristotelis De caelo, Louvain-Paris-Dudley 2008, p. $29^{*}$.

(114) MARKOWSKI, Repertorium commentariorum medii aevi in Aristotelem Latinorum quae in Bibliotheca Amploniana Erffordiae asservantur, p. 69.

(115) Le manuscrit contient d'autres textes de Nicole Oresme: les Questions sur le Du ciel, aux f. 1r-50v, et les Questions sur les Parva naturalia, aux f. 128r-157v. Pour la liste des textes contenus dans ce codex, $c f$. MARKOWSKI, Repertorium commentariorum medii aevi in Aristotelem latinorum quae in Bibliotheca Amploniana Erffordiae asservantur, p. 202-203. 
Les Questions sur les Météorologiques transmises aux f.69ra-130ra du codex CA $4^{\circ} 342$ de la Bibliothèque Amploniana d'Erfurt sont anonymes ${ }^{116}$. Le catalogue de Schum attribue ce texte aussi à Buridan ${ }^{117}$, suivi par Faral ${ }^{118}$ et Lohr ${ }^{119}$, et cela peut-être à cause de la présence, peu avant dans le même manuscrit, d'une Expositio sur les Météorologiques attribuée à Jean Buridan ${ }^{120}$. Michael, en revanche, ne se prononce pas sur l'attribution de ces Questions ${ }^{121}$, alors que Markowski attribue ce texte au Pseudo-Scot ${ }^{122}$. Or, après l'examen direct du manuscrit, nous pouvons affirmer que, bien que l'explicit de ce texte diverge de celui de l'ouvrage édité par Wadding ${ }^{123}$, le texte des Questions sur les Météorologiques du manuscrit 342 correspond à celui des Questions éditées par Wadding, et par lui attribuées à un auteur scotiste de la fin du XIV ${ }^{\mathrm{e}}$ siècle.

Les Questions sur les Météorologiques transmises aux f.93ra-146rb du manuscrit Clm 6962 de la Bayerische Staatsbibliothek de Munich, anonymes, ont été attribuées à Buridan par les rédacteurs du catalogue ${ }^{124}$. Dans son répertoire des ouvrages et des manuscrits de Buridan, Faral fait sienne cette erreur ${ }^{125}$. Birkenmajer attribue ces Questions à Oresme, du moins pour autant que la question Utrum radius visualis posset reflecti ab aere uniformi, éditée par lui et

(116) Inc.: "Queritur primo circa librum Metheororum utrum de impressionibus metheorologicis tamquam de obiectis sit scientia. Arguitur primo quod non, quia de impressionibus metheorologicis solum habetur notitia»; expl.: «eo quod calor cordis etiam ad comparationem aliorum memborum est magis intensus et acutius, ad similitudinem caloris ignei ».

(117) ScHum, Beschreibendes Verzeichnis, p. 571.

(118) FARAL, « Jean Buridan », p. 21.

(119) LoHR, «Medieval Latin Aristotle Commentaries », p. 172.

(120) Aux f. 30ra-65vb. Inc.: «De primis quidem igitur causis nature. Iste liber Metheororum est quartus in ordine librorum naturalium, in quo Philosophus determinat de ente mobili ad formam mixti»; expl.: «Et cum illa faciunt nobis manifesta, tandem erit sic considerandum de aliis, que constituta sunt ex istis, scilicet de animalibus et plantis. Sequitur. Expliciunt dicta super librum Metheororum anno 1342, ascripte [sic] magistro Johanni Buridani, etc. ». Pour la liste des incipits et des explicits de l'Expositio de Buridan sur les Météorologiques, cf. MichaEL, Johannes Buridan, vol. II, p. 649. Pour la description de ce codex, cf. ibid., p. 650. Michael date ce texte de la fin des années '70 du XIV e siècle.

(121) MiCHAEL, Johannes Buridan, vol. II, p. 676.

(122) MARKOWSKI, Repertorium commentariorum in Aristotelem latinorum quae in Bibliotheca Amploniana Erffordiae asservantur, p. 70-71 et p. 208.

(123) Inc.: «Utrum de impressionibus meteoricis sit scientia, tamquam de subjecto? Arguitur quod non "; expl.: "potest tamen hoc esse digestio, et pepansis ad generationem alterius, sicut putrefactio bovis, est pepansis ad generationem apum».

(124) K. Halm - G. von LAUBMANn - W. Meyer, Catalogus codicum latinorum Bibliothecae Regiae Monacensis, vol. 1/3: Codices num. 5251 - 8100 complectens, secundum Andreae Schmelleri indices, Monachii 1873, p. 131.

(125) FARAL, "Jean Buridan», p.21. Sur les dix manuscrits des Questions de Jean Buridan cités par Faral (ibid., p. 21-22), cinq présentent une attribution erronée: Erfurt, Wissenschaftliche Allgemeinbibliothek, CA $4^{\circ} 299$, f. 53r-103v, Erfurt, Wissenschaftliche Allgemeinbibliothek, CA $4^{\circ}$ 342, f. 69ra-130ra, München, Bayerische Staatsbibliothek, Clm 4376, f. 1r-64r, München, Bayerische Staatsbibliothek, Clm6962, f.93r-146r, Wien, Österreichische National-bibliothek, Cod. Vind. lat. 5453, f. $49 \mathrm{r}-109 \mathrm{v}$, et une attribution partiellement erronée (valable seulement pour les trois premiers livres): Erfurt, Wissenschaftliche Allgemeinbibliothek Erfurt, CA $2^{\circ} 334$, f. 158v-167r. Cf. BAGEs, Les Questiones, p. 18-19. 
attribuée au maître Normand, se trouve dans ce recueil ${ }^{126}$. McCluskey ${ }^{127}$ affirme qu'il s'agit des Questions de Thémon le Juif, mais Michael les attribue à Buridan, tout en restant dubitatif ${ }^{128}$. Finalement, Markowski, dans son catalogue des commentaires des textes aristotéliciens conservés à la Bibliothèque de Vienne, opte pour une classification plus neutre: Quaestiones Wiennense ${ }^{129}$. Or, après un examen direct du texte, il nous a été possibile de valider l'affirmation de McCluskey.

Quelle est la leçon à tirer de ces considérations sur les difficultés posées par l'attribution des commentaires d'Aristote rédigés pour l'enseignement à la Faculté des Arts? En premier lieu, une invitation à la prudence. Pour attribuer un texte à tel ou tel maître, on ne peut pas se fier - du moins de façon exclusive - aux attributions présentes dans les manuscrits, d'autant plus que les textes qu'ils transmettent ont souvent été copiés longtemps après leur rédaction. Il n'est pas suffisant non plus de comparer les intitulés des questions, étant donné qu'ils reflètent d'un côté des thématiques présentes dans le texte aristotélicien, de l'autre des débats universitaires qui surgissaient à propos de celles-ci, et peuvent donc être présentes (presque) dans la même forme chez l'un ou l'autre maître ${ }^{130}$. Pour se prononcer sur l'attribution de tels ouvrages, il ne faut donc pas se contenter de ces éléments extrinsèques, mais il faut entrer dans les textes, en comparant minutieusement non seulement les incipit et les explicit des livres, mais aussi ceux des questions et, sourtout, en analysant les éléments doctrinaux qui leur sont propres. Or, si toutes ces difficultés peuvent à première vue paraître bien décourageantes, il est vrai aussi qu'elles témoignent d'un dialogue serré entre les auteurs et, surtout, de la richesse d'un débat dont la découverte et l'étude se présentent aujourd'hui comme une tâche, et en même temps comme un défi, pour l'historien de la philosophie médiévale.

(126) BirkenMajer, Études, p. 192. Pour l'édition de cette question, cf. ibid., p. 152-172.

(127) MCCluskeY, Nicole Oresme, p. 97.

(128) MichaEL, Johannes Buridan, vol. II, p. 676.

(129) MarkowSKI, Repertorium commentariorum medii aevi in Aristotelem Latinorum quae in bibliothecis Wiennae asservantur, p. 75.

(130) BAGES, Les Questiones, p. 19. 
ANNEXE I

\section{INDEX DES QUESTIONS SUR LES MÉTÉOROLOGIQUES DE NICOLE ORESME, REDACTIO ANTIQUA ET REDACTIO NOVA}

Puisque nous avons abordé le problème des rapports entre les Questions sur les Météorologiques de Nicole Oresme et de celles d'Albert de Saxe et de Thémon le Juif, et puisque ces textes n'ont pas encore été édités, il nous semble utile d'en présenter la liste des questions, accompagnées de leurs incipit et explicit. Nous espérons ainsi fournir un outil pour des recherches ultérieures.

Afin d'établir la liste des questions de la redactio antiqua des Questions sur les Météorologiques de Nicole Oresme, nous avons consulté tous les manuscrits complets de ce texte que nous avons identifiés: Darmstadt, Universitäts- und Landesbibliothek (olim Hessische Landes- und Hochschulbibliothek), 2197, f. 58r-79v; 85r-92v (D); München, Bayerische Staatsbibliothek, Clm 4375, f. 19r46r $(M)$; Kraków, Uniwersytet Jagielloński, Biblioteka Jagiellońska, 753, f. 51ra$83 \mathrm{vb}(C)$. Pour les trois questions du quatrième livre, nous nous sommes basés sur le seul témoin qui les transmet, à savoir Darmstadt, Universitäts- und Landesbibliothek (olim Hessische Landes- und Hochschulbibliothek), 2197, f. 125ra-127vb (D1). La division des livres suivie dans les trois témoins est différente. Tandis que $M$ et $D 1$ - du moins pour la portion de $D 1$, très exiguë, qui nous est parvenue - suivent en effet la même numérotation, comptant, pour le premier livre, trente-deux questions, $D$, qui en compte trente-trois, suit une numérotation différente. $C$ suit presque complètement la numérotation de $M$ et $D 1$, mais s'en détache en situant la question Utrum quatuor elementa sint continue proportionalia à la fin du premier livre. Cette question, qui dans $D$ est la dixième du premier livre, est placée, dans $M$, à la fin du troisième livre. Un phénomène analogue se vérifie pour les questions Utrum halo fiat ex refractione radiorum ab ipsa nube, Utrum sit aliquis color spiritualis, utrum colores apparentes in yride sint ibi vere et realiter, et Utrum yris debeat apparere secundum circuli periferiam, qui dans le manuscrit de Darmstadt ont été incluses dans le deuxième livre, et qui constituent, avec deux autres questions d'optique, absentes dans la version de Darmstadt, Utrum yris possit apparere maior semicirculo et Utrum yris quandoque appareat secundum proportionem maioris et quandoque minoris circuli, le troisième livre du manuscrit de Munich. Dans le tableau ci-dessous, nous avons adoptée la numérotation des questions présente dans le manuscrit de Darmstadt. 


\begin{tabular}{|c|c|c|c|}
\hline No & Intitulé de la question & Incipit/Explicit de la question & Folio \\
\hline I.1 & $\begin{array}{l}\text { Utrum impressiones meteoro- } \\
\text { logice fiant secundum naturam } \\
\text { inordinatiorem ea que est primi } \\
\text { elementi corporum, id est } \\
\text { secundum naturam minus } \\
\text { ordinatam auam natura celi }\end{array}$ & $\begin{array}{l}\text { Arguitur primo quod non fiunt } \\
\text { secundum naturam, quia fiunt } \\
\text { raro et in paucioribus ...X... et } \\
\text { cum hoc possunt impediri per } \\
\text { liberum arbitrium. }\end{array}$ & $\begin{array}{l}\text { D58ra; } \\
\text { M19ra; } \\
\text { C51ra }\end{array}$ \\
\hline I. 2 & $\begin{array}{l}\text { Utrum iste mundus inferior sit } \\
\text { contiguus ipsi celo }\end{array}$ & $\begin{array}{l}\text { Et arguitur quod non : quia } \\
\text { contigua se invicem tangunt; } \\
\text { modo, celum non est } \\
\text { tangibile...X... ad inductionem in } \\
\text { singulari non sequitur propositio } \\
\text { de plurali }{ }^{131} \text {. }\end{array}$ & $\begin{array}{l}\text { D58vb; } \\
M 19 \mathrm{va} ; \\
C 51 \mathrm{vb}\end{array}$ \\
\hline I. 3 & $\begin{array}{l}\text { Utrum omnis virtus inferior a } \\
\text { superioribus, scilicet a } \\
\text { supercelestibus, gubernetur }\end{array}$ & $\begin{array}{l}\text { Et arguitur quod non. Primo : quia } \\
\text { voluntas nostra est libera et est } \\
\text { virtus inferior ...X... sed non de } \\
\text { agente universali, sicut est celum. }\end{array}$ & $\begin{array}{l}\text { D58va; } \\
\text { M20ra; } \\
\text { C52va }\end{array}$ \\
\hline I. 4 & $\begin{array}{l}\text { Utrum aliquis motus localis in } \\
\text { istis inferioribus sit effective a } \\
\text { celo }\end{array}$ & $\begin{array}{l}\text { Quia in precedenti questione } \\
\text { dictum est quod celum agit in istis } \\
\text { inferioribus mediante motu, } \\
\text { lumine et etiam influentia. Ideo } \\
\text { nunc queritur de motu ...X... } \\
\text { quantum ad hoc est nobilior quam } \\
\text { terra, et magis assimilatur suis } \\
\text { propinquis. }\end{array}$ & $\begin{array}{l}\text { D60ra; } \\
\text { M20va; } \\
\text { C53ra }\end{array}$ \\
\hline I.5 & $\begin{array}{l}\text { Utrum, cessante motu celi, } \\
\text { fierent generationes, alterationes, } \\
\text { impressiones et similia in istis } \\
\text { inferioribus }\end{array}$ & $\begin{array}{l}\text { Arguitur quod sic. Primo : quia } \\
\text { non videtur quin ignis adhuc } \\
\text { calefaceret stuppam } \\
\text { approximatam ...X... et adhuc } \\
\text { magis dependent inferiora a celo et } \\
\text { a Deo. }\end{array}$ & $\begin{array}{l}\text { D60vb; } \\
M 21 \mathrm{rb} ; \\
C 53 \mathrm{vb}\end{array}$ \\
\hline I.6 & $\begin{array}{l}\text { Utrum, solo primo motu } \\
\text { superiorum cessante, fierent } \\
\text { generationes, impressiones, etc., } \\
\text { posito quod Sol et alii planete } \\
\text { moverentur }\end{array}$ & $\begin{array}{l}\text { Arguitur quod non : quia, cessante } \\
\text { primo motu, cessaret tempus } \\
\text {...X... et sic adhuc esset ordo } \\
\text { causarum. }\end{array}$ & $\begin{array}{l}\text { D61va; } \\
\text { M21va; } \\
\text { C54va }\end{array}$ \\
\hline I.7 & $\begin{array}{l}\text { Utrum motus localis sit causa } \\
\text { caloris }\end{array}$ & $\begin{array}{l}\text { Et arguitur quod non. Primo sic: } \\
\text { motus non est motus; igitur motus } \\
\text { non calefacit ...X... Consimiliter } \\
\text { est dicendum de febribus. }\end{array}$ & $\begin{array}{l}\text { D62ra; } \\
M 22 \mathrm{ra} ; \\
C 54 \mathrm{vb}\end{array}$ \\
\hline
\end{tabular}

(131) Les manuscrits $C$ et $M$ ajoutent: «sic etiam non sequitur: ante istum hominem fuit aliquis homo, et sequitur de singulis; ergo ante omnes homines fuit aliquis homo. Non valet consequentia ». 
Utrum aer superior et ignis in sua spera calefaciant ex motu celi

Utrum lumen in istis inferioribus a corporibus celestibus generetur

Utrum quatuor elementa sint continue proportionalia

Utrum omne lumen sit calefactivum

Utrum omnecorpus oppositum luminoso sit calefactibile per lumen

Utrum aliquod agens possit ager in passum distans ab eo sine hoc quod agat in intermedium

Utrum aliquod agens fortius agat in remotum quam in sibi propinquum

Utrum unum contrarium possit movere localiter alterum sibi contrarium

Utrum media regio aeris sit semper frigida

Utrum flamme apparentes de nocte in aere fiant ibi naturaliter
Arguitur primo quod non, quia

motus est actus imperfectus ...X.. . Et hoc facit natura propter generationem impressionum et similium.

Et arguitur quod non, quia agens non agit in distans nisi per medium ...X... quod lux est prima qualitas corporum.

Arguitur primo quod sic, quia elementa sunt continue proportionalia secundum raritatem et densitatem ...X... ideo ratio est solummodo persuasiva.

Arguitur primo quod non, quia aliqua inferiora generant frigiditatem ...X... posset tamen experiri per speculum concavum magnum.

Arguitur quod non. Primo : quia sequeretur quod aliquid

illuminaretur et calefaceret infinite ...X... scilicet fractio radiorum ad unum locum.

Et arguitur quod sic. Primo : quia Sol calefacit ista inferiora

mediante motu et lumine...X...

Etiam: scientia non causat species suorum accidentium in medio.

Et arguitur quod non. Primo : quia omne agens prius agit in propinquum quam in remotum...X... sed etiam partes illius difformis coagunt cum illo.

Et arguitur primo quod non, quia ferrum frigidum positum iuxta ignem non movetur localiter $a b$ ipso igne...X... non quibuscumque, sed contrariis activis et passivis.

Arguitur quod non, quia aer est elementum naturaliter calidum et humidum ...X... nec oportet quod sit omnimode dispositio unius sicut alterius.

Et videtur quod non. Primo : quia aer naturaliter est humidus, et flamma et tale igneum est calidum et siccum ...X... quod esset lumen nimis intensum, et ita visum est multoties.
D63ra ;

M22vb;

C55vb

D63va;

M23rb;

C56rb

D64rb ;

M45ra;

C71rb

D66rb ;

M23vb;

C56vb

D67rb ;

M24va;

C57ra

D68rb ;

M25ra;

C58rb

D69ra ;

M25vb;

C59rb

D69vb;

M26rb ;

C59vb

D70va;

M27ra;

C60va

D71ra;

M27va;

C61ra 
Utrum, serenitate existente, appareant in celo de nocte hiatus, seu aperture, et voragines et sanguinei colores

Utrum stelle comate sint de natura celi aut elementari

Utrum motus stelle comete sit naturalis

Utrum comete significent guerras, mortes principum, pestilentias et huiusmodi

Utrum omnes comete sint eiusdem speciei inter se et cum galaxia

Utrum impressiones humide fiant a calido

Utrum omnes impressiones aque sint eiusdem speciei

Utrum nix et pluvia generentur in media aeris regione

Utrum grando debeat magis fieri in hieme vel estate aut in temporibus intermediis, sicut in vere aut autumno

Utrum nebula sit signum serenitatis
Et videtur quod non, quia tales colores magis deberent apparere de die in lumine ...X... Et ideo de causa formali et finali potest dici sicut dicebatur alias.

Et primo arguitur quod sint de natura celi ex motu ...X... iste est unus de primis effectibus, ideo suspicantur alia evenire.

Et arguitur quod non. Primo : quia nullum inanimatum movetur ad utramque partem positionis

...X... nisi cause moventes fortificentur vel maneant in eodem statu.

Et videtur quod non, quia in eadem regione habitant simul dives et pauperi, et reges et subdita ...X... si veniat inundatio aquarum hoc est per accidens et per antiparistasim.

Et arguitur quod non. Primo, quia comete differunt in figura: quidam sunt caudati et alii non ...X... secundum hoc quod disponitur ad diversos cometas.

Et videtur quod non, quia contrariorum cause sunt a contrario ...X... quia tempore calido est parum de materia que possit elevari.

Et videtur quod non. Primo : quia quedam sunt ex materia grossa, ut grando et pluvia ...X... non conceditur quod nix est aqua, licet ex ea possit fieri aqua.

Et videtur quod non generentur in eodem loco, quia aliquando simul cadunt et nix et pluvia ...X... Et ita aliqualiter de nive, licet quandoque modicum velocitetur.

Et arguitur primo quod numquam possit fieri, ratione Aristotelis in textu ...X... nec in estate, sicut dictum est in positione.

Arguitur quod non, quia materia nubis et pluvie non est huiusmodi signum ...X... in eternum testis in celo fidelis etc.
D71va;

M28ra ;

C61va

D72ra;

M28va ;

C62rb

D72va ;

M29ra;

C62vb

D73rb;

M29va ;

C63va

D73vb;

M29vb;

C64ra

D74ra ;

M30rb ;

C64va

D74vb;

M30vb;

C65ra

D75rb ;

M31rb;

C65vb

D76ra ;

M32ra;

C66va

D76rb;

M32va;

C66vb 
Utrum aqua naturaliter ascendat ad orificia fontium

Utrum fontes et fluvii veniant ex aqua pluviali vel ex mari vel aliunde

Utrum fontes et flumina derivantur a montibus

Utrum habitationes permutentur

Utrum habitatio terre permutetur propter mare

Utrum habitatio terre permutetur propter permutationem in qualitatibus secundis

Utrum locus naturalis elementi aque sit ubi nunc est mare

Utrum mare fluat et refluat

\section{Utrum aqua maris sit salsa}

Utrum fontes et fluvii debeant esse salsi
Arguitur quod sic: primo, quia

omne elementum naturaliter exit et movetur de loco sibi innaturali

...X... de monte in quo est generatio aque que descendit ad fontem.

Et arguitur primo quod non ex aqua pluviali, per rationes Senece. Primo: quia ipse dicit se esse expertum quod aqua pluvie ...X... sed sicut sunt pauci vapores super terram, ita etiam sub terra.

Arguitur quod non, quia tunc ex quolibet monte deberet oriri aliquis fons vel fluvius ...X... et ideo aqua fontium est melior.

Arguitur quod non, quia descriptio orbis terrarum que fuit olim data adhuc habet

locum...X... unde illud quod debet durare per multos annos apud ipsos est eternum.

Arguitur quod non.

Primo probando quod mare non exeat limites suas ...X... si noviter exeat super aliquam partem, tunc dimittet aliam.

Et videtur quod non, quia, si est intemperatio in primis, tunc reducendum est ad primum modum vel secundum ...X... ideo non est verisimile, nec debemus continue formidare hoc.

Et videtur quod non. Primo : quia aqua deberet circuire totam terram ...X... et ibidem erit aliquando e contrario.

Et videtur quod non, quia alie aque non habent fluxum et refluxum

...X... de spera ignis non nescimus, ymo dubitamus.

Et arguitur quod non. Primo : quia alie aque non sunt salse ...X... plus evaporare de dulci, et fiunt ibi plures fumi.

Et videtur quod non, quia salsedo $\quad$ D 87ra; causatur in mare ex radiis Solis ...X... licet non ita perfecta sicut sunt animalia.
D77ra ;

M33ra;

C67va

D77va ;

M33va;

C68rb

D78rb;

M34rb;

C68vb

D79ra ;

M34vb;

C69va

D85ra ;

M35vb;

C70ra

D85ra;

M35vb;

C70vb

D85va;

M36rb;

C73ra

D86ra ;

M36vb;

C73va

D86va ;

M37rb;

C74ra

M37vb;

C74ra 


\begin{tabular}{|c|c|c|c|}
\hline II. 5 & Utrum ventus sit exalatio sicca & $\begin{array}{l}\text { Arguitur quod non. Primo: } \\
\text { sequeretur quod venti magis } \\
\text { deberent fieri tempore sicco } \\
\text {...X... adducunt aerem et vapores } \\
\text { frigidos de aliis, et e contrario. }\end{array}$ & $\begin{array}{l}\text { D87va; } \\
\text { M38rb; } \\
\text { C75ra }\end{array}$ \\
\hline II.6 & $\begin{array}{l}\text { Utrum Auster veniat a polo } \\
\text { antartico et Boreas ab artico }\end{array}$ & $\begin{array}{l}\text { Et arguitur quod sic, quia sicut se } \\
\text { habet Boreas ad polum ...X... ad } \\
\text { unam partem, et alter ad aliam. }\end{array}$ & $\begin{array}{l}\text { D88rb; } \\
\text { M39ra; } \\
C 75 \mathrm{vb}\end{array}$ \\
\hline II.7 & Utrum terremotus sit possibilis & $\begin{array}{l}\text { Et antequam arguatur sciendum } \\
\text { est quod terram moveri potest } \\
\text { ymaginari ...X... ideo plus } \\
\text { violentatur et fortificatur in } \\
\text { movendo. }\end{array}$ & $\begin{array}{l}\text { D88vb; } \\
\text { M39va; } \\
C 76 \mathrm{va}\end{array}$ \\
\hline II. 8 & $\begin{array}{l}\text { Utrum terremotus, ventus et } \\
\text { tonitrum et similia sint eiusdem } \\
\text { nature }\end{array}$ & $\begin{array}{l}\text { Arguitur quod non. Primo : quia } \\
\text { loca generationis ...X... aut } \\
\text { propter loca, aut propter motum, } \\
\text { aut aliquid tale. }\end{array}$ & $\begin{array}{l}\text { D89rb; } \\
\text { M40ra; } \\
\text { C77ra }\end{array}$ \\
\hline II.9 & $\begin{array}{l}\text { Utrum fulgur sit exalatio calida et } \\
\text { sicca ignita }\end{array}$ & $\begin{array}{l}\text { Arguitur quod non, quia talis } \\
\text { exalatio deberet moveri sursum } \\
\text {...X... sicut dictum fuit in tractatu } \\
\text { de grandine. }\end{array}$ & $\begin{array}{l}D 89 \mathrm{vb} ; \\
M 40 \mathrm{va} ; \\
C 78 \mathrm{ra}\end{array}$ \\
\hline II. 10 & $\begin{array}{l}\text { Utrum visus refrangantur a } \\
\text { corporibus densis et politis }\end{array}$ & $\begin{array}{l}\text { Et arguitur quod non. Primo : quia } \\
\text { visio non fit extramittendo ...X... } \\
\text { est causa quare magis a politis } \\
\text { quam ab asperis. }\end{array}$ & $\begin{array}{l}\text { D90va; } \\
\text { M41ra; } \\
\text { C78vb }\end{array}$ \\
\hline II.11 & $\begin{array}{l}\text { Utrum halo fiat ex refractione } \\
\text { radiorum ab ipsa nube }\end{array}$ & $\begin{array}{l}\text { Videtur quod non, quia tunc } \\
\text { semper appareret quando est } \\
\text { nubis ...X... et si non essent } \\
\text { secundum circulum non essent } \\
\text { equales. }\end{array}$ & $\begin{array}{l}\text { D91va; } \\
\text { M42ra; } \\
\text { C79vb }\end{array}$ \\
\hline II.12 & Utrum sit aliquis color spiritualis & $\begin{array}{l}\text { Arguitur quod non, quia omnis } \\
\text { color est vera res ...X... et causa } \\
\text { nigredinis maris patet ex } \\
\text { positione. }\end{array}$ & $\begin{array}{l}\text { D92ra; } \\
\text { M42rb; } \\
C 80 \mathrm{rb}\end{array}$ \\
\hline II.13 & $\begin{array}{l}\text { Utrum colores apparentes in } \\
\text { yride sint ibi vere et realiter }\end{array}$ & $\begin{array}{l}\text { Arguitur quod sic, quia sensus non } \\
\text { decipitur circa proprium } \\
\text { obiectum ...X... nisi color Solis } \\
\text { apparens per talia media. }\end{array}$ & $\begin{array}{l}D 92 \mathrm{rb} ; \\
M 42 \mathrm{vb} ; \\
C 80 \mathrm{vb}\end{array}$ \\
\hline II.14 & $\begin{array}{l}\text { Utrum yris debeat apparere } \\
\text { secundum circuli periferiam }\end{array}$ & $\begin{array}{l}\text { Arguitur quod non. Primo: quia } \\
\text { tota nubis est colorata ...X... alie } \\
\text { due rationes sunt solute per } \\
\text { positionem. }\end{array}$ & $\begin{array}{l}\text { D92vb; } \\
\text { M43rb; } \\
\text { C81va }\end{array}$ \\
\hline II.15 & $\begin{array}{l}\text { Utrum yris possit apparere maior } \\
\text { semicirculo }\end{array}$ & $\begin{array}{l}\text { Et videtur quod sic, quia halo } \\
\text { apparet secundum totum } \\
\text { circulum ...X... solutio rationum } \\
\text { patet in positione. }\end{array}$ & $\begin{array}{l}\text { M44ra; } \\
\text { C82ra }\end{array}$ \\
\hline II.16 & $\begin{array}{l}\text { Utrum yris quandoque appareat } \\
\text { secundum proportionem } \\
\text { maioris et quandoque minoris } \\
\text { circuli }\end{array}$ & $\begin{array}{l}\text { Videtur quod sic, argumento } \\
\text { Aristotelis in principio tractatus } \\
\text { de yride ...X... eius gloria pleni } \\
\text { erunt celi et terra. }\end{array}$ & $\begin{array}{l}M 44 \mathrm{va} ; \\
C 82 \mathrm{va}\end{array}$ \\
\hline
\end{tabular}




\begin{tabular}{|c|c|c|c|}
\hline IV.1 & $\begin{array}{l}\text { Utrum sint tantum quatuor } \\
\text { qualitates prime }\end{array}$ & $\begin{array}{l}\text { Arguitur quod non, quia non est } \\
\text { nisi una qualitas prima, ergo non } \\
\text { sunt quatuor ...X... scilicet } \\
\text { durum ad siccum et molle ad } \\
\text { humidum, etc. }\end{array}$ & D1 125ra \\
\hline IV.2 & $\begin{array}{l}\text { Utrum qualitatum primarum } \\
\text { due sint active et due passive, } \\
\text { scilicet caliditas et siccitas active, } \\
\text { et alie passive }\end{array}$ & $\begin{array}{l}\text { Arguitur primo quod caliditas et } \\
\text { frigiditas non solum sunt active, } \\
\text { sed passive, quia sunt active, ergo } \\
\text { passive ...X...tamen non oportet } \\
\text { quod sit corruptio qualitatis sibi } \\
\text { contrarie, ergo etc. }\end{array}$ & D1 125rb \\
\hline IV.3 & $\begin{array}{l}\text { Utrum caliditas sit magis qualitas } \\
\text { activa quam frigiditas }\end{array}$ & $\begin{array}{l}\text { Arguitur primo quod frigiditas sit } \\
\text { magis activa, quia illa est magis } \\
\text { activa que habet congregare } \\
\text {...X... [textus imperfectus] }\end{array}$ & D1 125vb \\
\hline
\end{tabular}

Nous avons établi la liste des questions de la redactio nova des Questions sur les Météorologiques de Nicole Oresme sur la base de trois manuscrits: Paris, BnF, lat.15156, f. 226r-265v $(P)^{132}$, Klagenfurt, Bischöfliche Bibliothek, XXXI.b. 5, f. 1r-124r $(K l)$, et Basel, Universtitätsbibliothek, F I 11, f. 4r-85v $(B a)$.

\begin{tabular}{|c|c|c|c|}
\hline Numéro & Intitulé de la question & $\begin{array}{c}\text { Incipit / Explicit } \\
\text { de la question }\end{array}$ & Folio \\
\hline I.1 & $\begin{array}{l}\text { Utrum possibile sit de } \\
\text { impressionibus } \\
\text { meteorologicis habere simul } \\
\text { scientiam et opinionem }\end{array}$ & $\begin{array}{l}\text { Et arguitur primo quod non, } \\
\text { quia de impressionibus } \\
\text { meteorologicis non contingit } \\
\text { habere scientiam, nec etiam } \\
\text { opinionem ...X... ita } \\
\text { ordinate quod sufficit ad hoc } \\
\text { quod de eis habeatur } \\
\text { scientiam }^{133} \text {. }\end{array}$ & $\begin{array}{l}\text { P226r; } \\
\text { Kl 1ra; } \\
B a 4 \text { ra }\end{array}$ \\
\hline I. 2 & $\begin{array}{l}\text { Utrum impressiones } \\
\text { meteorologice fiant } \\
\text { secundum naturam } \\
\text { inordinatiorem quam sit } \\
\text { natura celi }\end{array}$ & $\begin{array}{l}\text { Et arguitur primo quod non: } \\
\text { impressiones meteorologice } \\
\text { non fiunt secundum naturam } \\
\text {...X... tamen, hoc non } \\
\text { obstante, fiunt minus } \\
\text { ordinate quam motus celi. }\end{array}$ & $\begin{array}{l}P 227 \mathrm{v} ; \\
K l 2 \mathrm{va} ; \\
B a 5 \mathrm{ra}\end{array}$ \\
\hline
\end{tabular}

(132) Les questions transmises aux f. 267r-288v sont plutôt à attribuer à Albert de Saxe.

(133) Le manuscrit de Paris ajoute: « Et de hoc fusius in aliqua questione dicetur». 


\begin{tabular}{|c|c|c|c|}
\hline I. 3 & $\begin{array}{l}\text { Utrum iste mundus inferior } \\
\text { sit contiguus lationibus } \\
\text { superioribus ut virtus eius } \\
\text { inde gubernetur }\end{array}$ & $\begin{array}{l}\text { Ista questio querit primo } \\
\text { utrum iste mundus inferior } \\
\text { sit continuus lationibus } \\
\text { superioribus...X... quam } \\
\text { cito prima causa omnem } \\
\text { suam influentiam } \\
\text { retraheret }^{134} \text {. }\end{array}$ & $\begin{array}{l}\text { P228v; } \\
\text { Kl 4rav; } \\
\text { Ba } 4 \mathrm{vb}\end{array}$ \\
\hline I. 4 & $\begin{array}{l}\text { Utrum, cessante motu celi, } \\
\text { cessarent motus in isto } \\
\text { mundo inferiori }\end{array}$ & $\begin{array}{l}\text { Et arguitur primo quod non. } \\
\text { Nam, si sic, sequeretur quod, } \\
\text { si cessaret motus celi, ista } \\
\text { inferiora ...X... ad tertiam: } \\
\text { ex eadem radice; ad quartam: } \\
\text { consimili modo. }\end{array}$ & $\begin{array}{l}\text { P230v; } \\
\text { Kl6ra; } \\
\text { Ba 7rb }\end{array}$ \\
\hline I. 5 & $\begin{array}{l}\text { Utrum eedem opiniones } \\
\text { infinities reiterentur }\end{array}$ & $\begin{array}{l}\text { Et arguitur primo quod non: } \\
\text { nam, si sic, sequeretur quod } \\
\text { mundus esset eternus ...X... } \\
\text { de quorum numero non est } \\
\text { eternitas mundi, et ex hoc } \\
\text { patet solutio argumenti. }\end{array}$ & $\begin{array}{l}\text { P232r; } \\
K l 7 \mathrm{ra} \\
\mathrm{Ba} 8 \mathrm{rb}\end{array}$ \\
\hline I.6 & $\begin{array}{l}\text { Utrum elementa sint } \\
\text { continue proportionalia ad } \\
\text { invicem }\end{array}$ & $\begin{array}{l}\text { Et arguitur quod sic. Et primo } \\
\text { quod sint continue } \\
\text { proportionalia in quantitate } \\
\text {...X... an sint continue } \\
\text { proportionalia in raritate vel } \\
\text { in gravitate vel levitate, } \\
\text { videbitur in questione } \\
\text { sequenti. }\end{array}$ & $\begin{array}{l}P 233 \mathrm{v} \\
K l 8 \mathrm{vb} \\
\mathrm{Ba} 9 \mathrm{rb}\end{array}$ \\
\hline I.7 & $\begin{array}{l}\text { Utrum quatuor elementa } \\
\text { semper et immutabiliter } \\
\text { habeant eandem } \\
\text { proportionem ad invicem }\end{array}$ & $\begin{array}{l}\text { Et arguitur quod sic: } \\
\text { continue tantum est de } \\
\text { raritate sicut modo est ...X... } \\
\text { et sic non proportionaliter } \\
\text { quantum est hic calidius est } \\
\text { ibi frigidius. }\end{array}$ & $\begin{array}{l}\text { P235v; } \\
\text { Kl11rb; } \\
\text { Ba } 11 \mathrm{ra}\end{array}$ \\
\hline I. 8 & $\begin{array}{l}\text { Utrum motus celi sit causa } \\
\text { calefactionis ignis in sua } \\
\text { spera et etiam aeris superioris }\end{array}$ & $\begin{array}{l}\text { Et arguitur primo in generali } \\
\text { quod motus localis non est } \\
\text { causa caloris ...X... et ex hoc } \\
\text { potest dici ad formam } \\
\text { argumenti. }\end{array}$ & $\begin{array}{l}\text { P237r; } \\
\text { Kl 12va; } \\
\text { Ba } 12 \mathrm{ra}\end{array}$ \\
\hline I.9 & $\begin{array}{l}\text { Utrum lumen sit } \\
\text { productivum caloris }\end{array}$ & $\begin{array}{l}\text { Et arguitur quod non. Omne } \\
\text { quod fit et generatur fit a sibi } \\
\text { simili in specie ...X... de } \\
\text { squamis piscium: dictum est } \\
\text { in corpore questionis }{ }^{135} \text {. }\end{array}$ & $\begin{array}{l}P 238 \mathrm{v} ; \\
\text { Kl 13va; } \\
\text { Ba 13va }\end{array}$ \\
\hline
\end{tabular}

(134) L'explicit de cette question diverge sensiblement dans les manuscrits que nous avons utilisés pour notre édition. La version que nous en avons donnée est celle du manuscrit de Paris. En revanche, dans le manuscrit de Klagenfurt on lit: « et sic est de prima causa »; tandis que le manuscrit de Bâle a : «tam cito etiam lumen deficeret».

(135) Le manuscrit de Klagenfurt et de Bâle transmettent une forme erronée de cet explicit : «patebit in questione sequenti». 
Utrum omnium impressionum meteorologicarum vapor et exalatio fuerit principium materiale

Utrum impressiones ignite, seu ille que fiunt per inflammationem, fiant naturaliter in aere

Utrum de nocte, serenitate existente, debeant apparere hyatus et voragines et sanguinei colores in celo celi vel elementari

Utrum cometa sit exalatio calida et inflammata

Utrum motus comete sit naturalis vel violentus

Et arguitur primo quod non : contrarium circumstans suum contrarium agit in ipsum destruendo ipsum ...X... verum etiam partes extreme in quibus est ipsa caliditas.

Et arguitur primo quod non: semper media regio aeris est calida ...X... de quibus dicebatur in secundo articulo huius questionis.

Arguitur primo quod non : impressionum ignitarum nullum istorum est principium materiale ...X... et extrahitur vapor propter aqueum sibi permixtum. Et sic patet ad articulum.

Et arguitur quod non : nam impressiones ignite videntur esse de natura ignis ...X... ista elevatio est motus naturalis, quamvis eam precessit motus violentus.

Et arguitur quod huiusmodi impressiones non debeant apparere in celo, quia celum non est receptivum huiusmodi impressionum ...X...non est apta nata facere apparere huiusmodi colores.

Et arguitur quod sit de natura celi : illud est de natura celi cui convenit motus naturalis ipsius celi ...X... de significatione comete: videbitur seorsum in una questione.

Et arguitur quod non : nam talis exalatio vel esset multa, vel pauca ...X... et ergo, non obstante quod sit in umbra Terre, adhuc apparet lucere.

Et arguitur primo quod non sit naturalis. Corpora elementaria non moventur naturaliter motu circulari ...X... non tamen probant quin insit sibi preter naturam.
P240r;

Kl 16va;

$B a 14 v b$

P241v;

Kl 18va;

$\mathrm{Ba} 16 \mathrm{rb}$

P244r;

Kl21va;

$\mathrm{Ba} 18 \mathrm{va}$

P245r;

Kl23rb;

$\mathrm{Ba} 19 \mathrm{va}$

P246r;

Kl25vb;

Ba 20vb

P247r;

Kl26ra ;

Ba 21va

P248v;

$K l 27 \mathrm{vb}$;

Ba 22vb

P249r;

Kl28vb;

Ba 23va 
I.18

Utrum comete significent mortem principum, siccitatem et ventos et motus terre
Et arguitur primo quod non significent mortem principum, quia indifferenter respiciunt homines populares sicut principes ...X... non tunc fiunt venti, sed motus terre.

Et arguitur primo quod sit de natura elementari, auctoritate Aristotelis ...X... propter hoc quod plures antiquorum crediderunt galaxiam esse de natura elementari.

Et arguitur primo quod non. Nullum elementum debet generari extra locum sibi naturalem...X... ad quartam : patet quid sit dicendum ex questione. Et probatur quod non : illud quod est naturaliter calidum et humidum ...X... nechoc est aliquod inconveniens.

Et arguitur quod magis in hieme, nam grando est aqua fortiter congelata ...X... et, ipsis congelatis, fiunt grandines.

Et arguitur primo quod non : ubi est maior resistentia passi ad aliquod agens ...X... quam si fuisset frigida, propter causas predictas.

Et arguitur primo quod non. Rubedo vespertina non est signum pluvie ...X... possunt aliquando impediri, sed tamen hoc fit valde raro.

Et arguitur quod sic, quia caligo causatur ex elevatione vaporum ...X... nisi fingeremus, satis difficiliter possemus reddere rationem.
P250r;

Kl30ra;

Ba24ra

P251r;

Kl31rb;

Ba25ra

P253v;

Kl33rb;

$B a 26 v b$

P254r;

Kl34ra;

Ba 28ra

P256v;

Kl36vb;

Ba 29ra

P257v;

Kl38rb ;

Ba30rb

$P 258 \mathrm{v}$;

Kl39va;

$\mathrm{Ba} 31$ ra

P260r;

Kl41ra;

Ba 32rb 
Utrum aqua naturaliter ascendat ad orificia fontium

Et arguitur quod sic: illud

P261r; quod movetur a loco sibi

Kl41vb; innaturali ad locum sibi naturalem ...X... sit altior.

$\mathrm{Ba} 33 \mathrm{ra}$

Utrum aque fon tium generentur in terra.

Ad secundam : consimili modo; ad tertiam et quartam : similiter ${ }^{136}$.

Et arguitur primo quod non:

P262r; aque fontium fiunt ex aqua pluviali ...X... quibus repletis, iterum generatur aqua.

Utrum mare sit perpetuum vel aliquando fuit factum.

...X... et rationes hinc inde sunt solute ${ }^{137}$.

Et videtur quod non. Nam, si sic, cum hoc fiat ordinate ...X... solutiones rationum faciliter patent intuenti.

Et arguitur quod non :

$\mathrm{Ba} 33 \mathrm{vb}$

Utrum aqua maris debeat esse salsa unumquodque elementum debet esse purum maxime ...X... sicut alia que sunt versus viam Solis.

Utrum aque puteales esse debeant salse

Et videtur quod non : nam salsedo, sicut dicebatur prius, causatur a calore Solis ...X...

ad rationes in oppositum: patet in secundo articulo.

Utrum ventus sit exalatio

Et arguitur quod non sit exalatio calida : nam, si sic, sequeretur quod in temporibus ventosis ...X... sed preter naturam, ut visum est alibi, ut in primo Celi. illam.

(136) L'explicit du manuscrit de Bâle est : «est altior. Ad alias rationes omnes : dico similiter». Le manuscrit de Klagenfurt ajoute un autre paragraphe est se termine ainsi: «quod semper oportet principium originis fontium esse altius quam sit scaturies ipsorum ».

(137) Au lieu de cet explicit, dans le manuscrit de Paris, on lit : " et sic rationes vadunt viis suius ». 


\begin{tabular}{|c|c|c|c|}
\hline III.3 & $\begin{array}{l}\text { Utrum Boreas veniat a polo } \\
\text { artico et Auster a polo } \\
\text { antartico }\end{array}$ & $\begin{array}{l}\text { Et arguitur primo quod non, } \\
\text { quia polus, ut capitur in } \\
\text { proposito ...X... sed est } \\
\text { Boreas similis Boree nostro. }\end{array}$ & $\begin{array}{l}\text { Kl53ra; } \\
B a 41 v b\end{array}$ \\
\hline III.4 & $\begin{array}{l}\text { Utrum motus terre sit } \\
\text { possibilis }\end{array}$ & $\begin{array}{l}\text { Et arguitur quod non : nam, si } \\
\text { terre motus esset possibilis, } \\
\text { circa terram ascendere et } \\
\text { descendere esset possibile } \\
\text {...X... licet ibi non sit locus } \\
\text { naturalis aque. }\end{array}$ & $\begin{array}{l}\text { Kl54va; } \\
B a 42 \mathrm{vb}\end{array}$ \\
\hline III.5 & $\begin{array}{l}\text { Utrum tranquillitas sit } \\
\text { signum terre motus }\end{array}$ & $\begin{array}{l}\text { Et arguitur quod non, quia } \\
\text { sepe est tranquillitas et tamen } \\
\text { propter hoc non fit } \\
\text { terremotus ...X... ibi } \\
\text { minores fiunt terre motus et } \\
\text { pauciores. Rationes solute } \\
\text { sunt in questione }{ }^{138} \text {. }\end{array}$ & $\begin{array}{l}\text { Kl56ra; } \\
\mathrm{Ba} 44 \mathrm{ra}\end{array}$ \\
\hline III.6 & $\begin{array}{l}\text { Utrum tonitrum sit extinctio } \\
\text { ignis in nube }\end{array}$ & $\begin{array}{l}\text { Et arguitur primo quod sic, } \\
\text { quia sicut est de sono causato } \\
\text { ex ferro ignito ...X... ipsa } \\
\text { extinguebitur quod petebatur } \\
\text { in argumento. }\end{array}$ & $\begin{array}{l}K l 57 \mathrm{rb} \\
B a 44 \mathrm{vb}\end{array}$ \\
\hline III.7 & $\begin{array}{l}\text { Utrum exalatio ex qua fiunt } \\
\text { tonitrua et corruscationes } \\
\text { debeat descendere versus } \\
\text { terram }\end{array}$ & $\begin{array}{l}\text { Arguitur quod non, quia illud } \\
\text { quod est leve non debet } \\
\text { descendere ...X... una nubes } \\
\text { plura facit tonitrua et } \\
\text { corruscationes. }\end{array}$ & $\begin{array}{l}\text { Kl58vb; } \\
B a 46 \mathrm{rb}\end{array}$ \\
\hline III.8 & $\begin{array}{l}\text { Utrum corruscatio sit } \\
\text { possibilis }\end{array}$ & $\begin{array}{l}\text { Et arguitur primo quod non, } \\
\text { quia si sic, tunc fieret ex } \\
\text { materia ex qua fit tonitruum } \\
\text {...X... ut dictum est in primo } \\
\text { huius, non corruscat. }\end{array}$ & $\begin{array}{l}\text { Kl60ra; } \\
\mathrm{Ba} 47 \mathrm{ra}\end{array}$ \\
\hline III.9 & $\begin{array}{l}\text { Utrum fulmen aliquod sit } \\
\text { penetrans et aliud adurens }\end{array}$ & $\begin{array}{l}\text { Et arguitur primo quod } \\
\text { nullum sit penetrans, quia si } \\
\text { sic, sequeretur quod tale } \\
\text { posset exire nubem ...X... } \\
\text { secundum magis et minus } \\
\text { rarum et densum sue materie, } \\
\text { scilicet exalationis. }\end{array}$ & $\begin{array}{l}\text { Kl61ra; } \\
\mathrm{Ba} 48 \mathrm{ra}\end{array}$ \\
\hline III.10 & $\begin{array}{l}\text { Utrum indifferenter } \\
\text { quodlibet posset percuti } \\
\text { fulmine }\end{array}$ & $\begin{array}{l}\text { Et arguitur quod sic, quia non } \\
\text { videtur esse ratio quare magis } \\
\text { percutiatur unum quam } \\
\text { aliud...X... solutiones } \\
\text { rationum possunt patere ex } \\
\text { dictis. }\end{array}$ & $\begin{array}{l}\text { Kl62vb; } \\
\text { Ba } 49 \mathrm{ra}\end{array}$ \\
\hline
\end{tabular}

(138) Le manuscrit de Klagenfurt omet cette dernière phrase. 
III. 11

Utrum tiphon et ecnephia et incensio sint exalationes calide et sicce

Utrum visus frangatur in occursu medii densioris vel rarioris, puta aque vel aeris

Utrum cuiuslibet corporis superficies reflectat virtutes super ipsam incidentes, sicut sunt lumen, species coloris et huiusmodi

Utrum virtutes reflexe sint debiliores virtutibus non reflexis

Utrum aliqua specula representent solum colorem et non figuram, accipiendo colorem prout extendit se ad lucem et ad colorem proprie dictum

Utrum in apparitione ipsius halonis interponatur vapor inter visum et astrum

Utrum halo fiat per refractionem vel per reflexionem radiorum visualium super vaporem medium inter astrum sub quo halo apparet et visum nostrum

Utrum halo debeat apparere secundum circuli periferiam vel circumferentiam
Et arguitur primo quod non: si sic, seque- retur quod essent leves, et non graves ...X... quanta requiritur ad generationem tiphonis et ecnephie et incensionis.

Et arguitur primo quod non: nam, si sic, hoc esset accipiendo visum pro potentia visiva...X... et propter hoc non sunt eiusdem nature.

Et arguitur primo quod non : nam, si sic, sequeretur quod accidens migraret de subiecto in subiectum ...X... in cognitionem speciei, soni vel odoris.

Et arguitur primo quod sunt fortiores, nam alique cause requiruntur ...X... supposito adhuc quod lumen esset ibi intensius.

Et arguitur quod non : nam speculum non representat visum nisi...X... denarius in aqua apparet esse alibi quam sit in rei veritate.

Et arguitur primo quod non: nam, si sic, sequeretur quod gravius aere quiesceret ...X... ad sextam: patet ex secundo articulo.

Et arguitur primo quod fiat per refractionem, primo auctoritate, secundo ratione ...X... ad angulum acutum vel ad angulum rectum.

Et arguitur quod non, quia circumferentia est linea sine latitudine et profunditate ...X... ista ratio valet pro secunda parte conclusionis $^{139}$.
Kl63rb ;

Ba 49va

Kl64rb ;

$\mathrm{Ba} 50 \mathrm{rb}$

Kl66vb;

Ba 52ra

Kl69vb ;

$\mathrm{Ba} 54 \mathrm{ra}$

Kl70rb ; Ba 55 ra

$K l 72 \mathrm{rb}$;

Ba 56va

$K l 73 \mathrm{vb}$; $\mathrm{Ba} 57 \mathrm{ra}$

$K l 75 \mathrm{vb}$;

Ba 58 va

(139) Au lieu de cet explicit, dans le manuscrit de Klagenfurt, on lit : « et hoc non erit contra conclusiones ». 
III.19

Utrum radius visualis debeat reflecti ab aere uniformi non condensato nec mixto vaporibus ad oculum videntis existentis in eodem aere sine adiutorio speculorum Utrum colores yridis sint colores secundum rei veritatem

Utrum yris sit forma realis nubi impressa vel sit solum forma ymaginaria

Utrum semper, apparentibus duabus yridibus, superior yris debeat habere colores conversim positos

Utrum yris superior vel secundaria necessarie debeat apparere et esse remissior in coloribus quam principalis yris
Et arguitur primo quod sic, per Aristotelem in tertio huius ...X... in statu innocentie velvel glorificatorum corporum, adhuc nichil nos scimus.

Et arguitur primo quod sint colores secundum rei veritatem, auctoritate Aristotelis ...X... apparet nobis quod tales sint ibi colores.

Et arguitur primo quod non sit forma realis ...X... sicut in precedentibus questionibus apparuit.

Et arguitur primo quod fiat per refractionem, quia yris fit ut halo ...X... cum hoc tamen reflectitur, et hoc non est inconveniens.

Et arguitur primo quod non fiat super guttulas...X... ad quintam: soluta est ex iam dictis in questione.

Et arguitur quod non, quia, si sic, hoc esset pro tanto quod radius visualis ...X...

reddendo causam huius diversitatis coloris.

Et arguitur quod non, quia tripliciter, et non dupliciter, potest apparere ...X... ad aliam : dico quod est pro conclusione secunda.

Et arguitur primo quod non, quia si sic, hoc maxime videtur esse propter colorem medium ...X... colores similiter situatos sicut media.

Et arguitur primo quod non, quia si sic, sequitur quod hoc esset maxime propter maiorem remotionem ...X... includende sunt alie cause sub ista quam tangit in littera.
Kl78ra ;

Ba60ra

Kl80vb;

$B a 61 v b$

Kl82va;

$\mathrm{Ba} 62 \mathrm{vb}$

Kl84ra ;

$B a 63 v b$

Kl86ra ;

$B a 64 \mathrm{vb}$

Kl87ra ;

$\mathrm{Ba} 65 \mathrm{va}$

Kl $88 \mathrm{rb}$;

$\mathrm{Ba} 66 \mathrm{rb}$

Kl90ra ;

$\mathrm{Ba} 67 \mathrm{rb}$

Kl91va ;

$\mathrm{Ba} 68 \mathrm{rb}$ 
III. 28

Utrum yris debeat apparere secundum circuli periferiam si non sit impedimentum

III. 29

Utrum semper, tempore apparitionis yridis, necesse sit centrum Solis et centrum orizontis et centrum yridis et polos eorundem esse in eadem linea recta

Utrum semper, tempore apparitionis yridis et halonis, dymeter yridis sit precise dupla ad dyametrum halonis

Utrum, omni hora diei artificialis, oculo existente in superficie orizontis, posset aliqua portio yridis apparere ubicumque fuerit homo vel oculus videntis

III.32

Utrum yris Lune potest pluries apparere quam bis in quinquaginta annis in consimilibus coloribus et proprietatibus sicut yris Solis Utrum, visa yride et sole vel astro elevato notabiliter, super orizontem apparet minor portio maioris circuli quam appareat Sole exeunte in fine orizontis

Utrum virge et parelii fiant ex reflexione vel refractione radiorum sicut yris vel halo

Utrum per iuvamen artis possunt fieri metalla
Et arguitur primo quod non, quia yris fit secundum sectionem ...X... ad oculum perveniant, saltem sensibiliter.

Et arguitur primo quod non, quia si sic, sequeretur quod centrum orizontis non esset idem cum centro mundi ...X... et sic non est in aliis. Per isto patet solutio quarte et sexte rationis ${ }^{140}$.

Et arguitur quod non, quia dyameter halonis est

aliquando valde parva ...X. . et non urinalis, nec alterius apparentis.

Et arguitur primo quod sic, quia omni hora diei longitudine ...X.... quia hoc in Norvegia non potest fieri.

Et arguitur primo quod non, quia Aristoteles in textu veteris translationis ...X... sed magis per refractionem, ut docet experientia ${ }^{141}$.

Et arguitur primo quod non, quia si sic, hoc maxime videretur propter maiorem densitatem vaporis ...X... et alias non, et hoc docet experientia.

Et arguitur primo quod non, quia si sic, tunc fierent secundum figuram circularem ...X... generatur materia virgarum sicut materia pareliorum.

Et arguitur primo quod non, quia si sic, tunc una species metallica posset transformari in aliam ...X.... dico quod non in vanum laborant, ex quo aliam artem ignorant.
Kl92vb ;

$\mathrm{Ba} 69 \mathrm{ra}$

Kl94vb; Ba $70 \mathrm{va}$

Kl97rb ;

$B a 71 v b$

Kl99rb ;

Ba 73ra

Kl101ra ;

$\mathrm{Ba} 74 \mathrm{ra}$

Kl103ra ;

Ba 75 ra

Kl 103ra ;

Ba 76 ra

Kl107ra；

$B a 76 \mathrm{vb}$

(140) Le manuscrit de Bâle omet cette dernière phrase.

(141) Au lieu de "per refractionem » dans le manuscrit $B a$, on lit «per reflexionem ». 


\begin{tabular}{|c|c|c|c|}
\hline IV.1 & $\begin{array}{l}\text { Utrum tantum quattuor sunt } \\
\text { qualitates prime, scilicet } \\
\text { caliditas, humiditas, } \\
\text { frigiditas, siccitas }\end{array}$ & $\begin{array}{l}\text { Et arguitur primo quod non, } \\
\text { quia quod per } \\
\text { superhabundantiam ...X... } \\
\text { oportet quod gravitas vel } \\
\text { levitas sint priores } \\
\text { qualitatibus predictis. }\end{array}$ & $\begin{array}{l}\text { Kl 109va; } \\
\text { Ba } 78 \mathrm{rb}\end{array}$ \\
\hline IV.2 & $\begin{array}{l}\text { Utrum quattuor qualitates } \\
\text { videlicet caliditas, frigiditas, } \\
\text { etc., sint principia activa in } \\
\text { generatione cuiuslibet mixti, } \\
\text { accipiendo tamen } \\
\text { generationem pro alteratione } \\
\text { precedente introductionem } \\
\text { forme substantialis mixti, eo } \\
\text { modo quo Aristoteles accipit } \\
\text { in secondo capitulo huius } \\
\text { quarti }\end{array}$ & $\begin{array}{l}\text { Et arguitur quod sic: ita sunt } \\
\text { principia generationis } \\
\text { mixtorum, secundum } \\
\text { quorum proportionem aliam } \\
\text { et aliam ...X... tamquam } \\
\text { causarum instrumentalium, } \\
\text { et non principalium. }\end{array}$ & $\begin{array}{l}\text { Kl110vb; } \\
\text { Ba79ra }\end{array}$ \\
\hline IV.3 & $\begin{array}{l}\text { Utrum putrefactio causetur a } \\
\text { calido extrinseco fugiente } \\
\text { intrinseco }\end{array}$ & $\begin{array}{l}\text { Et arguitur primo quod non: } \\
\text { nam Aristoteles dicit in littera } \\
\text { quod putrefactio est } \\
\text { corruptio calidi intrinseci } \\
\ldots . \text { X... cum hoc tamen stat } \\
\text { quod caliditas extrinseca } \\
\text { potest facere } \\
\text { putrefactionem } \\
142 .\end{array}$ & $\begin{array}{l}\text { Kl112ra; } \\
B a 79 \mathrm{vb}\end{array}$ \\
\hline IV.4 & $\begin{array}{l}\text { Utrum frigus preservat a } \\
\text { putrefactione }\end{array}$ & $\begin{array}{l}\text { Et arguitur primo quod non: } \\
\text { nam, si sic, tunc res } \\
\text { putrefactibiles diutius } \\
\text { preservarentur in terra } \\
\text {...X... non potente } \\
\text { corrumpere calorem } \\
\text { naturalem corporis } \\
\text { putrefactibilis. }\end{array}$ & $\begin{array}{l}\text { Kl113rb; } \\
\text { Ba 80ra }\end{array}$ \\
\hline IV.5 & $\begin{array}{l}\text { Utrum aliqua animalia } \\
\text { possunt generari per } \\
\text { putrefactionem }\end{array}$ & $\begin{array}{l}\text { Et arguitur primo quod non, } \\
\text { nam putrefactio est corruptio } \\
\text { que fit a perfecto ...X... } \\
\text { minus perfecte quam } \\
\text { animalia, quare si animalia } \\
\text { possunt, et plante. }\end{array}$ & $\begin{array}{l}\text { Kl 114va; } \\
\text { Ba 80vb }\end{array}$ \\
\hline IV.6 & $\begin{array}{l}\text { Utrum diffinitio digestionis } \\
\text { sit bona in qua dicitur: } \\
\text { digestio est perfectio a calido } \\
\text { naturali et proprio ex } \\
\text { oppositis passivis }\end{array}$ & $\begin{array}{l}\text { Et arguitur primo quod non, } \\
\text { quia digestio non est } \\
\text { perfectio ...X... et sunt } \\
\text { materia in qua ista alteratio } \\
\text { que vocatur digestio habet } \\
\text { fieri. }\end{array}$ & $\begin{array}{l}\text { Kl115vb; } \\
B a 81 \mathrm{rb}\end{array}$ \\
\hline
\end{tabular}

(142) Dans le manuscrit Klon lit, au lieu de «putrefactionem », « corruptionem ». 


\begin{tabular}{|c|c|c|c|}
\hline IV.7 & $\begin{array}{l}\text { Utrum balnea conferant ad } \\
\text { digestionem }\end{array}$ & $\begin{array}{l}\text { Et arguitur primo quod non, } \\
\text { quia si sic, vel igitur in hora in } \\
\text { qua fit digestio ...X... in } \\
\text { corpore humano, caput } \\
\text { autem eius sicut caninus. }\end{array}$ & $\begin{array}{l}\text { Kl 116vb; } \\
\text { Ba } 82 \mathrm{ra}\end{array}$ \\
\hline IV.8 & $\begin{array}{l}\text { Utrum sint tantum tres } \\
\text { digestiones }\end{array}$ & $\begin{array}{l}\text { Et arguitur quod non, quia } \\
\text { digestio est alteratio } \\
\text { calefactiva ...X... tunc } \\
\text { diceretur talis digestio epsesis } \\
\text { vel opsesis. }\end{array}$ & $\begin{array}{l}\text { Kl 118va; } \\
\text { Ba } 82 \mathrm{vb}\end{array}$ \\
\hline IV.9 & $\begin{array}{l}\text { Utrum frixata debeant magis } \\
\text { dici assata quam elixata }\end{array}$ & $\begin{array}{l}\text { Et arguitur primo quod sint } \\
\text { elixata, quia ista que } \\
\text { digeruntur a calido } \\
\text { extrinseco humido...X... ad } \\
\text { quartam non solvo, quia est } \\
\text { una conclusio, et similiter nec } \\
\text { eius confirmationem. }\end{array}$ & $\begin{array}{l}\text { Kl 121va; } \\
\text { Ba } 83 \mathrm{vb}\end{array}$ \\
\hline IV.10 & $\begin{array}{l}\text { Utrum vermes qui } \\
\text { generantur in ventribus } \\
\text { animalium generentur in } \\
\text { stomacho vel in intestinis }\end{array}$ & $\begin{array}{l}\text { Et arguitur primo quod } \\
\text { generentur in stomacho, et } \\
\text { hoc sic: quia huiusmodi } \\
\text { vermes ...X... nec ibi est } \\
\text { materia putrefacta ad } \\
\text { generationem huiusmodi } \\
\text { verminum requisita. }\end{array}$ & $\begin{array}{l}\text { Kl 122va; } \\
\text { Ba } 84 \mathrm{va}\end{array}$ \\
\hline IV.11 & $\begin{array}{l}\text { Utrum in quolibet mixto } \\
\text { dominetur terra vel aqua vel } \\
\text { ambo }\end{array}$ & $\begin{array}{l}\text { Et videtur quod non, quia si } \\
\text { sic, sequitur quod omnia } \\
\text { mixta essent frigida a } \\
\text { dominio ...X... et ideo, quia } \\
\text { non uritur ab igne, dicimus } \\
\text { quod tale animal habitet in } \\
\text { igne. }\end{array}$ & $\begin{array}{l}\text { Kl 123rb; } \\
\text { Ba } 84 \mathrm{vb}\end{array}$ \\
\hline
\end{tabular}




\section{ANNEXE II}

\section{INDEX DES QUESTIONS SUR LES MÉTÉOROLOGIQUES D'ALBERT DE SAXE}

Nous avons établi la liste des questions sur les Météorologiques d'Albert de Saxe en nous basant sur les quatre manuscrits de ce texte qui ont été identifies: Erfurt, Wissenschaftliche Allgemeinbibliothek, CA $4^{\circ}$ 299, f. 53r-103v (E); Berlin, Staatsbibliothek zu Berlin - Preußischer Kulturbesitz, lat. $2^{\circ} 387$, f. 63r-102v (B); Kraków, Uniwersytet Jagielloński, Biblioteka Jagiellońska, 635, p. 177r236v (C1); Kraków, Uniwersytet Jagielloński, Biblioteka Jagiellońska, 686, f. 101ra-134va (C2). Comme nous l'avons vu plus haut ${ }^{143}$, les deux derniers manuscrits ne transmettent pas les Questions d'Albert de Saxe dans leur entiereté, les questions I. 15-22 et II. 1-6 y étant absentes. Quant au manuscrit d'Erfurt, il transmet, à la fin du quatrième livre, la question Utrum in quolibet mixto dominetur terra aut aqua, vel ambo ${ }^{144}$. Comme cela a été montré par la collation du texte, cette question dérive du recueil d'Oresme, raison pour laquelle nous ne l'avons pas incluse dans la liste des questions d'Albert.

\begin{tabular}{|c|c|c|c|}
\hline Numéro & Intitulé de la question & Incipit / Explicit de la question & Folio \\
\hline I.1 & $\begin{array}{l}\text { Utrum de impressionibus } \\
\text { meteorologicis sit scientia }\end{array}$ & $\begin{array}{l}\text { Et arguitur quod non, quia } \\
\text { huiusmodi impressiones, sicut } \\
\text { nubes, tonitrua ...X... sed tamen } \\
\text { non sine ordine }{ }^{145} \text {. }\end{array}$ & $\begin{array}{l}\text { E53ra; } \\
\text { B63ra; } \\
\text { C1 177a; } \\
\text { C2101ra }\end{array}$ \\
\hline I. 2 & $\begin{array}{l}\text { Utrum impressiones } \\
\text { meteorologice fiant secundum } \\
\text { naturam inordinatiorem quam } \\
\text { sit natura celi }\end{array}$ & $\begin{array}{l}\text { Et primo arguitur quod non fiant } \\
\text { secundum naturam, quia aliqua } \\
\text { talia fiunt raro ...X... dico quod } \\
\text { illa regula non tenet semper, licet } \\
\text { ut in pluribus forte. }\end{array}$ & $\begin{array}{l}E 54 \mathrm{r} \\
B 63 \mathrm{vb} \\
C 1178 \mathrm{a} \\
C 2101 \mathrm{va}\end{array}$ \\
\hline I. 3 & $\begin{array}{l}\text { Utrum iste mundus inferior } \\
\text { gubernetur a motibus celi }\end{array}$ & $\begin{array}{l}\text { Arguitur quod non, primo quia } \\
\text { sequeretur quod ista inferiora } \\
\text { fierent ita ordinate sicut fiunt } \\
\text { motus celi ...X... si sequeretur } \\
\text { inclinationem naturalem et } \\
\text { impetum celi. }\end{array}$ & $\begin{array}{l}\text { E 55r; } \\
\text { B64va; } \\
\text { C1 180a; } \\
\text { C2 102va }\end{array}$ \\
\hline
\end{tabular}

(143) Cf. supra, p.\#\#.

(144) Au f. 102v. Inc.: «Videtur quod non, quia tunc mixta essent frigida a dominio »; expl. : «sed est talis complexionis quod non est ussibilis ab igne».

(145) Le manuscrit d'Erfurt ajoute: «non est aliqua ratio plus ad solvendum ». 
\begin{tabular}{l|l|} 
I.4 & Utrum eedem opiniones \\
reiterentur pluriesautinfinities
\end{tabular} reiterentur pluries aut infinities apud homines

Arguitur quod non : primo, quia sicut sensus ad sensibilia, ita intellectus ad intelligibilia ...X... in practicis et in factis particularibus, et propter hoc non sequitur quod ita sit in scientiis speculativis $^{146}$.

Utrum elementa sint sibi invicem Arguitur quod sic: primo, quia si equalia unum esset maius in quantitate, tunc esset maius in virtute ...X... forte est plus in mundo de caliditate quam de frigiditate.

Utrum quatuor elementa sint continue proportionalia

Arguitur quod sic, primo, quia sunt continue proportionalia in raritate et in densitate ...X... ita est sicut apparebit in sequenti questione. Arguitur quod sic : primo, quia proportionem, ita quod terra non sit maior una vice quam alia, et ita de aliis continue est equaliter de densitate ...X... per accessum et recessum in zodiaco, sed etiam per appropinquationem ad terram.

Utrum motus celi sit causa calefactionis ignis in spera sua et etiam aeris superioris

Utrum omnelumen sit calefactivum

Et primo in generali arguitur quod motus non sit causa caloris, quia non ...X... de aliis qui tremunt quando habent febres.

Arguitur quod non, quia omne quod fit, fit a sibi simili ...X... dico

E61v; quod non sunt luminosa et etiam frigefaciunt propter alias causas.

Utrum unum contrarium Arguitur quod non, quia omne

E62v; circumstans aliud contrarium fortificat aliud contrarium applicatum alteri contrario agit in illud destruendo

$B 70$ ra;

C1 187b; ...X... et sic dictum sit de ista C2 107ra

Utrum media regio aeris sit ortificatione quam Aristoteles vocat antiparistasim.

Et quia statim sophistice opponeretur quod nullus aer est

E63v; semper ...X... et sic alie cause frigiditatis, ut visum est.

$B 70 \mathrm{vb}$;

C1 187b; C2 107va Et videtur quod non, quia ista

Utrum vapor et exalatio sint materie impressionum segregantur a terra et aqua, ut dicit

(146) Le manuscrit d'Erfurt omet la dernière partie de la phrase: «et propter hoc non sequitur quod ita sit in scientiis speculativis». 


\begin{tabular}{|c|c|c|c|}
\hline I.13 & $\begin{array}{l}\text { Utrum sidera volantia et flamme } \\
\text { tales apparentes in aere fiant } \\
\text { naturaliter }\end{array}$ & $\begin{array}{l}\text { Et videtur quod non, quia talia } \\
\text { sunt de natura ignis; ergo non } \\
\text { generantur in aere ...X... et } \\
\text { secundum hoc non dicuntur fieri } \\
\text { naturaliter. }\end{array}$ & $\begin{array}{l}E 66 \mathrm{r} ; \\
B 72 \mathrm{vb} ; \\
C 1192 \mathrm{a} \\
C 2109 \mathrm{va}\end{array}$ \\
\hline I. 14 & $\begin{array}{l}\text { Utrum, serenitate existente, } \\
\text { appareant de nocte in celo hyatus } \\
\text { sive aperture et voragines et } \\
\text { sanguinei colores }\end{array}$ & $\begin{array}{l}\text { Arguitur quod non de nocte, } \\
\text { immo ymaginandum de die in } \\
\text { lumine ...X... situs non est } \\
\text { proprium obiectum conveniens. }\end{array}$ & $\begin{array}{l}E 67 \mathrm{r} \\
B 73 \mathrm{rb} \\
C 1192 \mathrm{~b} \\
C 2110 \mathrm{ra}\end{array}$ \\
\hline I. 15 & $\begin{array}{l}\text { Utrum stella comata sit de natura } \\
\text { celi aut de natura elementari }\end{array}$ & $\begin{array}{l}\text { Et primo arguitur quod non sit de } \\
\text { natura materiali per rationes } \\
\text { Senece ...X... de significatione } \\
\text { videbitur postea in una } \\
\text { questione }^{147} \text {. }\end{array}$ & $\begin{array}{l}E 67 \mathrm{v} \\
B 74 \mathrm{ra}\end{array}$ \\
\hline I. 16 & $\begin{array}{l}\text { Utrum stella comata sit exalatio } \\
\text { calida ignita }\end{array}$ & $\begin{array}{l}\text { Arguitur quod non, quia talis } \\
\text { materia vel esset pauca vel multa } \\
\text {...X... vel inter nos et ipsam non } \\
\text { appareat maius lumen. }\end{array}$ & $\begin{array}{l}E 68 \mathrm{v} \\
B 74 \mathrm{va}\end{array}$ \\
\hline I. 17 & $\begin{array}{l}\text { Utrum comete significant ventos, } \\
\text { siccitates, mortes principum et } \\
\text { similia }\end{array}$ & $\begin{array}{l}\text { Et arguitur quod non significant } \\
\text { ventos et siccitates, quia dicit } \\
\text { Aristoteles ...X... non oportet, } \\
\text { quia galaxia non est de natura } \\
\text { celi }^{148} \text {. }\end{array}$ & $\begin{array}{l}E 69 \mathrm{v} \\
B 75 \mathrm{rb}\end{array}$ \\
\hline I. 18 & $\begin{array}{l}\text { Utrum pluvia generatur in media } \\
\text { aeris regione }\end{array}$ & $\begin{array}{l}\text { Et arguitur quod non, primo quia } \\
\text { ibi fiunt impressiones ignite } \\
\text {...X... cadunt cum pluvia et } \\
\text { grandine et alie impressiones. }\end{array}$ & $\begin{array}{l}E 70 \mathrm{r} \\
B 75 \mathrm{vb}\end{array}$ \\
\hline I.19 & $\begin{array}{l}\text { Utrum nix, ros et pruina sunt } \\
\text { eiusdem speciei }\end{array}$ & $\begin{array}{l}\text { Videtur quod non : primo, quia } \\
\text { habent diversas diffinitiones seu } \\
\text { descriptiones ...X... et secundum } \\
\text { hoc diversi mode } \\
\text { describuntur }{ }^{149} \text {. }\end{array}$ & $\begin{array}{l}E 71 \mathrm{r} \\
B 76 \mathrm{va}\end{array}$ \\
\hline I. 20 & $\begin{array}{l}\text { Utrum grando magis debeat fieri } \\
\text { temporibus mediis, scilicet vere } \\
\text { et autumno, quam hieme et estate }\end{array}$ & $\begin{array}{l}\text { Et primo arguitur quod non possit } \\
\text { fieri, quia aut vapor in nubes } \\
\text { congelatur ...X... hic inferius } \\
\text { quod propter hoc sit superius, } \\
\text { sicut apparet in montibus. }\end{array}$ & $\begin{array}{l}E 71 \mathrm{v} \\
B 77 \mathrm{rb}\end{array}$ \\
\hline I. 21 & $\begin{array}{l}\text { Utrum rubedo matutina sit } \\
\text { signum pluvie }\end{array}$ & $\begin{array}{l}\text { Arguitur quod non, quia rubedo } \\
\text { verspertina non est signum quod } \\
\text { pluet ...X... ex illis vaporibus de } \\
\text { quibus fit ros aut pruina. }\end{array}$ & $\begin{array}{l}E 72 \mathrm{v} \\
B 78 \mathrm{ra}\end{array}$ \\
\hline
\end{tabular}

(147) Le manuscrit de Berlin omet « in una questione».

(148) Au lieu de «non est de natura celi », le manuscrit de Berlin a «non est de natura comete, ut videbitur postea".

(149) Le manuscrit de Berlin omet « diffinitiones seu». 
\begin{tabular}{l|l} 
I.22 Utrum caligo nebule sit signum & U
\end{tabular} serenitatis

Utrum aqua naturaliter ascendat ad orificia fontium

Utrum locus naturalis elementi aque sit ubi nunc est mare

Utrum mare fluat et refluat

Utrum aqua maris sit salsa.

Utrum aliqui fontes et fluvii et putei sint salsi

Utrum ventus sit exalatio calida

\section{Eta}

Et videtur quod non, quia veniunt antiparistasim causatur ibi calor

Et videtur quod non, quia in loco et sicca.
Et arguitur quod non, quia tale quid est materia nubis ...X... et Seneca, libro de Naturalibus Questionibus. Rationes sunt solute.

quod sic, quia omne elementum naturaliter movetur exeundo ${ }^{150}$ de loco sibi innaturali ...X... sed magis descensus totius aggregati. Ad quartam: de fontibus, solutum est ${ }^{151}$. ex aqua pluviali ...X... et per et frigus competens. naturali debet esse elementum maxime in sua propria

dispositione ...X... dico quod non oportet quod quiescat omnino, quia potest per accidens moveri.

Et videtur quod ${ }^{152}$ non quia alie aque, sicut flumina et stagna, non fluunt nec refluunt ...X.... per adequationem, ut tota superficies aque sit equidistans centro ${ }^{153}$

Arguitur quod non. Primo: quia alie aque, sicut stagna et flumina, non sint salse ...X... alie aque sunt salse propter alias causas, ut videbitur.

E73r;

$B 78 \mathrm{vb}$

E73v;

$B 79 \mathrm{rb}$

E74v;

$B 79 \mathrm{vb}$

E75v;

$B 80 \mathrm{vb}$

E76v;

$B 81$ va

$E 77 \mathrm{v}$;

$B 82 \mathrm{va}$

E78v;

$B 83 \mathrm{rb}$ causatur a calore radiorum Solis ...X... hoc intelligebatur de salsedine maris

Primo videtur quod sit aer motus, $\quad$ E79v; quia aliquis aer motus est ventus $\quad B 84 \mathrm{rb}$; ...X...concedo quod illa exalatio $\quad$ C1209b; movetur sursum, ut dictum est, $\quad$ C2 120rb donec repellitur a frigido.

(150) Le manuscrit d'Erfurt a « ascendendo ».

(151) L'explicit du manuscrit Berlin est suivant: « sed magis descensus totius aque congregate ».

(152) Le manuscrit d'Erfurt omet « quod non ».

(153) Le manuscrit de Berlin omet « centro ». 
trum tonitrum sit extinctio ignis in nube

Utrum corruscatio sit possibilis

Utrum indifferenter quodlibet aliquando possit percuti sive percutiatur a fulmine

Utrum fulgur sit exalatio calida, sicca et ignita et aliud aduret
Videtur quod non, quia permovet eos, ut dicit Aristoteles ...X... tunc possibile est quod fiant maiores de nocte

Et primo videtur quod sic de Austro, quia venti contrarii veniunt a locis contrariis...X... et ideo forte Aristoteles negaret istam experientiam.

Et sciendum quod potest ymaginari quod terra moveatur primo se totam simul circulariter ...X... sed habet viam liberam, et ideo non ita fortiter proiciatur

Et videtur quod non, quia sepe est tranquillitas, et tamen non statim sequitur terremotus ...X... et sic dictum sit de causis, signis et effectibus et aliis circumstantibus terremotum

Et videtur quod sic, per Aristotelem et Lincolniensem ...X... ad tertiam : concedo quod est simile, non tamen omnino, sed sicut dictum fuit.

Videtur quod non, quia exalatio inflammata ${ }^{154}$ in nocte serena ...X... etiam, postquam talia sunt inflammata, statim consumuntur, et deficit flamma propter siccitatem materie.

Utrum quoddam fulgur penetret moveretur sursum, quod est
Et videtur quod non, quia tunc falsum, ymmo deorsum ...X... generatur in media regione, quia circundatur calido ab utraque parte.

Et primo arguitur quod nullum sit penetrans, quia tunc sequeretur quod posset exire de nube ...X... nisi forte aliquando rarissime, et tunc dicitur esse fulmen tempore sereno, sicut prius tactum est.

Videtur quod sic, quia eadem ratione qua unum percutitur, eadem ratione aliud...X... ad rationes: omnes solute sunt $\mathrm{ex}$ positione.
E80v;

$B 84 \mathrm{vb}$;

C1211b;

C2 120vb

E81r;

$B 85 \mathrm{va}$;

C1212b;

C2 121va

E82r;

$B 86$ ra;

C1213a;

C2 122ra

E83r;

$B 87$ ra;

C1214b;

C2 122va

E83v;

$B 87 \mathrm{vb}$;

C1215b;

C2 123ra

$E 84 \mathrm{v}$;

$B 88 v a$;

C1216b;

C2 123vb

E85v;

B 89ra;

C1217b;

C2 124rb

E86r;

B90ra;

C1218b;

C2 124vb

E87r;

$B 90 \mathrm{vb}$;

C1219b;

C2 125rb

(154) Le manuscrit de Berlin a « elevata». 
Utrum iste impressiones, scilicet thifo et enephia et incensio, sint exalationes sicce.

Utrum visus refrangatur a corporibus densis

Utrum in visione fiat reflexio a corporibus politis et densis

Utrum aliqua specula representant colorem tantum, et non figuram

Utrum halo fiat per fractionem radii visualis

Utrum halo fiat per reflextionem ab ipsa nube

Utrum colores apparentes in yride sunt in ipsa

Utrum omnis yris sit tricolor
Et primo, de tyfone, arguitur quod non, quia movetur circulariter, ut dicit Aristoteles ...X.... ad quartam: dico quod possibile est tantam exalationem concludi in nube, sed hoc est raro contingens. Et videtur quod non. Primo : aut hoc esset capiendo visum pro potentia visiva...X... et habet reflectere et refrangere, ut postea magis videbitur.

Arguitur quod non, quia reflexio significat motum localem ...X... ad tertiam: concedo quod a corporibus asperis fit reflexio, sed quomodo hoc sit maior quam a planis videbitur postea.

Et videtur quod non, quia nichil representat aliquid visui nisi secundum aliquam figuram ...X... ad tertiam : peridem. Et cum hoc conceditur quod semper videtur vel ipsius partis vel alicuius alterius.

Arguitur quod sic. Primo : auctoritate, Aristotelis, qui sepe dicit istud ...X.... non est ita de isto radio, ymmo reflectitur a tali superficie ad modum speculi.

Arguitur quod non, nam tunc semper apparet quando est nubes intra Solem et Lunam ...X... ad primam: dicitur quod quando nubes est magis densa, non est ad hoc apta. Ad alias, dictum est.

Videtur quod sic, quia dicitur, secundo De anima: sensus non decipitur ...X... ad tertiam: concedo quod cum hoc videtur nigredo et densitas ipsius nubis.

Et videtur quod non, quia sicut ibi sunt tres colores, pari rationes deberent esse alii ...X... rationes in oppositum sunt solute.
E88r;

$B 91 \mathrm{rb}$;

C1220a;

C2 125vb

$E 88 \mathrm{v}$;

B92ra;

C1221a;

C2 126rb

E90r;

B93ra;

C1 222b;

C2 127ra

E91r;

$B$ 93vb;

C1 223b;

C2 127va

E 92v;

$B 95 \mathrm{ra}$;

C1 226a;

C2 128rb

E93r;

$B$ 95va;

C1 226b ;

C2 129ra

E94r;

$B 96$ ra;

C1 227a;

C2 129va

E95r;

$B$ 96vb;

C1 228b;

C2 130ra 


\begin{tabular}{|c|c|c|c|}
\hline III. 8 & $\begin{array}{l}\text { Utrum yris appareat secundum } \\
\text { circuli perifieriam }\end{array}$ & $\begin{array}{l}\text { Et arguitur quod non, quia dictum } \\
\text { est prius quod ...X... ad rationes: } \\
\text { patet solutio ex dictis, quia licet } \\
\text { colores sint ubique, ut sepe } \\
\text { dictum est, tamen non apparent } \\
\text { nisi ad determinatum situm et } \\
\text { angulum. }\end{array}$ & $\begin{array}{l}E 95 \mathrm{v} ; \\
B 97 \mathrm{rb} \\
C 1229 \mathrm{~b} \\
C 2130 \mathrm{va}\end{array}$ \\
\hline III.9 & $\begin{array}{l}\text { Utrum yris posset apparere omni } \\
\text { hora diei }\end{array}$ & $\begin{array}{l}\text { Et videtur quod sic, quia ita est de } \\
\text { halo...X... tunc videtur remotior, } \\
\text { ergo ceteris paribus, ex hoc } \\
\text { videtur maior, sicut patet in } \\
\text { perspectiva. }\end{array}$ & $\begin{array}{l}E 96 \mathrm{r} ; \\
B 96 \mathrm{va} ; \\
C 230 \mathrm{a} ; \\
C 2130 \mathrm{vb}\end{array}$ \\
\hline IV.1 & $\begin{array}{l}\text { Utrum primarum qualitatum } \\
\text { due sunt active, scilicet calidum } \\
\text { et frigidum, et due passive, } \\
\text { scilicet humidum et siccum }\end{array}$ & $\begin{array}{l}\text { Arguitur primo quod calidum et } \\
\text { frigidum sint qualitates passive, } \\
\text { quia frigidum corrumpitur a } \\
\text { calido...X... ad rationes : prime } \\
\text { solute sunt per primam } \\
\text { conclusionem, et alie per alias. }\end{array}$ & $\begin{array}{l}E 96 \mathrm{v} ; \\
B 98 \mathrm{ra} ; \\
C 1230 \mathrm{~b} ; \\
C 2131 \mathrm{ra}\end{array}$ \\
\hline IV.2 & $\begin{array}{l}\text { Utrum generatio simplex fiat a } \\
\text { calido et frigido }\end{array}$ & $\begin{array}{l}\text { Et arguitur quod non, quia iste } \\
\text { sunt qualitates alterative, ergo } \\
\text { sunt effective...X... et per hoc pro } \\
\text { ultimum responditur ad rationes } \\
\text { in oppositum. }\end{array}$ & $\begin{array}{l}E 97 \mathrm{v} ; \\
B 98 \mathrm{va} ; \\
C 1231 \mathrm{~b} \\
C 2131 \mathrm{va}\end{array}$ \\
\hline IV.3 & $\begin{array}{l}\text { Utrum putrefactio fit a calido } \\
\text { extrinseco et frigido intrinseco }\end{array}$ & $\begin{array}{l}\text { Et videtur quod non a tali calido, } \\
\text { quia generatio est contraria } \\
\text { putrefactioni ...X... et postea aer } \\
\text { putrefacit istud }^{155} \text {. }\end{array}$ & $\begin{array}{l}E 98 \mathrm{v} \\
B 98 \mathrm{rb} \\
C 1232 \mathrm{~b} \\
C 2132 \mathrm{ra}\end{array}$ \\
\hline IV.4-5 & $\begin{array}{l}\text { Utrum frigus preservet a } \\
\text { putrefactione, et secundo utrum } \\
\text { animal generetur ex } \\
\text { putrefactione }\end{array}$ & $\begin{array}{l}\text { Ad primum arguitur quod non, } \\
\text { quia putrefactio est diminutio } \\
\text { calidi et humidi ...X... ad aliam: } \\
\text { conceditur quod quandoque } \\
\text { planta generatur ex putrefactione. }\end{array}$ & $\begin{array}{l}\text { E99r; } \\
B 100 \mathrm{ra} \\
C 1233 \mathrm{~b} \\
C 2133 \mathrm{ra}\end{array}$ \\
\hline IV.6 & $\begin{array}{l}\text { Utrum diffinitio digestionis sit } \\
\text { bona, in qua dicitur }:<\text { digestio est } \\
\text { perfectio a naturali et a principio } \\
\text { calido ex oppositis passivis }>\end{array}$ & $\begin{array}{l}\text { Et videtur quod non sit perfectio, } \\
\text { quia sola forma substantialis est } \\
\text { perfectio mixti ...X... ad ultimum } \\
\text { :dico quod per opposita passiva } \\
\text { indendit humidum et siccum. }\end{array}$ & $\begin{array}{l}\text { E100r; } \\
\text { B100va; } \\
\text { C1244a; } \\
\text { C2133ra }\end{array}$ \\
\hline IV.7 & $\begin{array}{l}\text { Utrum sint tres digestiones } \\
\text { tantum }\end{array}$ & $\begin{array}{l}\text { Et videtur quod non, quia digestio } \\
\text { est alteratio facta a calido ...X... } \\
\text { de quarta: satis dictum est, quia, } \\
\text { licet sint plures, possunt reduci ad } \\
\text { istas. }\end{array}$ & $\begin{array}{l}E 100 \mathrm{v} \\
B 101 \mathrm{rb} \\
C 1235 \mathrm{a}\end{array}$ \\
\hline
\end{tabular}

(155) Le manuscrit de Berlin ajoute « puta animal». 


\section{ANNEXE III}

\section{INDEX DES QUESTIONS SUR LES MÉTÉOROLOGIQUES DE THÉMON LE JUIF}

Nous avons établi la liste des questions du commentaire de Thémon le Juif sur les Météorologiques d'Aristote en nous basant sur quatre manuscrits: Paris, BnF, lat.6547, f.1r-33r $(\mathrm{Pa})^{156}$; München, Bayerische Staatsbibliothek, Clm 6962, f. 93r-146r $(M)$; Ferrara, Biblioteca comunale Ariostea, ms. Classe II, n. 380, f. 1r$60 \mathrm{v}(F)$; Padova, Seminario vescovile, cod. 24 , f. $1 \mathrm{r}-50 \mathrm{v}(P d)^{157}$; et sur deux éditions, publiées à Paris en 1516 et en 1518 par G. Lockert (comme le texte de l'édition de 1518 constitue une réimpression de celui de l'édition 1516, nous les avons collationés ensemble, et nous nous y référerons avec le sigle $E^{158}$ ). Le texte des manuscrits Paris, BnF, lat.6547, f.1r-33r et Padova, Seminario vescovile, cod. $24, \mathrm{f} .1 \mathrm{r}-50 \mathrm{v}$ est incomplet : tandis que le premier s'arrête à la fin du deuxième livre, le second arrive jusqu'à la question III. 8, Utrum vapor ubi apparet halo sit figure sperice, au f. $33 \mathrm{ra}^{159}$. Les lignes qui, jusqu'au f. 39vb (40vb), avaient été tracées pour accueillir le texte, sont restées vides. Le manuscrit de Munich, quant à lui, présente, à la fin du troisième livre, des différences par rapport aux éditions et à la liste fournie par Birkenmajer: les questions III.23, Utrum yris Lune possit apparere pluries quam bis in.l. annis consimilibus coloribus et proprietatibus, sicut yris Solis et III.24, Utrum, visa yride cum Sole elevato notabiliter super orizontem, appareat minor portio maioris circuli quam appareat Sole existente in fine orizontis, manquent, et les questions suivantes, à savoir les trois dernières du troisième livre, présentent un ordre altéré. En outre, le manuscrit Clm 6962 ne contient que la première question du quatrième livre; cette question, qui s'interrompt avec les mots: "ista sunt quandoque impedimenta», est incomplète. Dans son édition des Questiones in De generatione et corruptione de Nicole Oresme, Caroti a fourni la liste des Questions sur les Météorologiques de Thémon le Juif telle qu'elles sont transmises par le manuscrit Città del Vaticano, Biblioteca Apostolica Vaticana, Vat.lat. 2177, f. $1 \mathrm{r}-92 \mathrm{v}^{160}$ : cette liste diffère de celle que nous présentons ci-dessous en tant que les questions III. 10 et III. 17 n’ont pas été transmises par ce manuscrit. Dans le manuscrit Ferrara, Biblioteca

(156) Sur ce manuscrit, voir W. SENKo, Repertorium commentariorum Medii Aevi in Aristotelem Latinorum quae in bibliothecis publicis Parisiis asservantur: Bibliothèque Nationale, Arsenal, Mazarine, Sorbonne, Ste Geneviève, Varsovie 1982, p. 93-94.

(157) Pour une description de ce codex, voir I Manoscritti della biblioteca del Seminario Vescovile di Padova (Biblioteche e Archivi 2. Manoscritti medievali del Veneto 1), ed. A. Donello et alii, Firenze 1998, p. 11-12.

(158) Pour la liste complète des manuscrits et des éditions des Questiones sur les Météorologiques de Thémon le Juif, cf. supra,p.\#\#.

(159) En réalité 34ra. Les lignes qui, jusqu'au f. 39vb (40vb), avaient été tracées pour accueillir le texte, sont restées vides.

(160) Nicolaus ORESME, Questiones super De generatione et corruptione, ed. CAROTI, p. $48^{\star}-49^{*}$. 
comunale Ariostea, ms. Classe II, n. 380, f. 1r-60v, la question III. 25, Utrum yrides apparentes circa candelas sint realiter existentes circa ipsas candelas, est déplacée à la fin du troisième livre.

\begin{tabular}{|c|c|c|c|}
\hline Numéro & Intitulé de la question & Incipit / Explicit de la question & Folio \\
\hline I.1 & $\begin{array}{l}\text { Utrum de impressionibus } \\
\text { metheorologicis possit esse } \\
\text { scientia }\end{array}$ & $\begin{array}{l}\text { Et arguitur primo quod non, quia } \\
\text { de omnibus impressionibus est } \\
\text { solum ...X... non propter hoc alie } \\
\text { impressiones fierent a casu, sed } \\
\text { naturaliter. Et sic sit finis } \\
\text { questionis prime }^{161} \text {. }\end{array}$ & $\begin{array}{l}P a 1 \mathrm{ra} ; \\
M 93 \mathrm{ra} \\
F 1 \mathrm{ra} \\
P d 1 \mathrm{r}\end{array}$ \\
\hline I. 2 & $\begin{array}{l}\text { Utrum totus iste mundus } \\
\text { sensibilis sit subiectus } \\
\text { superioribus lationibus et } \\
\text { contiguus, ut inde tota eius virtus } \\
\text { gubernetur }\end{array}$ & $\begin{array}{l}\text { Et arguitur primo quod non, quia } \\
\text { si sic, sequeretur quod celum et } \\
\text { virtus celi ...X... unde si celum } \\
\text { non influeret ignis non } \\
\text { combureret, immo non maneret, } \\
\text { nec gravia descenderent. Et sic de } \\
\text { aliis. }\end{array}$ & $\begin{array}{l}E 155 \mathrm{va} \\
M 93 \mathrm{va} \\
P 1 \mathrm{vb} \\
F 1 \mathrm{vb} \\
P d 3 \mathrm{r}\end{array}$ \\
\hline I. 3 & $\begin{array}{l}\text { Utrum moles totius terre, id est } \\
\text { quantitas vel magnitudo, sit } \\
\text { quibusdam astris multo minor }\end{array}$ & $\begin{array}{l}\text { Et arguitur quod non, nam sol et } \\
\text { quodlibet astrum apparet } \\
\text { nobis...X... nec ista est fama } \\
\text { sequentium intellectum, et } \\
\text { propter hoc contingit error illis } \\
\text { etc. }\end{array}$ & $\begin{array}{l}E 156 \mathrm{rb} \\
M 94 \mathrm{rb} \\
P 2 \mathrm{vb} \\
F 2 \mathrm{rb} \\
P d 5 \mathrm{r}\end{array}$ \\
\hline I. 4 & Utrum celum sit nature ignis & $\begin{array}{l}\text { Et arguitur quod sic, quia si non, } \\
\text { sequitur quod hoc esset ideo: } \\
\text { quod nec posset sursum nec } \\
\text { deorsum moveri ...X... et tamen } \\
\text { retro possunt comburere et } \\
\text { causare ignem. }\end{array}$ & $\begin{array}{l}E 157 \mathrm{rb} \\
M 95 \mathrm{rb} \\
P 3 \mathrm{vb} \\
\text { F3rb; } \\
P d 6 \mathrm{v}\end{array}$ \\
\hline I. 5 & $\begin{array}{l}\text { Utrum eedem opiniones } \\
\text { reiterentur infinities in hominibus }\end{array}$ & $\begin{array}{l}\text { Et arguitur primo quod non, quia } \\
\text { alique opiniones simpliciter sunt } \\
\text { tenende et semper }{ }^{162} \ldots \mathrm{X} \ldots \text { ad } \\
\text { quintam : dicendum quod eedem } \\
\text { in specie, et non eedem in numero } \\
\text { reiterantur. }\end{array}$ & $\begin{array}{l}\text { E158ra; } \\
\text { M96ra; } \\
P 4 \mathrm{va} \\
\text { F3vb; } \\
P d 8 \mathrm{r}\end{array}$ \\
\hline
\end{tabular}

(161) Cette question manquée dans les éditions, ce qui fait que la numérotation des manuscrits est décalée par rapport à celle des éditions : la question suivante qui, dans les éditions, est la première du recueil, occupe dans les manuscrits la deuxième position, et ainsi de suite.

(162) Celui-ci est le texte transmis par les éditions. En lieu et place de cet argument, les manuscrits en ont un autre: "Et arguitur primo quod non, quia si sic, tunc scientie non fuissent ab eterno nec essent eterne, ut habetur primo primo Posteriorum. Antecedens est falsum ; consequentia tenet, quia si aliqua opinio non est scita et opinata ab hominibus, licet prius opinabatur ab aliis, vel etiam nunc sit scita, tunc ista scientia non fuit in eterno ». Cet argument est suivi par celui qui commence la question dans les éditions. À partir de là, il y a de nouveau accord entre les manuscrits et les éditions. 

significet mortem principum, siccitates et ventos et alia mala

Et arguitur primo quod sic, quia quodlibet elementum est infinite rarum ...X... nec oportet adhuc de aliis quod se habeant in gravitate proportionaliter. Arguitur quod non, quia motus celi nihil aliud est quam celo

...X... et etiam causat virtutes in aere, que ulterius causat caliditatem.

Et arguitur primo quod non, quia est semper calida ; ergo non frigida ...X... cum aliis causis concurrentibus, que non sic combureret ad infimam regionem etc.

Et arguitur quod non, quia tunc una species quecumque produceret aliam indifferenter ...X... que conveniunt corpori celesti, sicut sunt lumen et influentia.

Et arguitur quod non, quia vapor nihil est, et similiter exlalatio ..X... de ultima ratione, scilicet de galaxia, videbitur alias utrum opinio Aristotelis sit vera vel non.

Et arguitur quod non, nam talia sunt de natura ignis, ergo non generantur naturaliter ...X... quia talis motus bene fit ab aliquo alio quam a generante.

Et arguitur quod non, quia ista apparent existente vapore elevato ...X... ad aliam dicta iam est causa quare talia apparent coloris rubei et non viridis.

Et arguitur primo quod non sit nature elementaris, quia nulla impressio elementaris durat tantum...X... ad aliam consimiliter est dicendum et eodem modo etc.

Et arguitur primo quod non significet siccitatem per Aristotelem, ubi ponit quod cometa significat inundationes ...X... et aliud eiusdem nature sine tali influentia non est signum.
E158vb; $M 96 \mathrm{vb}$;

P5va;

F4va;

Pd10r

E160va;

M101ra;

$P 7 \mathrm{vb}$;

F6va;

$P d 13 \mathrm{v}$

E161ra;

$M 101 \mathrm{vb}$;

$P 8$ va;

F7rb;

Pd 15r

E162ra;

M103ra;

P9vb;

F8va;

$P d 17 \mathrm{v}$

E162vb;

$M 103 \mathrm{va}$;

$P$ 10va;

F9ra;

Pd 19r

E163va;

$M 104 v b$;

P11va;

F10ra;

Pd21r

E 164rb; M 105va;

P12rb;

F10vb;

$P d 22 \mathrm{v}$

E164vb;

$M$ 106ra;

$P 12$ vb;

F11rb;

Pd23v

E166ra;

$M 103 \mathrm{vb}$;

P13va;

F12ra;

Pd25v 
Utrum media regio aeris sit locus generationis pluvie

Utrum pluvia, ros et pruina differant specie specialissima

Utrum grando fiat magis in vere quam in autumno

Utrum rubedo matutina significet pluvias futuras

Utrum aque fontium et aque fluviales generentur in concavitatibus terre

Consequenter queritur circa secundum librum Metherorum utrum mare, quod est in loco naturali aque, sit generabile et corruptibile vel perpetuum Secundo queritur utrum mare fluat in uno tempore et refluat in alio

Utrum totum mare debeat esse salsum et amarum

Et arguitur primo quod sit de natura elementari auctoritate Aristotelis ...X... alie rationes que probant galaxiam esse de natura celi solute sunt pro secunda conclusione.

Et arguitur primo quod non, quia solum inferior regio est locus generationis pluvie ...X... et quandoque alia gutta superior supervenit in descensu. Et sic patet quid etc.

Et arguitur quod sic, quia in diversis locis et temporibus et ex diversis materibus generantur...X... quod ros est ex vapore tamquam ex materia; ergo etc.

Et arguitur quod non, quia non fit nec potest fieri ...X... nec permitteretgenerationem grandinum.

Et arguitur primo non, quia significat serenitas, ergo etc. $\mathrm{X}$...hoc non impedit conclusione que ponuntur de frequenter contingentibus.

Et arguitur primo quod non, quia omnes fontes veniunt a mari...X... ex aliis partibus elementorum aliorum etc. Et sic est finis questionum primi libri.

Et arguitur primo quod sit perpetuum, quia omnia elementa sunt perpetua ...X... sic non est de aere respectu suarum partium, et de igne et aliis elementis.

Et arguitur quod non, quia si sic, vel influeret ad unam differentiam positionis ...X... et causa est quia non sunt supposite sic Soli nec Lune sicut mare.

Et arguitur primo quod non, quia nullum mare est calidum ...X... talia animalia non potuissent fuisse; quare etc.
E166ra; $M 104 \mathrm{rb}$; $P 14$ ra; F12va; Pd26v

E166va; $M 197 \mathrm{vb}$; $P 14$ va; F13ra; $P d 27 \mathrm{v}$

E167ra; P15rb;

F13vb; $P d 29 \mathrm{v}$

E168ra;

P16ra;

F14rb;

$P d 31 \mathrm{r}$

E169ra;

$P 16 \mathrm{vb}$;

F14rb;

Pd33r

E169vb;

$P 17 \mathrm{vb}$;

F16ra;

Pd 34v

E171ra;

P19ra;

M112va;

$F 17$ va;

Pd 38r

E172ra;

P20ra;

M114ra;

F18vb;

Pd40r

E172vb; M114rb; P21ra;

F19va;

$P d 42 \mathrm{r}$ 


\begin{tabular}{|c|c|c|c|}
\hline II.4 & $\begin{array}{l}\text { Utrum que fluviales vel fontales } \\
\text { possint esse salse }\end{array}$ & $\begin{array}{l}\text { Et arguitur primo quod non, quia, } \\
\text { si sic, sequeretur quod elementa } \\
\text {...X... cum dicitur quod illa aqua } \\
\text { sit simplex etc., negatur, cum iam } \\
\text { dictum sit quod est mixta. }\end{array}$ & $\begin{array}{l}\text { E173va; } \\
\text { M115ra; } \\
\text { P21va; } \\
\text { F20rb; } \\
P d 43 \mathrm{r}\end{array}$ \\
\hline II.5 & $\begin{array}{l}\text { Utrum ventus sit exalatio calida et } \\
\text { sicca }\end{array}$ & $\begin{array}{l}\text { Et arguitur quod non, quia tunc } \\
\text { tempore ventoso deberet esse } \\
\text { calor et siccitas ...X... dico quod } \\
\text { non sunt proprie venti, sed motus } \\
\text { aeris vel aer. }\end{array}$ & $\begin{array}{l}E 173 \mathrm{vb} \\
M 115 \mathrm{ra} \\
P 21 \mathrm{vb} \\
F 20 \mathrm{va} \\
P d 43 \mathrm{v}\end{array}$ \\
\hline II.6 & Utrum sol faciat cessare ventos & $\begin{array}{l}\text { Et arguitur quod non, quia tunc } \\
\text { simul et semel Sol ...X... sed Sol } \\
\text { consumendo huiusmodi vapores } \\
\text { facit cessare ventos etc. }\end{array}$ & $\begin{array}{l}\text { E174ra; } \\
M 115 \mathrm{va} ; \\
P 22 \mathrm{ra}^{163} \\
F 21 \mathrm{ra} \\
P d 44 \mathrm{r}\end{array}$ \\
\hline II.7 & Utrum terremotus sit possibilis & $\begin{array}{l}\text { Et arguitur quod non, quia terra } \\
\text { necessario quiescit in } \\
\text { medio...X.... non fuit factus per } \\
\text { exalationem inclusam, sed alio } \\
\text { modo, puta miraculose. }\end{array}$ & $\begin{array}{l}\text { E174va; } \\
\text { M116ra; } \\
P 22 \mathrm{va} \\
F 21 \mathrm{va} \\
P d 45 \mathrm{r}\end{array}$ \\
\hline II. 8 & $\begin{array}{l}\text { Utrum tranquillitas aeris sit } \\
\text { signum terre motus futuri }\end{array}$ & $\begin{array}{l}\text { Et arguitur primo quod non, quia } \\
\text { si sic, tunc plures fierent } \\
\text { terremotus ...X... est signum } \\
\text { certiorem de terremotu futuro }^{164} \text {. }\end{array}$ & $\begin{array}{l}\text { E175ra; } \\
\text { M116ra; } \\
\text { P23ra; } \\
\text { F22ra; } \\
P d 46 \mathrm{r}\end{array}$ \\
\hline II.9 & $\begin{array}{l}\text { Utrum tonitrum causetur ex igne } \\
\text { extincto in nube }\end{array}$ & $\begin{array}{l}\text { Et arguitur quod sic, quia sicut est } \\
\text { de ignito ferro ...X... oportet nos } \\
\text { coniecturari iuxta ea que videmus } \\
\text { hic. }\end{array}$ & $\begin{array}{l}\text { E175va; } \\
M 117 \mathrm{ra} \\
P 23 \mathrm{vb} \\
F 22 \mathrm{va} \\
P d 47 \mathrm{r}\end{array}$ \\
\hline II.10 & $\begin{array}{l}\text { Utrum typhon et ecnephias fiant } \\
\text { ex exalatione calida et sicca }\end{array}$ & $\begin{array}{l}\text { Et arguitur primo quod non, quia } \\
\text { infrigidant ...X... cum hoc } \\
\text { possunt esse plures parve que } \\
\text { elevant unam magnam. }\end{array}$ & $\begin{array}{l}E 176 \mathrm{rb} \\
M 117 \mathrm{vb} \\
P 24 \mathrm{va} \\
F 23 \mathrm{va} \\
P d 48 \mathrm{v}\end{array}$ \\
\hline II.11 & $\begin{array}{l}\text { Utrum fulmen sit ignis } \\
\text { descendens de nube }\end{array}$ & $\begin{array}{l}\text { Et arguitur quod non, quia, si sic, } \\
\text { tunc esset ibi genitus vel non } \\
\text {...X... ad quintam : dicitur quod } \\
\text { differunt dispositiones materie. }\end{array}$ & $\begin{array}{l}\text { E176vb; } \\
\text { M118ra; } \\
\text { P25ra; } \\
\text { F24ra; } \\
P d 49 \mathrm{r}\end{array}$ \\
\hline
\end{tabular}

(163) À partir d'ici, le manuscrit de Paris présente une erreur dans la foliotation : le folio 22r, en effet, n'a pas été numéroté ; la numérotation recommence à partir du folio $23 r$, qui a été numéroté 22. Nous n'avons pas maintenu cette numérotation erronée: dans la suite, donc, nous indiquerons comme folio 23 celui qui, dans le manuscrit, porte le numéro 22 , et ainsi de suite.

(164) L'explicit de cette question est assez divergent dans les témoins que nous avons consultés : celui que nous avons transcrit dans le tableau est transmis par le manuscrit de Munich; dans le manuscrit parisien, on lit en revanche: «est signum faciens timorem a terre motu futuro"; et les editions: « est signum faciens de tumore et tremore future; quare etc.». 


\begin{tabular}{|c|c|c|c|}
\hline III.1 & $\begin{array}{l}\text { Utrum omnis radius visualis } \\
\text { refrangatur in occursu medii } \\
\text { densioris vel rarioris }\end{array}$ & $\begin{array}{l}\text { Et arguitur primo quod non, nam } \\
\text { radius perpendicularis } \\
\text { reflectitur...X... refrangeretur ab } \\
\text { incessu recto vel a } \\
\text { perpendiculari }{ }^{165} \text {. }\end{array}$ & $\begin{array}{l}E 177 \mathrm{va} ; \\
M 118 \mathrm{vb} \\
P d 25 \mathrm{va} \\
F 23 \mathrm{vb}\end{array}$ \\
\hline III. 2 & $\begin{array}{l}\text { Utrum radius visualis procedens a } \\
\text { luminoso existente in medio unius } \\
\text { raritatis frangatur ad } \\
\text { perpedicularem vel a } \\
\text { perpendiculari occurrente medio } \\
\text { alterius densitatis }\end{array}$ & $\begin{array}{l}\text { Et arguitur primo quod non, quia } \\
\text { si sic, tunc occurrente medio } \\
\text { densiori ...X... et ideo non } \\
\text { oportet fieri tantum calorem. }\end{array}$ & $\begin{array}{l}E 178 \mathrm{vb} \\
M 120 \mathrm{ra} \\
P 26 \mathrm{vb} \\
F 26 \mathrm{ra}\end{array}$ \\
\hline III. 3 & $\begin{array}{l}\text { Utrum omnis radius visualis } \\
\text { reflectatur in occursu medii } \\
\text { densioris }\end{array}$ & $\begin{array}{l}\text { Et arguitur primo quod non, quia } \\
\text { si sic sequeretur quod duo } \\
\text { accidentia ...X... quod a politis } \\
\text { corporibus fieret reflexio, vel a } \\
\text { densis. }\end{array}$ & $\begin{array}{l}E 179 \mathrm{vb} ; \\
M 121 \mathrm{ra} \\
P 27 \mathrm{vb} \\
F 27 \mathrm{ra}\end{array}$ \\
\hline III.4 & $\begin{array}{l}\text { Utrum aliquis radius visualis } \\
\text { possit aliquibus speculis vel } \\
\text { corporibus sic incidere quod } \\
\text { reflectatur representans solum } \\
\text { colorem et non figuram }\end{array}$ & $\begin{array}{l}\text { Arguitur quod non, quia vel tales } \\
\text { radii representant rem visam vel } \\
\text { speculum ...X... tamen non sub } \\
\text { figura tali sicut est res visa, sed sub } \\
\text { alia. }\end{array}$ & $\begin{array}{l}E 180 \mathrm{vb} ; \\
M 122 \mathrm{ra} \\
P 29 \mathrm{ra} \\
F 28 \mathrm{rb}\end{array}$ \\
\hline III.5 & $\begin{array}{l}\text { Utrum halo appareat propter } \\
\text { radiorum refractionem in vapore } \\
\text { interposito inter visum et } \\
\text { luminosum circa quod apparet }\end{array}$ & $\begin{array}{l}\text { Et arguitur primo quod sic, } \\
\text { auctoritatibus Aristotelis ...X... } \\
\text { per reflexionem ad angulum } \\
\text { obscurum, aut per refractionem } \\
\text { improprie dictam. }\end{array}$ & $\begin{array}{l}E 182 \mathrm{vb} \\
M 124 \mathrm{ra} \\
P 31 \mathrm{ra} \\
F 30 \mathrm{rb}\end{array}$ \\
\hline III.6 & $\begin{array}{l}\text { Utrum halo fiat per refractionem } \\
\text { radiorum visualium }\end{array}$ & $\begin{array}{l}\text { Arguitur primo quod non, quia fit } \\
\text { per reflexionem solum ...X... sed } \\
\text { infinite, sicut infiniti sunt radii } \\
\text { oblique incidentes. }\end{array}$ & $\begin{array}{l}\text { E183rb; } \\
\text { M124va; } \\
\text { P31va; } \\
\text { F31ra }\end{array}$ \\
\hline III.7 & $\begin{array}{l}\text { Utrum, tempore apparitionis halo, } \\
\text { fit vapor interpositum inter visum } \\
\text { et astra }\end{array}$ & $\begin{array}{l}\text { Et primo arguitur quod non, quia } \\
\text { tunc maxime tempore nebularum } \\
\text { appareret halo ...X... ad hoc } \\
\text { etiam dictum fuit prius in } \\
\text { precedenti questione. }\end{array}$ & $\begin{array}{l}E 184 \mathrm{rb} \\
M 125 \mathrm{va} \\
P 32 \mathrm{va} \\
F 32 \mathrm{ra}\end{array}$ \\
\hline III.8 & $\begin{array}{l}\text { Utrum vapor ubi apparet halo sit } \\
\text { figure sperice }\end{array}$ & $\begin{array}{l}\text { Et arguitur primo quod sic, quia } \\
\text { talis vapor est plures } \\
\text { guttule...X... ideo non potest esse } \\
\text { unius figure, sed plurium } \\
\text { figurarum spericarum. }\end{array}$ & $\begin{array}{l}E 184 \mathrm{vb} \\
M 126 \mathrm{ra} \\
P 33 \mathrm{ra} \\
F 32 \mathrm{va}\end{array}$ \\
\hline III.9 & $\begin{array}{l}\text { Utrum halo debeat apparere } \\
\text { secundum circuli peripheriam vel } \\
\text { circumferentiam }\end{array}$ & $\begin{array}{l}\text { Arguitur primo quod non, quia } \\
\text { circumferentia est linea sine } \\
\text { latitudine ...X... hoc est per } \\
\text { defectum materie, et hoc non est } \\
\text { contra aliquam conclusionem. }\end{array}$ & $\begin{array}{l}E 185 \mathrm{vb} ; \\
M 127 \mathrm{ra} \\
P 34 \mathrm{ra} \\
F 33 \mathrm{va}\end{array}$ \\
\hline
\end{tabular}

(165) Le manuscrit $F$ ajoute: « sicut apparet in figura : data littera $c, p$ vel $d$, inter litteram $b, c$, et $d$, $c » ;$ le manuscrit $M$ ajoute un passage tout à fait semblable : «sicut apparet in figura dicta littera : $c, p$, intra litteram $a, b$ et $d, c$, quod debet scribi figura». 
III.10

Utrum radius visualis possit reflecti ab aere uniformi non condensato nec mixto vaporibus ad oculum eundem existentem in eodem aere, sine adiutorio speculorum

III.11 Utrum colores apparentes in yride sint ibi ubi apparent esse et sint veri colores

Utrum yris sit forma realis impressa in nubi vel solum sit forma imaginaria

Utrum yris sit forma diaphanalis vel specularis, vel utrum fiat per reflexionem et refractionem vel per refractionem, qui idem est

Utrum, supposito quod yris fiat per reflexionem radiorum, talis reflectio fiat in nube, vel super guttulas roridas, vel super stillicidia

III.15 Utrum omnis yris debeat esse tricolor

Utrum yris solum duplex et non multiplicior possit apparere

Utrum semper, apparentibus duabus yridibus, superior debeat habere duos colores conversim positos

Utrum semper yris superior ve secundaria necessario debeat apparere remissior in coloribus quam principalis

Utrum yris debeat apparere secundum circuli peripheriam, si non sit impedimentum
Et arguitur primo quod sic per Aristotelem ...X... in statu innocentie vel glorificatorum corporum, de hoc nichil scimus.

Et videtur primo quod sic, quia nos videmus omnes illos colores...X... alias non est rex, sicut nec isti sunt colores

Et arguitur primo quod non sit realis, quia si sic, tunc eodem modo ageret...X... per reflexionem, sicut satis visum est in questionibus secundi.

Et arguitur primo quod fiat per refractionem, quia yris fit sicut halo ...X... cum hoc etiam reflectitur, et hoc non est inconveniens.

Et arguitur primo quod non fiat per guttulas, quia tunc una sola guttula ...X... ad quintam autem dictum est in questione.

Et arguitur quod non, quia si sic, hoc esset pro tanto quia radius visualis ...X... licet non ita sensibiliter omnibus sicut Sol.

Et arguitur quod non, quia duplex et non solum ...X... ad aliam est solutum per conditiones premissas in questione.

Et arguitur quod non, quia si sic, hoc maxime videretur esse per medium colorem ...X... habens colores similiter situatos sicut in media.

Et arguitur primo quod non, quia si sic, hoc maxime esset propter maiorem remotionem ...X. . . licet Aristoteles non tetigerit omnes causas, tamen intelligende sunt alie sub ista quam tangit.

Et arguitur primo quod non, quia yris fit secundum sectionem...X... ne ad oculum perveniant, saltem sensibiliter.
E187rb; M128ra; F35ra

E188va; M129ra; F36rb

E189rb; M120va; F37rb

E190rb; $M 131 \mathrm{rb}$; F38ra

E 191rb; M132ra; F39ra

E191rb; $M 132 \mathrm{va}$; F39rb

E192ra； M133va; F40ra

E193ra; $M 134 \mathrm{rb}$; F41rb

E193vb; M135ra; F41vb

E 194rb; $M 135$ va; F42rb 
Utrum omni hora diei artificiali oculu existente in superficie orizontis possit aliqua portio yridis apparere ubicumque fuerit homo vel oculus videntis

Utrum yris Lune possit apparere pluries quam bis in .l. annis consimilibus coloribus et proprietatibus, sicut yris Solis

Utrum, visa yride cum Sole vel astro elevato notabiliter super orizontem, appareat minor portio maioris circuli quam appareat sole existente in fine orizontis

Utrum yrides apparentes circa candelas sint realiter existentes circa ipsas candelas

Utrum virge et paralleli fiant ex refractione radiorum, sicut yris vel halo

De his que fiunt sub terra queritur utrum per iuvamen artis possint fieri metalla, sicut yris et halo artificialiter quandoque fiunt

Circa quartum librum Metheororum queritur primo utrum putrefactio sit possibilis vel utrum possibile sit fieri vel esse putrefactione

IV.2 Utrum digestio sit perfectio causata a proprio et naturali calore ex oppositis passivis
Et arguitur primo quod non, quia si sic, tunc centrum ...X... et per hec etiam patet solutio quinte et sexte rationis.

Et arguitur primo quod non, quia quandoque diameter halo est

valde ...X... et non de halo urinalis vel alterius artificialis.

Arguitur primo quod sic, quia omni hora diei longissime ubicumque fuerit homo ...X... et quia hoc in Islandia sive in Venetia non potest fieri; ergo etc. Et arguitur primo quod non, auctoritate Aristoteles in textu veteris translationis ...X... sed magis per refractionem, ut experientia docet.

Et arguitur primo quod non, quia, si sic, tunc hoc maxime videret esse ...X... quandoque

consideravero forte melius dicam quam modo.

Et arguitur primo quod sic, auctoritatibus Aristotelis ...X... ut patet consideranti predicta.

Et arguitur primo quod non, quia si sic, tunc fieret secundum

figuram circularem ...X... sicut materia parallelorum.

Et arguitur primo quod non, quia si sic, tunc una species metallica posset in aliam transmutari ...X... quo ipsi aliam artem ignorant.

Et arguitur primo quod non, quia corruptio caliditatis a caliditate

...X... nec paucitas quelibet sufficit ad extinguendum.

Et arguitur primo quod non, quia digestio est imperfectio ...X... ut melius et specialiter postea videbitur.

Et arguitur primo quod non, quia omnis digestio ...X... propter diversitatem in modo agendi.
E195va; $M 136 \mathrm{vb}$; F43rb

E 196va; F44rb

E197ra; $M 138 v b$; F44ra

E198ra; $F 45 \mathrm{vb}$

E 198vb; F46rb

E199va; M 141va; F49ra

E200vb; M139rb; F47ra

E 101va; $M 139 \mathrm{vb}$; F47va

E203ra; M143ra; F50rb

E207va; F55ra

E209vb; F57rb 


\begin{tabular}{|c|c|c|c|}
\hline IV.4 & $\begin{array}{l}\text { Utrum digestio sanguinis et } \\
\text { nascentium a calore naturali sit } \\
\text { pepansis }\end{array}$ & $\begin{array}{l}\text { Et arguitur primo quod non, quia } \\
\text { sanguis non digeritur in } \\
\text { pericarpis ...X... loquendo iuxta } \\
\text { precessum Aristotelis in littera. }\end{array}$ & $\begin{array}{l}E 211 \mathrm{vb} \\
F 59 \mathrm{ra}\end{array}$ \\
\hline IV.5 & $\begin{array}{l}\text { Utrum simplex elementum possit } \\
\text { digeri vel pati digestionem }\end{array}$ & $\begin{array}{l}\text { Et arguitur quod non, quia } \\
\text { simplex elementum ...X....ibidem } \\
\text { existentibus ad loca nutriuntur. }\end{array}$ & $\begin{array}{l}E 212 \mathrm{rb} \\
F 59 \mathrm{rb}\end{array}$ \\
\hline IV.6 & $\begin{array}{l}\text { Utrum elixata sint sicciora quam } \\
\text { assata }\end{array}$ & $\begin{array}{l}\text { Et arguitur quod non, quia elixata } \\
\text { et assata ...X... sint sicciora ipsis } \\
\text { assatis, sed ceteris paribus. }\end{array}$ & $\begin{array}{l}E 212 \mathrm{va} ; \\
F 59 \mathrm{vb}\end{array}$ \\
\hline IV.7 & $\begin{array}{l}\text { Utrum frixata sint elixata vel } \\
\text { assata }\end{array}$ & $\begin{array}{l}\text { Et arguitur quod sint elixata, quia } \\
\text { ista digesta que sunt } \\
\text { sicciora...X... ideo ambulent viis } \\
\text { suiis. }\end{array}$ & $\begin{array}{l}\text { E213ra; } \\
\text { F60ra }\end{array}$ \\
\hline IV.8 & $\begin{array}{l}\text { Utrum diffinitio generationis } \\
\text { simplicis sit bona, in qua dicitur } \\
\text { quod generatio simplex et } \\
\text { naturaliter est permutatio ab his } \\
\text { virtutibus que habent rationem ex } \\
\text { subiecta materia unicuique nature }\end{array}$ & $\begin{array}{l}\text { Et arguitur quod non, primo, quia } \\
\text { illa diffinitio non est bona que non } \\
\text { competit ...X... potest esse } \\
\text { subiectum unicuique nature } \\
\text { generabili et corruptibili. }\end{array}$ & $\begin{array}{l}E 213 \mathrm{rb} \\
F 60 \mathrm{rb}\end{array}$ \\
\hline
\end{tabular}




\section{ANNEXE IV}

\section{LES QUESTIONS SUR LES MÉTÉOROLOGIQUES DU MS MÜNCHEN, BAYERISCHE STAATSBIBLIOTHEK, CLM 17226, F. 1RA-140RB}

Dans le tableau suivant, nous avons représenté de façon schématique le contenu de la compilation des Questions sur les Météorologiques transmise par le manuscrit München, Bayerische Staatsbibliothek, Clm 17226, f.1ra-140rb, et avons indiqué, pour les différentes questions, si elles proviennent du recueil de Nicole Oresme (redactio nova), de Jean Buridan ${ }^{166}$ ou de celui de Thémon le Juif. Dans les cas - très nombreux - où les questions avaient les mêmes intitulés chez ces auteurs, nous avons également comparé leurs incipit et leurs explicit. Pour ne pas alourdir le tableau, toutefois, nous nous sommes limités ici à présenter les intitulés des questions.

\begin{tabular}{|c|c|c|c|}
\hline Folio & Numéro & Intitulé de la question & Source \\
\hline $1 \mathrm{rb}$ & I. 1 & $\begin{array}{l}\text { Utrum de impressionibus metheorologicis sit } \\
\text { tradenda scientia naturalis distincta a scientia de celo } \\
\text { et mundo, de generatione et corruptione, de } \\
\text { mineralibus et de natura et naturalibus [sic ms. pro: de } \\
\text { anima et animalibus] }\end{array}$ & Buridan I.1 \\
\hline $2 \mathrm{va}$ & I. 2 & $\begin{array}{l}\text { Consequenter queritur utrum iste mundus inferior est } \\
\text { ex necessitate continuus lationibus superioribus, ut } \\
\text { omnis ipsius virtus gubernetur inde }\end{array}$ & Buridan I.2 \\
\hline $4 \mathrm{rv}$ & I.3 & $\begin{array}{l}\text { Consequenter queritur utrum aqua est maior terra et } \\
\text { aer maior aqua et ignis maior aere }\end{array}$ & Buridan I.3 \\
\hline $7 \mathrm{rb}$ & I. 4 & $\begin{array}{l}\text { Consequenter queritur utrum impressiones } \\
\text { metheorologice fiant secundum naturam } \\
\text { inordinatiorem quam sit natura corporum celestium }\end{array}$ & Oresme I.2 \\
\hline $8 \mathrm{rb}$ & I. 5 & $\begin{array}{l}\text { Consequenter queritur utrum, cessante motu celi, } \\
\text { cessarent motus in isto mundo inferiori }\end{array}$ & Oresme I.4 \\
\hline 9ra & I.6 & $\begin{array}{l}\text { Consequenter queritur utrum eedem opiniones } \\
\text { infinities reiterentur }\end{array}$ & Oresme I.5 \\
\hline $10 \mathrm{ra}$ & I.7 & $\begin{array}{l}\text { Utrum elementa sint continue proportionalia ad } \\
\text { invicem }\end{array}$ & Oresme I.6 \\
\hline $11 \mathrm{va}$ & I. 8 & $\begin{array}{l}\text { Utrum quattuor elementa sint continue } \\
\text { proportionalia vel habeant equalitatem communis } \\
\text { analoyce vel continua proportionalitatem }\end{array}$ & Thémon I.5 \\
\hline $14 \mathrm{vb}$ & I.9 & $\begin{array}{l}\text { Utrum contrarium circumstans suum contrarium } \\
\text { fortificet ipsum }\end{array}$ & Oresme I.10 \\
\hline $16 \mathrm{ra}$ & I. 10 & Utrum motus calefacit & Buridan I.4 \\
\hline
\end{tabular}

(166) Pour ce texte, dont seulement le premier livre a été édité, nous avons utilisé comme terme de comparaison la liste des questions présente chez FARAL, "Jean Buridan», p.22-24 et le texte du manuscrit Paris, BnF, lat. 14723, f. 167r-259v. 


\begin{tabular}{|c|c|c|c|}
\hline $18 \mathrm{rb}$ & I.11 & $\begin{array}{l}\text { Sicut de motu quesitum est, ita quinto querimus de } \\
\text { lumine, videlicet utrum omne lumen sit calefactivum }\end{array}$ & Buridan I.5 \\
\hline 20va & I. 12 & Utrum media regio aeris est semper frigida & Buridan I.6 \\
\hline $23 \mathrm{ra}$ & I.13 & $\begin{array}{l}\text { Utrum calor potest frigefacere et frigus calefacere per } \\
\text { antiparsistasim }\end{array}$ & Buridan I.7 \\
\hline $24 \mathrm{rb}$ & I.14 & $\begin{array}{l}\text { Utrum sidera cadentia, vel flamme et fulgura et } \\
\text { huiusmodi, fiunt et descendunt naturaliter }\end{array}$ & Buridan I.8 \\
\hline $25 \mathrm{ra}$ & I.15 & $\begin{array}{l}\text { Utrum omnes impressiones metheorologice ignite } \\
\text { sint eiusdem speciei }\end{array}$ & Buridan I.9 \\
\hline $27 \mathrm{rb}$ & I.16 & $\begin{array}{l}\text { Utrum impressionum metroloycarum vapor et } \\
\text { exalatio sint principium materiale }\end{array}$ & Oresme I.12 \\
\hline $28 \mathrm{ra}$ & I.17 & $\begin{array}{l}\text { Utrum impressiones ignite, sive que fiunt per } \\
\text { inflammationem exalationis, fiunt naturaliter in aere }\end{array}$ & Oresme I.13 \\
\hline 29ra & I.18 & $\begin{array}{l}\text { Utrum quandoque de nocte, serenitate existente, } \\
\text { debeant apparere in celo hyatus et voragines et } \\
\text { sanguinei colores }\end{array}$ & Buridan I.10 \\
\hline 30ra & I.18 & $\begin{array}{l}\text { Postea queritur magis de exalationibus, ex quibus } \\
\text { fiunt inflammationes, et cum hoc de vaporibus, ex } \\
\text { quibus fiunt pluvie, cuius nature sint, videlicet utrum } \\
\text { exalatio et vapor sint unumquodque specie, seu } \\
\text { natura, elementi ex qua elevantur, verbi gratia cum } \\
\text { exalatio elevetur ex corporibus terrestribus, vapor ex } \\
\text { aquosis, utrum exalatio sit de natura terre et vapor de } \\
\text { natura aque }\end{array}$ & Buridan I.11 \\
\hline $32 \mathrm{rb}$ & I.19 & Utrum stella comata sit de natura celesti & Buridan I.12 \\
\hline $33 \mathrm{vb}$ & I. 20 & Utrum motus comete sit naturalis vel violentus & Oresme I.17 \\
\hline $34 \mathrm{va}$ & I. 21 & $\begin{array}{l}\text { Utrum comete significent mortes principum, } \\
\text { siccitates, ventus et motus terre }\end{array}$ & Oresme I.18 \\
\hline $35 \mathrm{rb}$ & $\mathrm{I} .22$ & Utrum stella comata sit de natura elementari & Buridan I.13 \\
\hline $37 \mathrm{vb}$ & $\mathrm{I} .23$ & $\begin{array}{l}\text { Utrum galaxia sit de natura celesti vel de natura } \\
\text { elementari }\end{array}$ & Buridan I.14 \\
\hline $39 \mathrm{va}$ & $\mathrm{I} .24$ & $\begin{array}{l}\text { Utrum ros generatur in media regione aeris, vel in } \\
\text { inferiori, vel in superiori, vel omnino ubi }\end{array}$ & Buridan I.15 \\
\hline $40 \mathrm{vb}$ & $\mathrm{I} .25$ & Utrum similiter generantur pruina et nix & Buridan I.16 \\
\hline $43 \mathrm{vb}$ & I. 26 & $\begin{array}{l}\text { Utrum caligo est signum serenitatis (et vocatur hic } \\
\text { caligo nebula tenuis) }\end{array}$ & Buridan I.17 \\
\hline $45 \mathrm{ra}$ & I. 27 & $\begin{array}{l}\text { Utrum grandines debeant magis fieri vere vel } \\
\text { autumpno quam hieme }\end{array}$ & Buridan I.18 \\
\hline $46 \mathrm{vb}$ & I. 28 & Utrum aque fontium et fluviorum generantur in terra & Buridan I.19 \\
\hline $52 \mathrm{va}$ & $\mathrm{I} .29$ & $\begin{array}{l}\text { Utrum locus generationis pluviarum sit media regio } \\
\text { aeris }\end{array}$ & Oresme II.1 \\
\hline $53 \mathrm{vb}$ & I.30 & $\begin{array}{l}\text { Utrum grandines magis debeant generari in hieme } \\
\text { quam in vere et in autumpno }\end{array}$ & Oresme II.3 \\
\hline $55 \mathrm{vb}$ & I. 31 & Utrum rubedo matutina sit signum pluvie & Oresme II.5 \\
\hline $57 \mathrm{ra}$ & I.32 & $\begin{array}{l}\text { Utrum aqua calida applicata frigido seu frigori } \\
\text { congelato citius congelatur quam aqua frigida }\end{array}$ & Oresme II.4 \\
\hline $57 \mathrm{vb}$ & $\mathrm{I} .33$ & Utrum calido sit signum pluvie future & Oresme II.6 \\
\hline
\end{tabular}




\begin{tabular}{|c|c|c|c|}
\hline $58 \mathrm{rb}$ & $\mathrm{I} .34$ & Utrum aqua naturaliter ascendat ad orificia fontium & Oresme II.7 \\
\hline $59 \mathrm{rb}$ & I.35 & $\begin{array}{l}\text { Utrum, ubi nunc est mare, fuit arida, et e contrario ubi } \\
\text { nunc est arida, ibi fuit mare et erit }\end{array}$ & Buridan I.20 \\
\hline $61 \mathrm{rb}$ & I.36 & $\begin{array}{l}\text { Utrum possibile sit tantos montes naturaliter quanti } \\
\text { nobis apparent maxime destrui et reverti terram ad } \\
\text { planitiem, alios montes tantos alibi fieri de novo, et } \\
\text { utrum possibile est totam terre declinitatem, quanta } \\
\text { est nunc, ubi est magnum mare fieri altiorem parte } \\
\text { opposita ipsius terre, et partem oppositam, quam } \\
\text { nunc est alta, fieri decliviorem }\end{array}$ & Buridan I.21 \\
\hline $63 \mathrm{ra}$ & II.1 & $\begin{array}{l}\text { Iam de mari quesita fuerunt multa super primum } \\
\text { librum. Sed adhuc super secundum queritur de } \\
\text { perpetuitate vel generatione maris, scilicet utrum fuit } \\
\text { perpetuum vel aliquando factum }\end{array}$ & Buridan II.1 \\
\hline $63 \mathrm{va}$ & II.2 & $\begin{array}{l}\text { Secundo queritur utrum maria debeant continue } \\
\text { fluere in alia maria quamdiu durant }\end{array}$ & Buridan II.2 \\
\hline $64 \mathrm{va}$ & II. 3 & Utrum mare debeat fluere et refluere & Buridan II.3 \\
\hline $66 \mathrm{va}$ & II.4 & $\begin{array}{l}\text { Utrum locus quem mare occupat sit locus naturalis } \\
\text { aque secundum quod aqua, et non maris, secundum } \\
\text { quod mare }\end{array}$ & Buridan I.4 \\
\hline $67 \mathrm{vb}$ & II.5 & Utrum mare debeat esse salsum & Buridan II.5 \\
\hline $69 \mathrm{vb}$ & II.6 & Utrum aliqui fontes debeant esse salsi & Buridan II.6 \\
\hline $70 \mathrm{vb}$ & II.7 & Utrum ventus est exalatio calida et sicca & Buridan II.7 \\
\hline 72ra & II. 8 & $\begin{array}{l}\text { Utrum, adveniente pluvia, debeant cessare venti, post } \\
\text { pluvias fieri, ita quod aliquando pluvie faciant cessare } \\
\text { ventos et aliquando commoveant }\end{array}$ & Buridan II.8 \\
\hline $72 \mathrm{vb}$ & II.9 & Utrum Sol commovet et facit cessare ventos & Buridan II.9 \\
\hline 74ra & II.10 & $\begin{array}{l}\text { Utrum Boreas flat nobis a polo artico et Auster a polo } \\
\text { antartico, vel a tropico estivali, vel similiter queritur a } \\
\text { quibus locis isti venti incipiant flare }\end{array}$ & Buridan II.10 \\
\hline $75 \mathrm{va}$ & II.11 & Utrum precise venti debent distingui in duodecim & Buridan II.11 \\
\hline $76 \mathrm{rb}$ & II.12 & $\begin{array}{l}\text { Duodecimo queritur utrum debeant nobis flare plures } \\
\text { venti boreales et australes, quod adhuc et plures etiam } \\
\text { boreales quam astrales }\end{array}$ & Buridan II.12 \\
\hline $77 \mathrm{va}$ & II.13 & $\begin{array}{l}\text { Utrum Boreas, qui vocatur ab Archias (?), debeat esse } \\
\text { serenus }\end{array}$ & Buridan II.13 \\
\hline $79 \mathrm{rb}$ & II.14 & $\begin{array}{l}\text { Utrum exalatio similis exalationis ventose sit causa } \\
\text { terremotus. Non quero de causa materiali, quoniam } \\
\text { illa est terra que movetur, sed quero de causa efficiente } \\
\text { et movente ipsam terram }\end{array}$ & Buridan II.14 \\
\hline $80 \mathrm{rb}$ & II.15 & $\begin{array}{l}\text { Utrum causa prius assignata terremotus, scilicet } \\
\text { exalatio sicca in visceribus terre }[m s . \text { : terra] inclusa, } \\
\text { consonat accidentibus circa terremotum communiter } \\
\text { apparentibus }\end{array}$ & Buridan II.15 \\
\hline $81 \mathrm{vb}$ & II.16 & $\begin{array}{l}\text { Utrum exalatio ex qua fiunt tonitrua et corruscationes } \\
\text { debeat descendere ad terram vel versus terram }\end{array}$ & Oresme III.7 \\
\hline $82 \mathrm{vb}$ & II.17 & Utrum corruscatio sit possibilis & Oresme III.8 \\
\hline
\end{tabular}




\begin{tabular}{|c|c|c|c|}
\hline $83 \mathrm{vb}$ & II.18 & $\begin{array}{l}\text { Utrum fulmen quoddam sit penetrans et quoddam } \\
\text { adurens }\end{array}$ & Oresme III.9 \\
\hline $84 \mathrm{vb}$ & II.19 & Utrum indifferenter quodlibet posset percuti fulmine & Oresme III.10 \\
\hline $85 \mathrm{rb}$ & II. 20 & $\begin{array}{l}\text { Utrum corruscatio sit inflammatio exalationis sicce in } \\
\text { nube }\end{array}$ & Buridan II.16 \\
\hline 86rb & II. 21 & $\begin{array}{l}\text { Utrum diffinitio tonitrui quam innuit Aristoteles sit } \\
\text { bona, scilicet: }<\text { tonitrum est sonus in loco nubium ex } \\
\text { pressura violenta exalationis sicce ad continentes } \\
\text { nubes }>\end{array}$ & Buridan II.17 \\
\hline $88 \mathrm{vb}$ & II. 22 & $\begin{array}{l}\text { Utrum ecnephie et typhones descendant ad terram ex } \\
\text { nubibus }\end{array}$ & Buridan III.1 \\
\hline $91 \mathrm{vb}$ & III.1 & $\begin{array}{l}\text { Circa tertium librum metharorum queritur utrum } \\
\text { omnis radius visualis refrangatur in occursu medii } \\
\text { densioris vel rarioris }\end{array}$ & Thémon III.1 \\
\hline 94ra & III.2 & $\begin{array}{l}\text { Utrum radius visualis procedens a luminoso existente } \\
\text { in medio unius raritatis frangatur ad } \\
\text { perpendicularem, vel a perpendiculari occurrente } \\
\text { medio alterius densitatis }\end{array}$ & Thémon III.2 \\
\hline $95 \mathrm{va}$ & III.3 & $\begin{array}{l}\text { Utrum omnis radius visualis reflectatur in occursu } \\
\text { medii densioris }\end{array}$ & Thémon III.3 \\
\hline $97 \mathrm{rb}$ & III.4 & $\begin{array}{l}\text { Utrum aliquis radius visualis posset aliquibus speculis } \\
\text { vel corporibus sic incidere, quod reflectatur } \\
\text { representans solum colorem [ } m s . \text { : calorem] et non } \\
\text { figuram }\end{array}$ & Thémon III.4 \\
\hline $100 \mathrm{rb}$ & III.5 & $\begin{array}{l}\text { Utrum halo apparet propter refractionem radiorum } \\
\text { in corpore interposito inter visum et luminosum circa } \\
\text { quod apparet }\end{array}$ & Thémon III.5 \\
\hline $101 \mathrm{rb}$ & III.6 & Utrum halo fiat per refractionem radiorum visualium & Thémon III.6 \\
\hline $103 \mathrm{ra}$ & III.7 & $\begin{array}{l}\text { Utrum, tempore apparitionis halo, fit vapor } \\
\text { interpositus inter visum et astrum }\end{array}$ & Thémon III.7 \\
\hline $103 \mathrm{vb}$ & III.8 & Utrum vapor in quo apparet halo sit figure sperice & Thémon III.8 \\
\hline $105 \mathrm{rb}$ & III.9 & $\begin{array}{l}\text { Utrum halo debeat apparere secundum circuli } \\
\text { periferiam vel circumferentiam }\end{array}$ & Thémon III.9 \\
\hline $107 \mathrm{rb}$ & III.10 & $\begin{array}{l}\text { Utrum radius visualis posset reflecti ab aere uniformi } \\
\text { non condensato nec mixto vaporibus ad oculum } \\
\text { videntis et existentis in eodem aere sine adiutore } \\
\text { speculorum }\end{array}$ & Thémon III.101 \\
\hline $109 \mathrm{rb}$ & III.11 & $\begin{array}{l}\text { Utrum colores apparentes in yride sint ibi ubi } \\
\text { apparent esse et sint veri colores }\end{array}$ & Thémon III.11 \\
\hline $110 \mathrm{vb}$ & III.12 & $\begin{array}{l}\text { Utrum yris sit forma realiter impressa nubi vel sit } \\
\text { solum forma ymaginaria }\end{array}$ & Thémon III.12 \\
\hline $112 \mathrm{ra}$ & III.13 & $\begin{array}{l}\text { Utrum yris sit forma dyaphanalis vel specularis, vel } \\
\text { utrum fiat per reflexionem vel refractionem }\end{array}$ & Thémon III.13 \\
\hline $113 \mathrm{rb}$ & III.14 & $\begin{array}{l}\text { Utrum, supposito quod yris fiat per reflexionem } \\
\text { radiorum, talis reflexio fiat in nube vel supra guttulas } \\
\text { roridas, seu super stillicidia }\end{array}$ & Thémon III.14 \\
\hline $113 \mathrm{vb}$ & III.15 & Utrum omnis yris debeat esse tricolor & Thémon III.15 \\
\hline
\end{tabular}




\begin{tabular}{|c|c|c|c|}
\hline $115 \mathrm{ra}$ & III.16 & $\begin{array}{l}\text { Utrum yris solum duplex et non multiplicior possit } \\
\text { apparere }\end{array}$ & Thémon III.16 \\
\hline $116 \mathrm{rb}$ & III.17 & $\begin{array}{l}\text { Utrum semper, apparentibus duabus yridibus, } \\
\text { superior debeat habere colores conversim positos }\end{array}$ & Thémon III.17 \\
\hline $117 \mathrm{rb}$ & III.18 & $\begin{array}{l}\text { Utrum superior yris, vel secundaria, necessario debet } \\
\text { apparere remissior in coloribus quam principalis yris }\end{array}$ & Thémon III.18 \\
\hline $118 \mathrm{rb}$ & III.19 & $\begin{array}{l}\text { Utrum yris debet apparere secundum circuli } \\
\text { periferiam si non sit impedimentum }\end{array}$ & Thémon III.19 \\
\hline $119 \mathrm{vb}$ & III. 20 & $\begin{array}{l}\text { Utrum semper, tempore apparitionis yridis, necesse } \\
\text { sit centrum Solis et centrum orizontis et centrum } \\
\text { yridis et polos eiusdem esse in linea recta eadem }\end{array}$ & Thémon III.20 \\
\hline $121 \mathrm{rb}$ & III. 21 & $\begin{array}{l}\text { Utrum semper, tempore apparitionis yridis et halo, } \\
\text { dyameter yridis sit precise dupla ad dyametrum halo }\end{array}$ & Thémon III.21 \\
\hline $123 \mathrm{ra}$ & III.22 & $\begin{array}{l}\text { Utrum, omni hora diei artificiali, oculo existente in } \\
\text { superficie orizontis possit aliqua portio yridis } \\
\text { apparere ubicmque fuit homo vel oculus videntis }\end{array}$ & Thémon III.22 \\
\hline $124 \mathrm{ra}$ & III.23 & $\begin{array}{l}\text { Utrum yris Lune possit apparere plures quam bis in } 50 \\
\text { annis, consimilibus coloribus et proprietatibus, sicut } \\
\text { yris Solis }\end{array}$ & Thémon III.23 \\
\hline $125 \mathrm{rb}$ & III.24 & $\begin{array}{l}\text { Utrum, visa yride et Sole vel astro elevato notabiliter } \\
\text { super orizontem, appareat minor portio in fine } \\
\text { orizontis }\end{array}$ & Thémon III.24 \\
\hline $126 \mathrm{vb}$ & III. 25 & $\begin{array}{l}\text { Utrum parelii fiant ex reflexionem vel refractionem } \\
\text { radiorum sicut yris vel halo }\end{array}$ & Thémon III. $26^{167}$ \\
\hline $127 \mathrm{va}$ & III.26 & $\begin{array}{l}\text { Ultimo, circa ultimum tractatum de eis que fiunt sub } \\
\text { terram, queritur utrum per iuvamen artis possint fieri } \\
\text { metalla, sicut yris et halo artificialiter quandoque fiunt }\end{array}$ & Thémon III. $27^{168}$ \\
\hline 130ra & IV.1 & $\begin{array}{l}\text { Utrum tantum quatuor sint qualitates prime, scilicet } \\
\text { caliditas, humiditas, frigiditas et siccitas }\end{array}$ & Oresme IV.1 \\
\hline $131 \mathrm{rb}$ & IV.2 & $\begin{array}{l}\text { Utrum quatuor qualitates, videlicet caliditas, } \\
\text { frigiditas etc., sint principia activa in generatione } \\
\text { cuiuslibet mixti, accipiendo generationem pro } \\
\text { alteratione precedenti introductionem forme } \\
\text { substantialis mixti, eo modo quo Aristoteles accipit in } \\
\text { secundo capitulo huius quarti }\end{array}$ & Oresme IV.2 \\
\hline 132ra & IV.3 & $\begin{array}{l}\text { Utrum quatuor qualitates, videlicet caliditas, } \\
\text { frigiditas etc., sint principia activa in generatione } \\
\text { cuiuslibet mixti, accipiendo generationem pro } \\
\text { alteratione precedenti introductionem forme } \\
\text { substantialis mixti, eo modo quo Aristoteles accipit in } \\
\text { secundo capitulo huius quarti }\end{array}$ & Oresme IV.3 \\
\hline 133ra & IV.4 & Utrum frigus conservat a putrefactione & Oresme IV.4 \\
\hline
\end{tabular}

(167) Cette question est identique à la question III.34 de la redactio antiqua de Nicole Oresme (cf. BIRKENMAJER, Études, p. 218).

(168) Cette question est identique à la question III.35 de la redactio antiqua de Nicole Oresme (cf.ibid., p. 219). 


\begin{tabular}{|c|c|c|c|}
\hline 134ra & IV.5 & $\begin{array}{l}\text { Utrum aliqua animalia possunt generari per } \\
\text { putrefactionem }\end{array}$ & Oresme IV.5 \\
\hline $134 \mathrm{vb}$ & IV.6 & $\begin{array}{l}\text { Utrum diffinitio digestionis sit bona, in qua dicitur: } \\
<\text { digestio est perfectio a naturali et proprio calido ex } \\
\text { oppositis passivis }>\end{array}$ & Oresme IV.6 \\
\hline $135 \mathrm{va}$ & IV.7 & Utrum balnea conferant ad digestionem & Oresme IV.7 \\
\hline $136 \mathrm{vb}$ & IV.8 & Utrum tantum sunt tres digestiones & Oresme IV.8 \\
\hline $138 \mathrm{ra}$ & IV.9 & Utrum frixata debeant magis dici assata quam elixata & Oresme IV.9 \\
\hline $138 \mathrm{vb}$ & IV.10 & $\begin{array}{l}\text { Utrum vermes qui generantur in ventribus } \\
\text { animalium generentur in stomacho vel in intestinis }\end{array}$ & Oresme IV.10 \\
\hline $139 \mathrm{va}$ & IV.11 & $\begin{array}{l}\text { Consequenter queritur utrum in quolibet mixto } \\
\text { dominetur terra vel aqua }\end{array}$ & Oresme IV.11 \\
\hline
\end{tabular}


ANNEXE V

\section{LES QUESTIONS SUR LES MÉTÉOROLOGIQUES DU MS KRAKÓW, UNIWERSYTET JAGIELLOŃSKI, BIBLIOTEKA JAGIELLOŃSKA, 635, P. 177R-236V}

Nous avons montré plus haut ${ }^{169}$ que les manuscrits Kraków, Uniwersytet Jagielloński, Biblioteka Jagiellońska, 635, p.177r-236v et Kraków, Uniwersytet Jagielloński, Biblioteka Jagiellońska, 686, f. 101r-134v contiennent des compilations des Questions sur les Météorologiques réalisées à partir des recueils d'Albert de Saxe et de Nicole Oresme (redactio antiqua).

$\mathrm{Ci}$-dessous nous présentons, à titre d'exemple, un tableau du contenu des Questions sur les Météorologiques transmises aux pages $177 \mathrm{r}-236 \mathrm{v}$ du manuscrit Kraków, Uniwersytet Jagielloński, Biblioteka Jagiellońska, 635. Nous avons présenté les intitulés des questions, dont nous avons transcrit l'incipit et l'explicit, et avons indiqué, pour les questions empruntées au recueil de Nicole Oresme, leur place dans les manuscrits Kraków, Uniwersytet Jagielloński, Biblioteka Jagiellońska, 753, f.51ra-83vb $(C)$ et Darmstadt, Universitäts- und Landesbibliothek, 2197, f. 58r-92v(D).

\begin{tabular}{|c|c|c|c|c|}
\hline Folio & No & Intitulé de la question & Incipit / Explicit de la question & Oresme \\
\hline $177 \mathrm{a}$ & I.1 & $\begin{array}{l}\text { Utrum de metroloycis sit } \\
\text { scientia }\end{array}$ & $\begin{array}{l}\text { Et arguitur quod non, quia } \\
\text { huiusmodi impressiones, sicut } \\
\text { nubes et tonitrua, non sunt } \\
\text { perpetue...X... ita quod fiunt } \\
\text { minus ordinate quam illa que } \\
\text { fiunt in celo, sed non sine } \\
\text { ordine. Sequitur questio. }\end{array}$ & \\
\hline $178 \mathrm{a}$ & I. 2 & $\begin{array}{l}\text { Utrum impressiones } \\
\text { metroloyce fiant } \\
\text { secundum naturam } \\
\text { inordinatiorem quam sit } \\
\text { natura celi }\end{array}$ & $\begin{array}{l}\text { Et arguitur quod non fiant } \\
\text { secundum naturam, quia aliqua } \\
\text { talia fiunt raro, et non } \\
\text { frequenter, sicut comete et terre } \\
\text { motus...X... ista regula non } \\
\text { tenet semper, licet ut in pluribus } \\
\text { forte. Et sic est finis huius } \\
\text { questionis. }\end{array}$ & \\
\hline
\end{tabular}




\begin{tabular}{|c|c|c|c|}
\hline $180 \mathrm{a}$ & I. 3 & $\begin{array}{l}\text { Utrum iste mundus } \\
\text { inferior gubernetur a } \\
\text { motibus celi }\end{array}$ & $\begin{array}{l}\text { Et arguitur primo quod non, } \\
\text { quia sequitur quod ista inferiora } \\
\text { fierent ita ordinate sicut motus } \\
\text { celi, quod est contra } \\
\text { Aristotelem ...X... sed si } \\
\text { sequitur inclinationem reale et } \\
\text { impetum celi etc. Sequitur alia } \\
\text { questio bona et utilis quare. }\end{array}$ \\
\hline $181 \mathrm{~b}$ & I. 4 & $\begin{array}{l}\text { Utrum eedem opiniones } \\
\text { reiterentur pluries vel } \\
\text { infinities et apud homines }\end{array}$ & $\begin{array}{l}\text { Et arguitur quod non. Primo: } \\
\text { sicut sensus ad sensibilia, ita } \\
\text { intellectus ad intelligibilia ... et } \\
\text { propter hoc non sequitur quod } \\
\text { ita sit in istis speculativis. }\end{array}$ \\
\hline $182 \mathrm{~b}$ & I. 5 & $\begin{array}{l}\text { Utrum quatuor elementa } \\
\text { sint sibi invicem equalia }\end{array}$ & $\begin{array}{l}\text { Et arguitur quod sic, quia si } \\
\text { unum esset magis in quantitate, } \\
\text { tunc esset maius in virtute } \\
\text {...X... et forte est ibi plus de } \\
\text { caliditate in mundo quam de } \\
\text { frigido. Et sic finis. }\end{array}$ \\
\hline $184 a$ & I.6 & $\begin{array}{l}\text { Utrum quatuor elementa } \\
\text { fiunt continue } \\
\text { proportionalia }\end{array}$ & $\begin{array}{l}\text { Et arguitur quod sic. Primo: } \\
\text { quia fiunt continue } \\
\text { proportionalia in raritate et } \\
\text { densitate ...X... ad oppositum } \\
\text { monita est ut apparebit in } \\
\text { sequenti questione. }\end{array}$ \\
\hline $184 \mathrm{~b}$ & I.7 & $\begin{array}{l}\text { Utrum quatuor elementa } \\
\text { semper et immutabiliter } \\
\text { habeant eandem } \\
\text { proportionem, ita quod } \\
\text { terra non sit maior una vice } \\
\text { quam alia, et sic de aliis }\end{array}$ & $\begin{array}{l}\text { Et arguitur quod sic, quia } \\
\text { continue est equaliter in } \\
\text { densitate ...X... per accessum et } \\
\text { recessum in zodiaco, sed etiam } \\
\text { appropinquationem ad terram. } \\
\text { Sequitur alia questio. }\end{array}$ \\
\hline $185 b$ & I. 8 & $\begin{array}{l}\text { Utrum motus celi causa } \\
\text { calefactionis ignis in spera } \\
\text { sua, et etiam aeris } \\
\text { superioris }\end{array}$ & $\begin{array}{l}\text { Et primo in generali arguitur } \\
\text { quod motus non sit causa } \\
\text { caloris, quia ...X... quia sunt } \\
\text { alie cause frigidi. }\end{array}$ \\
\hline $186 \mathrm{~b}$ & I.9 & $\begin{array}{l}\text { Utrum omnelumen sit } \\
\text { calefactivum }\end{array}$ & $\begin{array}{l}\text { Et arguitur quod nullum, quia } \\
\text { omne lumen quod fit, fit a sibi } \\
\text { simile...X... dico quod non } \\
\text { sunt luminosa, et etiam } \\
\text { frigefaciunt per alias causas. }\end{array}$ \\
\hline $187 \mathrm{~b}$ & I.10 & $\begin{array}{l}\text { Utrum contrarium } \\
\text { circumstans aliud } \\
\text { contrarium fortificet istud. }\end{array}$ & $\begin{array}{l}\text { Et videtur quod non, cum omne } \\
\text { contrarium applicatum alteri } \\
\text { agat ...X... et sic dictum sit de } \\
\text { fortificatione illa quam } \\
\text { Aristoteles vocat } \\
\text { antiparistasim. Et patet questio. } \\
\text { Sequitur alia questio. }\end{array}$ \\
\hline
\end{tabular}




\begin{tabular}{|c|c|c|c|}
\hline $189 a$ & I.11 & $\begin{array}{l}\text { Utrum media regio aeris sit } \\
\text { semper frigida. }\end{array}$ & $\begin{array}{l}\text { Quia statim sophistice } \\
\text { opponerentur quod nullus aer } \\
\text { est semper ...X... et sunt alie } \\
\text { cause frigiditatis, ut dictum est } \\
\text { supra. Et sic patet questio ista } \\
\text { bona et utilis, ut patet bene } \\
\text { studenti et monenti. Hic non est } \\
\text { de istis [ms. iter. : hic non est de } \\
\text { istis]. }\end{array}$ \\
\hline $190 \mathrm{~b}$ & I. 12 & $\begin{array}{l}\text { Utrum vapor et exalatio } \\
\text { sint materie impressionum } \\
\text { metroloycarum, et nichil } \\
\text { aliud }\end{array}$ & $\begin{array}{l}\text { Et videtur quod non, quia ista } \\
\text { segregantur ex terra et aqua, ut } \\
\text { dicit Aristoteles ...X... quia ille } \\
\text { partes sunt mixte per } \\
\text { iuxtapositionem, vel per poros, } \\
\text { vel iuxta alia. Et sic est finis } \\
\text { questionis, etc. }\end{array}$ \\
\hline $192 \mathrm{a}$ & I.13 & $\begin{array}{l}\text { Utrum sydera volantia et } \\
\text { flamme tales apparentes in } \\
\text { aere fiant naturaliter. }\end{array}$ & $\begin{array}{l}\text { Et videtur quod non, quia talia } \\
\text { sunt de natura ignis ...X... et } \\
\text { propter hoc non dicuntur fieri } \\
\text { naturaliter, sed alio modo bene. } \\
\text { Et sic est finis questionis. }\end{array}$ \\
\hline $192 b$ & I.14 & $\begin{array}{l}\text { Utrum, serenitate } \\
\text { existente, appareant in } \\
\text { nocte in celo hyatus, seu } \\
\text { aperture et voragines [ } \mathrm{ms} .: \\
\text { suragines], et sanguinei } \\
\text { colores }\end{array}$ & $\begin{array}{l}\text { Et arguitur quod non de nocte, } \\
\text { ymo magis de die in } \\
\text { lumine...X... concedatur, nec } \\
\text { hoc est inconveniens propter } \\
\text { distantiam. Sequitur alia } \\
\text { questio. }\end{array}$ \\
\hline $194 a$ & I.15 & $\begin{array}{l}\text { Utrum stelle comate sint de } \\
\text { natura celi vel elementari }\end{array}$ & $\begin{array}{l}\text { Et videtur primo quod sint de } \\
\text { natura celi, et ex motu, quia } \\
\text { istud quod naturaliter movetur } \\
\text { circulariter sicut celum ... et iste } \\
\text { est unus de primis effectibus, } \\
\text { ideo suspicamur alia. Et patet } \\
\text { questio. }\end{array}$ \\
\hline $195 a$ & I. 16 & $\begin{array}{l}\text { Utrum motus stelle comete } \\
\text { sit naturalis }\end{array}$ & $\begin{array}{l}\text { Et videtur primo quod non, quia } \\
\text { nullum inanimatum movetur } \\
\text { ad utramque differentiam } \\
\text { positionis...X... ad ultimam, } \\
\text { cum dicitur quod motus } \\
\text { violentus etc., verum est, nisi } \\
\text { tamen violentantes fortificentur } \\
\text { vel in eodem statu manent. Et } \\
\text { sic patet questio. }\end{array}$ \\
\hline $196 b$ & I.17 & $\begin{array}{l}\text { Utrum comete significant } \\
\text { mortem principum, } \\
\text { guerras, pestilentias et } \\
\text { huiusmodi }\end{array}$ & $\begin{array}{l}\text { Et videtur primo quod non, quia } \\
\text { in eadem regione habitant } \\
\text { simul...X... ad quintam, } \\
\text { solutum est, quia de per se } \\
\text { significat siccitatem, et si } \\
\text { eveniat inundatio aquarum, hoc } \\
\text { est per accidens et per } \\
\text { antiparistasym, etc. }\end{array}$ \\
\hline
\end{tabular}




\begin{tabular}{|c|c|c|c|c|}
\hline $197 \mathrm{~b}$ & I.18 & $\begin{array}{l}\text { Utrum omnes comete sint } \\
\text { eiusdem speciei inter se et } \\
\text { cum galaxia }\end{array}$ & $\begin{array}{l}\text { Et arguitur primo quod non, } \\
\text { quia comete differunt in figura } \\
\text {...X... secundum hoc quod } \\
\text { exponitur per diversas cometas. }\end{array}$ & $\begin{array}{l}C \mathrm{I} .21 \\
(D \mathrm{I} .22)\end{array}$ \\
\hline $198 \mathrm{~b}$ & I.19 & $\begin{array}{l}\text { Utrum impressiones } \\
\text { humide fiunt a calido }\end{array}$ & $\begin{array}{l}\text { Et videtur quod non, quia } \\
\text { contrariorum cause sunt } \\
\text { contrarie...X... et parum de } \\
\text { materia illa que sic posset } \\
\text { elevari. Sequitur alia questio. }\end{array}$ & $\begin{array}{l}C \mathrm{I} .22 \\
(D \mathrm{I} .23)\end{array}$ \\
\hline $199 \mathrm{~b}$ & I. 20 & $\begin{array}{l}\text { Utrum omnes } \\
\text { impressiones aque sint } \\
\text { eiusdem speciei }\end{array}$ & $\begin{array}{l}\text { Et videtur primo quod non, quia } \\
\text { quedam sunt ex materia grossa, } \\
\text { ut grando et pluvia ...X... non } \\
\text { conceditur quod nix est [ } m s . \\
\text { iter. : est] aqua, licet ex ea possit } \\
\text { fieri aqua. Et patet questio. }\end{array}$ & $\begin{array}{l}C \mathrm{I} .23 \\
(D \mathrm{I} .24)\end{array}$ \\
\hline $200 \mathrm{~b}$ & I. 21 & $\begin{array}{l}\text { Utrum nix et pluvia } \\
\text { generantur in media } \\
\text { regione aeris. }\end{array}$ & $\begin{array}{l}\text { Et videtur quod non generantur } \\
\text { in eodem loco, quia aliquando } \\
\text { simul cadunt ...X... vel aliquod } \\
\text { tale impeditur, sicut videmus de } \\
\text { pluvia, et ita equaliter est de } \\
\text { nive, licet quandoque modicum } \\
\text { velociter etc. }\end{array}$ & $\begin{array}{l}C \mathrm{I} .24 \\
(D \mathrm{I} .25)\end{array}$ \\
\hline $202 \mathrm{a}$ & I. 22 & $\begin{array}{l}\text { Utrum grando magis debet } \\
\text { fieri hieme vel estate vel } \\
\text { temporibus mediis, sicut } \\
\text { vere et autumpno }\end{array}$ & $\begin{array}{l}\text { Et videtur primo quod non } \\
\text { potest fieri, ratione Aristotelis } \\
\text { in textu...X... propter causam } \\
\text { dictam in positione, nec etiam } \\
\text { in estate, sicut dictum est. Et hoc } \\
\text { solvit quartum. Sequitur alia } \\
\text { questio. }\end{array}$ & $\begin{array}{l}C \mathrm{I} .25 \\
(D \mathrm{I} .26)\end{array}$ \\
\hline 203a & I. 23 & $\begin{array}{l}\text { Utrum nebula sit signum } \\
\text { serenitatis }\end{array}$ & $\begin{array}{l}\text { Et arguitur primo quod non, } \\
\text { quia nulla nubis et pluvie non } \\
\text { est signum serenitatis ...X... } \\
\text { sed nebula post pluviam est } \\
\text { signum serenitatis, ut patet in } \\
\text { questione. Ad secundam: } \\
\text { dicitur eodem modo. Sequitur } \\
\text { alia. }\end{array}$ & $\begin{array}{l}C \mathrm{I} .26 \\
(D \mathrm{I} .27)\end{array}$ \\
\hline $204 \mathrm{~b}$ & I. 24 & $\begin{array}{l}\text { Utrum aqua naturaliter } \\
\text { ascendat ad orificium } \\
\text { fontium et habet locum de } \\
\text { generatione fontium et } \\
\text { fluviorum, circa tractatu } \\
\text { illorum }\end{array}$ & $\begin{array}{l}\text { Et videtur primo quod sic, quia } \\
\text { omne elementum naturaliter } \\
\text { exit et movetur de loco sibi } \\
\text { naturali ...X... de monte in quo } \\
\text { est generatio aque que descendit } \\
\text { ad fontes. }\end{array}$ & $\begin{array}{l}C \mathrm{I} .27 \\
(D \mathrm{I} .28)\end{array}$ \\
\hline 205b & I. 25 & $\begin{array}{l}\text { Utrum fontes et flumina } \\
\text { veniant ex aqua pluviali vel } \\
\text { ex mari vel aliunde etc. }\end{array}$ & $\begin{array}{l}\text { Et arguitur primo quod non ex } \\
\text { pluviali, per rationem } \\
\text { Senece...X... sunt pauci } \\
\text { vapores super terram, ita } \\
\text { similiter sub terra. Et patet } \\
\text { questio. }\end{array}$ & $\begin{array}{l}C \mathrm{I} .28 \\
(D \mathrm{I} .29)\end{array}$ \\
\hline
\end{tabular}




\begin{tabular}{|c|c|c|c|}
\hline $207 a$ & I. 26 & $\begin{array}{l}\text { Utrum fontes et pluvia } \\
\text { deriventur ex montibus }\end{array}$ & $\begin{array}{l}\text { Et videtur primo quod non, quia } \\
\text { non ex quolibet monte ...X... } \\
\text { magis sunt ex aqua pluviali } \\
\text { quam fontes. Et ideo aqua fontis } \\
\text { est melior, etc. }\end{array}$ \\
\hline $208 b$ & I. 27 & $\begin{array}{l}\text { Utrum habitationes terre } \\
\text { permutentur }\end{array}$ & $\begin{array}{l}\text { Et videtur primo quod non, quia } \\
\text { descriptio orbis terrarum que } \\
\text { olim fuit facta ...X... et ideo } \\
\text { quandoque apparet maior, } \\
\text { quandoque minor. Tertio } \\
\text { supponitur... [textus } \\
\text { imperfectus] }\end{array}$ \\
\hline $209 b$ & II.1 & $\begin{array}{l}\text { Utrum ventus sit exalatio } \\
\text { calida et sicca }\end{array}$ & $\begin{array}{l}\text { Et primo videtur quod sit aer } \\
\text { motus, nam aliquis aer motus } \\
\text { est ventus ...X... et minute et } \\
\text { converse a Soli... [textus } \\
\text { imperfectus] }\end{array}$ \\
\hline $211 a$ & II. 2 & $\begin{array}{l}\text { Utrum quidam fulgor } \\
\text { penetrat et aliud aduret }\end{array}$ & $\begin{array}{l}\text { Et primo arguitur quod nullum } \\
\text { sit penetrans, nam tunc sequitur } \\
\text { quod posset exire ...X... ad } \\
\text { octavam: dico quod illa exalatio } \\
\text { movetur sursum, ut dictum est, } \\
\text { donec repellitur a frigido. } \\
\text { Sequitur alia questio. }\end{array}$ \\
\hline $211 b$ & II. 3 & $\begin{array}{l}\text { Utrum Sol faciat cessare } \\
\text { ventos. }\end{array}$ & $\begin{array}{l}\text { Et videtur quod non, nam } \\
\text { permovet eos, ut dicit } \\
\text { Aristoteles ...X... et possibile } \\
\text { est quod fiunt magis de nocte } \\
\text { maiores. Sequitur alia questio. }\end{array}$ \\
\hline $212 b$ & II.4 & $\begin{array}{l}\text { Utrum auster veniat a polo } \\
\text { antartico et boreas ab } \\
\text { artico. }\end{array}$ & $\begin{array}{l}\text { Et primo videtur quod sic de } \\
\text { austro, nam venti contrarii } \\
\text { veniunt a locis contrariis ...X... } \\
\text { sed forte Aristoteles negaret } \\
\text { illam experientiam. Sequitur } \\
\text { alia questio. }\end{array}$ \\
\hline $213 a$ & II.5 & $\begin{array}{l}\text { Circa tractatum de motu } \\
\text { terre: utrum terre motus sit } \\
\text { possibilis. }\end{array}$ & $\begin{array}{l}\text { Et sciendum quod potest } \\
\text { ymaginari quod terra moveatur } \\
\text { secundum se totum simul } \\
\text { circulariter...X... sed habet } \\
\text { viam liberam, et ita fortiter } \\
\text { movetur. Et patet questio, etc. }\end{array}$ \\
\hline $214 b$ & II.6 & $\begin{array}{l}\text { Utrum tranquillitas sit } \\
\text { signum terre motus. }\end{array}$ & $\begin{array}{l}\text { Videtur quod non, nam sepe est } \\
\text { tranquillitas quod non sequitur } \\
\text { terre motus ...X... sic dictum sit } \\
\text { de causis et signis et effectibus } \\
\text { circunstantiis terre motum. } \\
\text { Sequitur alia questio. }\end{array}$ \\
\hline
\end{tabular}




\begin{tabular}{|c|c|c|c|}
\hline $215 b$ & II.7 & $\begin{array}{l}\text { Utrum tonitrum sit } \\
\text { extinctio ignis in nube. }\end{array}$ & $\begin{array}{l}\text { Et videtur quod sic, per } \\
\text { Aristotelem et Lyncolniensem } \\
\text {...X... ad tertiam, concedo } \\
\text { quod est simile, non tamen } \\
\text { omnino, sicut dictum fuit. } \\
\text { Sequitur alia questio. }\end{array}$ \\
\hline $216 \mathrm{~b}$ & II. 8 & $\begin{array}{l}\text { Utrum coruscatio sit } \\
\text { possibilis. }\end{array}$ & $\begin{array}{l}\text { Et videtur quod non, nam } \\
\text { exalatio inflammata in nocte } \\
\text { serena...X... et etiam postquam } \\
\text { talia sunt inflammata propter } \\
\text { siccitatem materie, statim } \\
\text { consumuntur et deficit flamis. } \\
\text { Sequitur alia. }\end{array}$ \\
\hline $217 \mathrm{~b}$ & II.9 & $\begin{array}{l}\text { Utrum fulgur sit exalatio } \\
\text { calida et sicca ignita. }\end{array}$ & $\begin{array}{l}\text { Et videtur quod non, nam tunc } \\
\text { movetur }<\text { sursum }>\text { quod est } \\
\text { falsum, ymo deorsum ...X... fit } \\
\text { in media regione, quia } \\
\text { circundatur ab utramque parte. } \\
\text { Et sic est finis questionis. }\end{array}$ \\
\hline $218 \mathrm{~b}$ & II.10 & $\begin{array}{l}\text { Utrum quidam fulgur } \\
\text { penetrat et adurit. }\end{array}$ & $\begin{array}{l}\text { Et primo arguitur quod nullum } \\
\text { sit penetrans, nam tunc } \\
\text { sequeretur quod posset exire de } \\
\text { nube ...X... nisi forte rarissime } \\
\text { aliquando, et tunc dicitur esse } \\
\text { fulmen tempore sereno, sicut } \\
\text { dictum est prius. }\end{array}$ \\
\hline $219 b$ & II.11 & $\begin{array}{l}\text { Utrum indifferenter } \\
\text { quodlibet aliquando } \\
\text { percutiatur fulmine. }\end{array}$ & $\begin{array}{l}\text { Et videtur quod sic, quia eadem } \\
\text { ratione qua unum percutitur, } \\
\text { alia ratione aliud ...X... ad } \\
\text { rationes: omnes solute sunt ex } \\
\text { positione. Et patet questio. }\end{array}$ \\
\hline $220 \mathrm{a}$ & II.12 & $\begin{array}{l}\text { Utrum iste impressiones, } \\
\text { videlicet typho, enophya, } \\
\text { vel incensio, sunt } \\
\text { exalationes sicce. }\end{array}$ & $\begin{array}{l}\text { Et primo, de tyfone, arguitur } \\
\text { quod non, nam movetur } \\
\text { circulariter, ut dicit Aristoteles } \\
\text {...X... ad quartam, dico quod } \\
\text { possibile est tantam } \\
\text { exalationem includi in nube, } \\
\text { sed tamen hoc est raro } \\
\text { contingens. Et sic est finis } \\
\text { questionum secundi libri. } \\
\text { Incipiunt questiones tertii } \\
\text { Metheororum. }\end{array}$ \\
\hline $221 \mathrm{a}$ & III.1 & $\begin{array}{l}\text { Utrum visus refrangatur a } \\
\text { corporibus densis. }\end{array}$ & $\begin{array}{l}\text { Videtur quod non. Primo : istud } \\
\text { esset capiendo pro ipsa potentia } \\
\text { visiva ...X... et habet reflecti et } \\
\text { etiam refrangi ut postea } \\
\text { videbitur. }\end{array}$ \\
\hline
\end{tabular}




\begin{tabular}{|c|c|c|c|}
\hline $222 b$ & III.2 & $\begin{array}{l}\text { Utrum in visione fiat } \\
\text { reflexio a corporibus politis } \\
\text { et densis. }\end{array}$ & $\begin{array}{l}\text { Et videtur quod non, nam } \\
\text { reflexio significat motum } \\
\text { localem...X... ad tertiam, } \\
\text { concedo quod a corporibus } \\
\text { spericis fit reflexio, sed } \\
\text { quomodo istud fit maior quam } \\
\text { ab aliis videbitur postea. }\end{array}$ \\
\hline $223 b$ & III.3 & $\begin{array}{l}\text { Utrum specula } \\
\text { representant colorem } \\
\text { tantum, et non figuram. }\end{array}$ & $\begin{array}{l}\text { Arguitur quod figuram } \\
\text { represen tant, quia nichil } \\
\text { representat aliquod visum nisi } \\
\text { secundum aliquam figuram } \\
\text {...X... ad tertiam: dicetur per } \\
\text { idem. }\end{array}$ \\
\hline $226 a$ & III.4 & $\begin{array}{l}\text { Utrum halo fiat per } \\
\text { fractionem radii visualis. }\end{array}$ & $\begin{array}{l}\text { Arguitur quod sic. Primo: } \\
\text { auctoritate Aristotelis, ubi sepe } \\
\text { dicit hoc ...X... non est ita de } \\
\text { isto radio, ymo reflectitur a tali } \\
\text { superficie ad modum speculi. }\end{array}$ \\
\hline $226 b$ & III.5 & $\begin{array}{l}\text { Utrum halo fiat per } \\
\text { reflectionem ab ipso }[\text { sic }] \\
\text { nube. }\end{array}$ & $\begin{array}{l}\text { Arguitur quod non, nam tunc } \\
\text { semper apparet quando est } \\
\text { nubes inter Solem et Lunam } \\
\text {...X... ad primam, dictum est } \\
\text { quando nubes est magis densa } \\
\text { non est adhuc apta. De hiis } \\
\text { dictum est, et patet quod sit. }\end{array}$ \\
\hline $227 a$ & III.6 & $\begin{array}{l}\text { Utrum colores apparentes } \\
\text { in yride sunt in ipsa. }\end{array}$ & $\begin{array}{l}\text { Et videtur quod sic: sicut dicitur } \\
\text { in secundo De anima, sensus } \\
\text { non decipitur ...X... ad } \\
\text { tertiam : concedo quod cum hoc } \\
\text { videtur nigredo et densitas } \\
\text { ipsius nubis. Sequitur questio } \\
\text { alia. }\end{array}$ \\
\hline $228 b$ & III.7 & $\begin{array}{l}\text { Utrum omnis yris sit } \\
\text { tricolor. }\end{array}$ & $\begin{array}{l}\text { Et videtur quod non, nam sicut } \\
\text { sunt colores tres, pari rationes } \\
\text { deberent alii ...X... ad rationes } \\
\text { in oppositum : solute sunt. }\end{array}$ \\
\hline $229 b$ & III.8 & $\begin{array}{l}\text { Utrum yris appareat } \\
\text { secundum circuli } \\
\text { periferiam [ms. add.: } \\
\text { appareat]. }\end{array}$ & $\begin{array}{l}\text { Et arguitur quod non, nam } \\
\text { dictum est prius quod ...X... ad } \\
\text { rationes: patet solutio, nam licet } \\
\text { colores ubique, tamen apparent } \\
\text { ad determinatum situm et } \\
\text { angulum. }\end{array}$ \\
\hline $230 \mathrm{a}$ & III.9 & $\begin{array}{l}\text { Utrum yris posset apparere } \\
\text { omni hora diei. }\end{array}$ & $\begin{array}{l}\text { Et videtur quod sic, nam ita est } \\
\text { de halo ...X... tunc videtur } \\
\text { remotior, vel ceteris paribus, ex } \\
\text { hoc videtur maior, et sic patet in } \\
\text { perspectiva. }\end{array}$ \\
\hline
\end{tabular}




\begin{tabular}{|c|c|c|c|}
\hline $230 \mathrm{~b}$ & IV.1 & $\begin{array}{l}<\mathrm{Q}>\text { ueritur circa quartum } \\
\text { librum Methaurorum, } \\
\text { utrum primarum } \\
\text { qualitatum due sunt active } \\
\text { (calidum et frigidum) et } \\
\text { due passive, sicut } \\
\text { humidum et siccum. }\end{array}$ & $\begin{array}{l}\text { Arguitur quod calidum et } \\
\text { frigidum sunt qualitates } \\
\text { passive, nam frigidum } \\
\text { corrumpitur a calido ...X... ad } \\
\text { rationes : prius solute sunt per } \\
\text { primam conclusionem, et alie } \\
\text { per alias. Alia questio sequitur. }\end{array}$ \\
\hline $231 \mathrm{~b}$ & IV.2 & $\begin{array}{l}<\mathrm{Q}>\text { ueritur consequenter } \\
\text { utrum generatio simplex a } \\
\text { calido et frigido. }\end{array}$ & $\begin{array}{l}\text { Et arguitur quod non, nam ille } \\
\text { sunt qualitates alterative, ergo } \\
\text { non sunt effective ...X... et pro } \\
\text { hoc pro ultimo responditur ad } \\
\text { rationes in oppositum. Patet } \\
\text { questio. }\end{array}$ \\
\hline $232 \mathrm{~b}$ & IV.3 & $\begin{array}{l}\text { Utrum putrefactio fit a } \\
\text { calido extrinseco et a } \\
\text { frigido intrinseco. }\end{array}$ & $\begin{array}{l}\text { Et videtur quod non a tali calido, } \\
\text { nam generatio est contraria } \\
\text { putrefactioni ...X... et postea } \\
\text { aer putrefacit istud. Et sic patet } \\
\text { questio. }\end{array}$ \\
\hline $233 \mathrm{~b}$ & IV.4 & $\begin{array}{l}\text { Utrum frigus preservat a } \\
\text { putrefactione, et secundo } \\
\text { utrum animal generatur a } \\
\text { putrefactione. }\end{array}$ & $\begin{array}{l}\text { Ad primum arguitur quod non, } \\
\text { nam putrefactio est preservatio } \\
\text {...X... per hoc ad alia dicetur } \\
\text { quod quandoque planta } \\
\text { generatur ex putrefactione. }\end{array}$ \\
\hline 234a & IV.5 & $\begin{array}{l}\text { Utrum diffinitio } \\
\text { digestionis sit bona, } \\
\text { quando dicitur: }<\text { digestio } \\
\text { est perfectio a naturali et a } \\
\text { principio calido ex } \\
\text { oppositis passivis }>\text {. }\end{array}$ & $\begin{array}{l}\text { Et videtur quod non sit perfecta, } \\
\text { nam sola forma sine alio est } \\
\text { perfectio mixti ...X... ad } \\
\text { ultimam: dico per opposita } \\
\text { intendit humidum et siccum. }\end{array}$ \\
\hline $234 a$ & IV.6 & $\begin{array}{l}\text { Utrum sint tres digestiones } \\
\text { tantum. }\end{array}$ & $\begin{array}{l}\text { Et videtur }<\text { quod non }>\text { nam } \\
\text { digestio est alteratio facta a } \\
\text { calido...X... ad quartam: } \\
\text { dictum est, quia licet sint plures, } \\
\text { possunt reduci ad illas. }\end{array}$ \\
\hline
\end{tabular}




\section{ANNEXE VI}

\section{LES QUESTIONS SUR LES MÉTÉOROLOGIQUES DU MS KRAKÓW, UNIWERSYTET JAGIELLOŃSKI, BIBLIOTEKA JAGELLOŃSKA, 686, F. 81RA-97VA}

Nous avons vu plus haut que les Questions sur les Météorologiques transmises aux f. 81ra-97va du manuscrit Kraków, Uniwersytet Jagielloński, Biblioteka Jagellońska, 686, jusqu'à présent considérées comme anonymes, constituent des excerpta tirés des Questions sur les Météorologiques de Nicole Oresme ${ }^{170}$. Nous présentons ci-dessous la liste de ces questions, accompagnées de leurs incipit et leurs explicit, et indiquons, pour chaque question, la place qu'elle occupe dans les autres témoins de la redactio antiqua des questions oresmiennes.

\begin{tabular}{|c|c|c|c|}
\hline Folio & Intitulé de la question & Incipit / Explicit de la question & Oresme \\
\hline $81 \mathrm{ra}$ & $\begin{array}{l}\text { Utrum omnis virtus inferior a } \\
\text { superioribus, id est a } \\
\text { supercelestibus, gubernetur }\end{array}$ & $\begin{array}{l}\text { Et arguitur quod non, quia } \\
\text { voluntas nostra est libera, et est } \\
\text { virtus inferior ...X... sed non de } \\
\text { universali, sicut est celum. Et sic } \\
\text { patet questio. Sequitur. }\end{array}$ & I. 3 \\
\hline $82 \mathrm{rb}$ & $\begin{array}{l}\text { Utrum omne corpus opacum, vel } \\
\text { oppositum luminoso, sit } \\
\text { calefactibile per lumen }\end{array}$ & $\begin{array}{l}\text { Et arguitur primo quod non, quia } \\
\text { sequeretur quod aliquid } \\
\text { illuminaretur ...X... scilicet } \\
\text { radiorum fractio ad unum locum } \\
\text { vel ad unum punctum. Sequitur } \\
\text { queritur. }\end{array}$ & I.12 \\
\hline $83 \mathrm{ra}$ & $\begin{array}{l}\text { Utrum aliquod corpus agat in } \\
\text { distans ab eo ita quod non agat in } \\
\text { intermedium sive propinquum }\end{array}$ & $\begin{array}{l}<\text { Arguitur quod sic }>\text { quia Sol } \\
\text { calefacit ista inferiora mediante } \\
\text { motu et lumine...X... scientia } \\
\text { non causat speciem in medio } \\
\text { suorum accidentorum }(\text { sic), quia } \\
\text { est agens principale. Et sic patet } \\
\text { hec questio. }\end{array}$ & I.13 \\
\hline $84 \mathrm{ra}$ & $\begin{array}{l}\text { Utrum aliquod agens agat fortius } \\
\text { sibi in remotum quam } \\
\text { propinquum }\end{array}$ & $\begin{array}{l}\text { Et arguitur quod non, quia omne } \\
\text { agens prius agit sibi in } \\
\text { propinquum quam in remotum } \\
\text {...X... ymo partes eius difforme } \\
\text { coagunt simul. Et sic patet } \\
\text { questio. }\end{array}$ & I.14 \\
\hline $85 \mathrm{ra}$ & $\begin{array}{l}\text { Utrum contrarium posset movere } \\
\text { alterum contrarium sibi, adhuc } \\
\text { localiter }\end{array}$ & $\begin{array}{l}\text { Arguitur quod non, quia ferrum } \\
\text { frigidum positum iuxta ignem } \\
\text {...X... non quibuscumque, sed } \\
\text { contrariis, sicut dicebatur quod } \\
\text { album positum iuxta nigrum non } \\
\text { movet illud. Patet questio. }\end{array}$ & I.15 \\
\hline
\end{tabular}

(170) Cf. supra, p.\#\#. 
Utrum media regio aeris sit semper frigida

Utrum flamme de nocte apparentes in aere fiant ibi naturaliter principum, guerras, pestilentias et

$89 \mathrm{vb}$
Utrum comete significent mortes huiusmodi

Utrum, serenitate existente, possunt in celo de nocte apparere hiatus, seu aperture, et voragines et sanguinei colores

Utrum stelle comate sint de natura celi aut elementari.

Utrum motus stelle comete sit naturalis

Utrum omnes comete sint eiusdem speciei inter se et cum galaxia

Utrum impressiones humide fiant a calido
Et arguitur quod non, quia aer est elementum naturaliter calidum et humidum...X... nec oportet quod sit omnimode [ $m s$. : omnimoda] dispositio unius. Et sic patet questio.

Arguitur primo quod non, quia aer naturaliter est humidus, et flamma et tale igneum est calidum et siccum ...X... ad aliud: potest dici quod patet ex dictis. Et sic patet hec questio.

Arguitur primo quod non, quia tales colores magis deberent apparere de die in lumine quam in tenebris ...X... Et ideo de causa formali et finali potest dici sicut de aliis. Patet questio.

Arguitur primo quod sint de natura celi ex motu, quia illud quod naturaliter movetur ...X... et iste est unus de primis effectibus, ideo suspicantur alia advenire. Patet hec questio.

Et arguitur primo quod non, quia nullum inanimatum movetur ad utramque differentiam positionis ...X... nisi cause violentantes fortificentur ut in eodem statu maneant. Et sic patet hec questio.

Et videtur primo quod non, quia in eadem regione habitant simul divites et pauperi ...X... et si veniat inundatio aquarum hoc est vel per accidens vel per antiparistasim

Videtur primo quod non, quia comete differunt in figura ...X... secundum hoc quod disponitur ad diversas cometas. Patet questio.

Et videtur quod non, quia contrariorum cause sunt contrarie ...X... quia tempore nimis calido est parum de materia que possit elevari. Patet hec questio. 
Utrum omnes impressiones aquee sint eiusdem speciei

Utrum nix et pluvia generantur in media regione aeris

Utrum grando magis debeat fieri hieme quam estate vel temporibus intermediis, sicut in vere vel autumno

Utrum nebula sit signum serenitatis

Utrum aqua naturaliter ad orificia fontium ascendat - et questio habet locum circa tractatum de generatione fontium et fluviorum

Utrum fontes et fluvii veniant ex aqua pluviali vel ex mari vel aliunde

Utrum fontes et pluvia [sic] deriventur a montibus

Utrum habitationes terre permutentur

Utrum habitatio terre permutetur propter mare
Et videtur quod non, quia quedam sunt ex materia grossa, ut grando et pluvia...X... non conceditur quod nix est aqua, licet ex ea possit fieri aqua.

Et videtur quod non, quia aliquando simul cadunt et nix et pluvia ...X... licet quandoque modicum velocitatur. Et sic patet questio.

Et primo videtur quod numquam possit fieri, ratione Aristotelis in textu ...X... non oportet quod fit in hieme, propter causam dictam in questione, et etiam in estate, sicut dictum est. Et pro hoc solvitur quartum.

Arguitur quod non, quia materia nubis et pluvie non est signum serenitatis ...X... ad secundum: dicitur de eodem. Patet questio.

Arguitur primo quod sic, quia omne elementum naturaliter exit et movetur de loco sibi innaturali ...X... in quo est generatio fontis seu aqua que descendit ad locum illum. Et sic patet questio.

Arguitur primo quod non ex aqua pluviali, per rationes Senece

...X... sed sunt pauci vapores super terram, ita similiter sub terra. Et sic patet questio.

Et arguitur quod non, quia ut sic [sic] ex quolibet monte proportionaliter deberet oriri aliquis fons ...X... et ideo fontes sunt meliores. Et sic patet questio.

Et arguitur primo quod non, quia descriptio terrarum que fuit olim facta adhuc habet locum ...X... debet durare per mille annos, dicunt quod istud eternum. Et sic patet questio.

Et arguitur quod non, probando quod mare non exeat locum suum vel limites suos ...X... sicut quadam vesti, et ideo dicit Avicenna ... [textus imperfectus] 